University of San Diego

Digital USD

1989

\title{
A Delphi Study of California Community College Counselors' Responsibilities and Competencies for the 1990's as Perceived by Chief Student Services Administrators
}

Noelia Vela EdD

University of San Diego

Follow this and additional works at: https://digital.sandiego.edu/dissertations

Part of the Leadership Studies Commons

\section{Digital USD Citation}

Vela, Noelia EdD, "A Delphi Study of California Community College Counselors' Responsibilities and Competencies for the 1990's as Perceived by Chief Student Services Administrators" (1989).

Dissertations. 532.

https://digital.sandiego.edu/dissertations/532

This Dissertation: Open Access is brought to you for free and open access by the Theses and Dissertations at Digital USD. It has been accepted for inclusion in Dissertations by an authorized administrator of Digital USD. For more information, please contact digital@sandiego.edu. 
A DELPHI STUDY OF CALIFORNIA COMMUNITY COLLEGE COUNSELORS' RESPONSIBILITIES AND COMPETENCIES FOR THE 1990'S AS PERCEIVED BY CHIEF STUDENT SERVICES ADMINISTRATORS

\author{
by \\ Noelia Vela \\ A dissertation submitted in partial fulfillment \\ of the requirements for the degree of \\ Doctor of Education \\ University of San Diego
}

1989

\author{
Dissertation Committee \\ Wallace Cohen, Ed.D., Director \\ Susan M. Zgliczynski, Ph.D. \\ Samuel M. Ciccati, Ph.D.
}


(C) Copyright by NOELIA VELA, 1989

All Rights Reserved 
A DELPHI STUDY OF CALIFORNIA COMMUNITY COLLEGE COUNSELORS' RESPONSIBILITIES AND COMPETENCIES FOR THE 1990'S AS PERCEIVED BY CHIEF STUDENT SERVICES ADMINISTRATORS

VELA, NOELIA, Ed.D., University of San Diego, 1989. 307 pp.

Director: Wallace Cohen, Ed.D.

ABSTRACT OF THE DISSERTATION

California's demographic changes and recent legislative reform mandates will impact what community college counselors will be expected to do in the 1990's. The purpose of this study was to identify the responsibilities and competencies of California community college counselors in light of the changes.

The Delphi Method, selected for its consensusbuilding and forecasting qualities, was used for this study. A panel of 23 chief student services administrators, identified as experts in student services and counseling, completed three rounds of surveys. The Delphi instruments were developed to address counselor responsibilities and associated competencies for the 1990's, staff development needs of currently employed counselors and professional preparation needs of prospective counselors to effectively meet the challenges of the 1990's. 
Some of the major findings and conclusions of the study were: (1) Counselors' responsibilities and associated competencies for the 1990's will address the specific needs of the "new" student populations including older adults, limited English speakers and underprepared students. (2) Counselors will be more involved in process-oriented counseling activities and less involved in information dissemination activities. (3) Counselors will be more involved in "indirect" student service activities such as program development and evaluation, student retention activities and institutional policy development. (4) Key staff development needs relate to the key community college issues of cultural and language diversity, adult development, learning styles, affirmative action and traditional counseling topics. (5) Five crucial professional preparation topics for prospective community college counselors include: Community College Mission and Philosophy, Cultures in American Society, Community College Counseling Practicum, Adult Development Theory and Learning Theory.

Major recommendations include using the information from this study as a basis for: (1) discussion between chief student services administrators and counselors about local counseling services; (2) planning counseling services, staff development programs, job descriptions and new hires; and (3) as a basis for the California 
Community College Chief Student Services Administrators' Association to develop and forward recommendations to the field and to community college counselor educators.

Finally, a local assessment of the issues addressed in this study could be conducted to better address students' needs in the $1990^{\prime} \mathrm{s}$. 


\section{DEDICATION}

\section{TO MY PARENTS}

To Guadalupe and Jesus Vela who instilled in me an interest and appreciation for learning and who, throughout my life, have given me love and understanding and have encouraged me to set goals and to do my best. 


\section{ACKNOWLEDGEMENTS}

My heartfelt gratitude and appreciation are expressed to many people without whose support, reassurance and assistance this study could not have been completed.

To my committee members, Dr. Wallace Cohen, Dr. Susan Zgliczynski and Dr. Samuel Ciccati who provided guidance and assistance throughout the process.

To Ron Kong, my college President, who provided understanding and support when an adjustment to my work schedule was requested.

To Judy Strattan, who has been my mentor and friend over the last sixteen years and who has always been a source of encouragement and perspective.

To Gail Prentiss, fellow doctoral student and friend, who insisted through persistent but gentle prodding that I not give up.

To numerous personal friends who provided moral support and patiently understood when time couldn't be shared with them.

To Patsy Emmert, who transformed my handwritten pages to final copy and who, on numerous occasions, gladly adjusted her schedule to assure that deadlines were met to keep this work on track. 
TABLE OF CONTENTS

Page

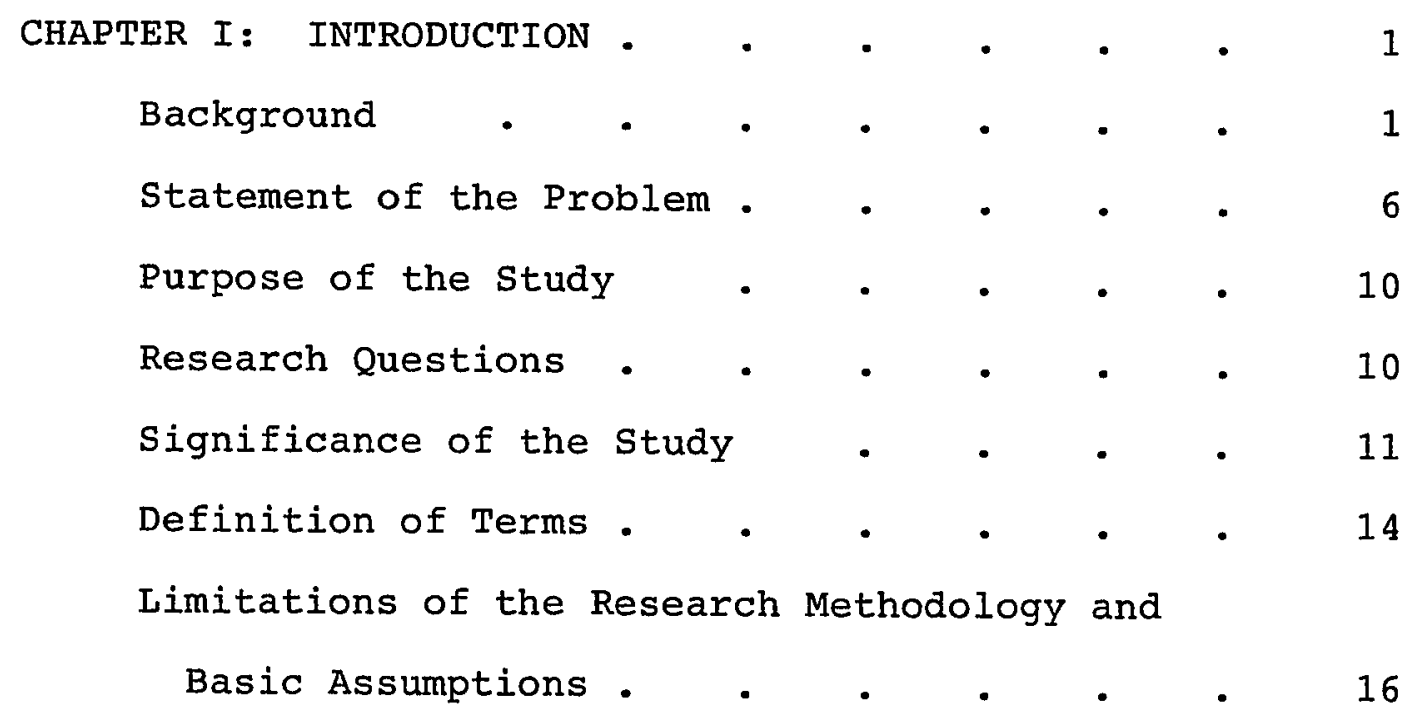

CHAPTER II: REVIEW OF THE LITERATURE - • • • 19

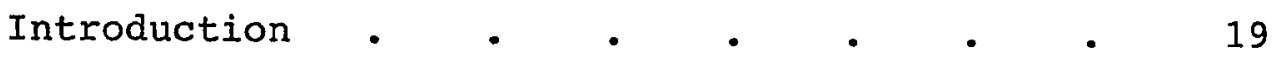

The Community College $\quad$ • $\quad$ • . 20

Reform Recommendations for California

Community Colleges . . . . . . 36

Demographics Affecting California Community

Colleges 1990-2000 . . . . . . . 53

Implications for Community Colleges . 58

Counseling and Other Student Services in

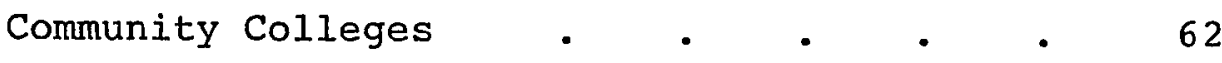

iv 
CHAPTER II: REVIEW OF THE LITERATURE (continued)

Studies of Community College Counseling

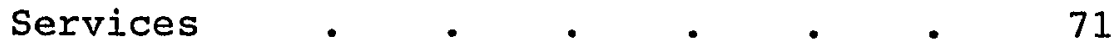

Professional Development and Counselor

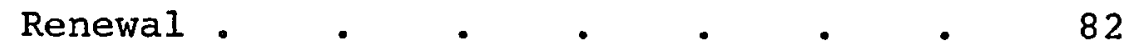

Examination of Counselor Responsibilities 85

The Delphi Technique . $\quad$ - $\quad$ - $\quad$ - $\quad$ - 96

The Use of the Delphi Technique in

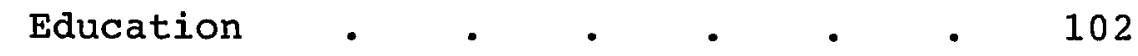

Delphi Advantages . . . . . . 106

Delphi Disadvantages $\quad$. $\quad . \quad$. 108

CHAPTER III: RESEARCH DESIGN AND METHODOLOGY • 112

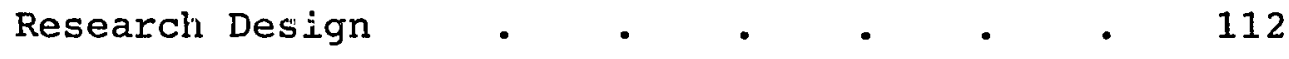

The Delphi Methodology • • • • • • 115

Demographic Questionnaire and Delphi

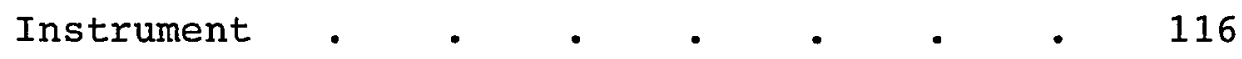

Pilot Study Description . . . . . . 122

Expert Panel Selection . . . . . . 123

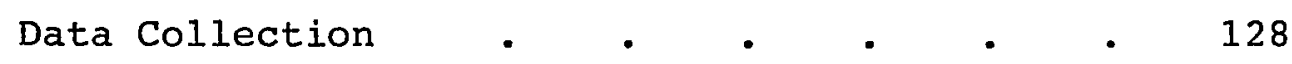

Data Analysis • • • • • • • • 131

Weaknesses of the Delphi Methodology • • 133 
$\underline{\text { Page }}$

CHAPTER IV: FINDINGS OF THE STUDY • • • • • • 135

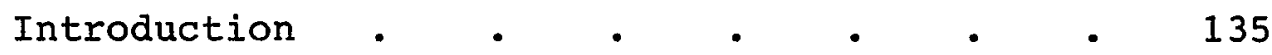

Demographic Questionnaire Analysis . . . 136

Expert Panel Characteristics . . . . 137

Panelist Profile . . . . . . . 147

Institutional Characteristics . . . . 149

Institutional Profile . . . . . . 151

Delphi Analysis . . . . . . . 152

Round One Results . $\quad$. $\quad$. $\quad$. 153

Round Two Resuits . . . . . . 155

Community College Counselor

Responsibilities for the 1990's:

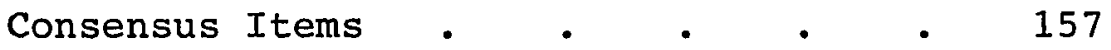

Community College Counselor

Competencies for the 1990's:

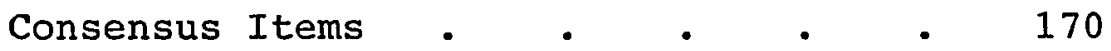

Job Description for California

Community College Counselors for

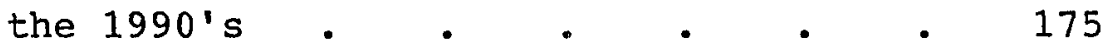

Round Three Results • • . • . • 176

Staff Development Needs of Currently

Employed California Community

College Counselors $\quad$ • $\quad . \quad$. $\quad$. 179

vi 
CHAPTER IV: FINDINGS OF THE STUDY (continued)

Professional Preparation Needs of

Prospective California Community

College Counselors _ . . . . 182

CHAPTER V: SUMMARY AND RECOMMENDATIONS • • • 186

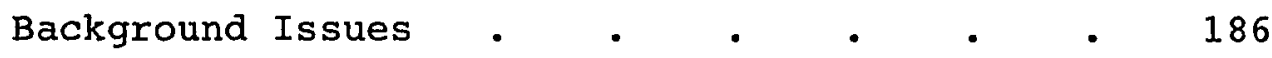

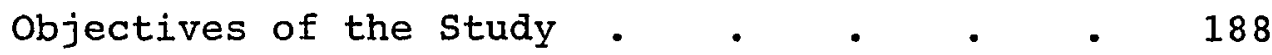

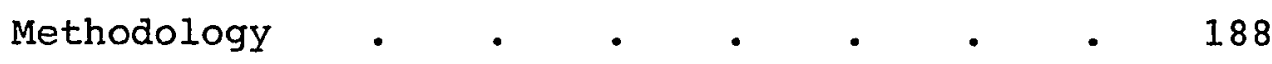

Findings and Conclusions . . . . . 190

Community College Counselor

Responsibilities for the 1990's . . 191

California Community College

Competencies for the 1990's . . . 199

Job Description for Community College

Counselors for the 1990's . . . 201

Staff Development Needs of Currently

Employed Counselors . . . . . 202

Professional Preparation Needs of

Prospective Counselors . . . . . 204

Recommendations for Chief student Services

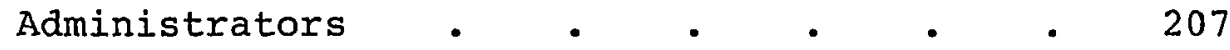

vii 
Page

CHAPTER V: SUMMARY AND RECOMMENDATIONS (continued)

Recommendations for the California

Community College Chief Student Services

Administrators' Association . . . . 208

Recommendations for Further Research . . 210

REFERENCES $\quad \bullet \quad \cdot \quad \cdot \quad \cdot \quad \cdot \quad \cdot \quad \cdot \quad \cdot \quad 212$

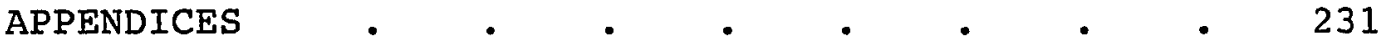

viii 


\section{LIST OF TABLES}

\section{Table}

Page

1. Job Titles of Respondents . . . . 138

2. Direct Supervisor's Job Title • • • . 139

3. Years in Present Position . . . $\quad 140$

4. Immediate Previous Position . . . . $\quad$ - 141

5. Years in Previous Position . . . . 142

6. Community College Counseling Experience • • 143

7. Student Services Profession Experience • • 144

8. Age and Gender Distribution . . . . 145

9. Student Enrollment . . . . . . 150

10. Ethnic Breakdown of Enrollment . . . 151

11. Responsibilities Added During Round One . - 168

12. Competencies Added During Round One . 173 


\section{IIST OF FIGURES}

Figure

Page

1. Delphi Summary of Ratirgs for Rounds one

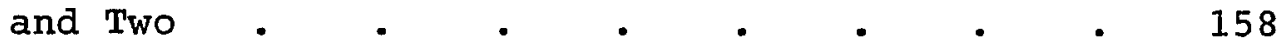

2. Community College Counselor Responsibilities

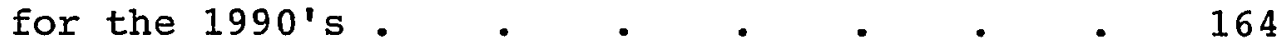

3. Community College Counselor Competencies for the 1990's . $\quad . \quad$. $\quad . \quad$. $\quad . \quad 171$

4. Job Description for California Community College Counselors for the 1990's . • . 177

5. Ranked and Unranked Staff Development Topics . 181

6. Ranked and Unranked Professional Preparation Topics $\quad . \quad \cdot \quad \cdot \quad \cdot \quad \cdot \quad \cdot \quad \cdot \quad 184$ 


\section{APPENDICES}

$\underline{\text { Page }}$

Appendix A: Background Information . . . 231

Appendix B: Demographic Questionnaire • . . 232

Appendix C: Delphi Instrument, Parts 1 and 2 for

Round One $\quad \cdot \quad$ - $\quad$ - $\quad$ - $\quad$ - $\quad$ - 234

Appendix D: Delphi Instrument, Parts 1 and 2 for

Round Two and Delphi Summary for

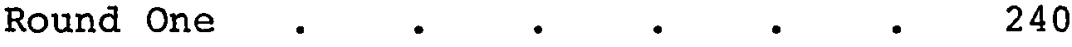

Appendix E: Delphi Instrument, Parts 3 and 4 for

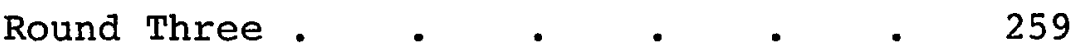

Appendix F: Delphi Summary for Round Two . . 265

Appendix G: Abbreviated Delphi Summary for

Round Two $\quad . \quad \ldots \quad . \quad . \quad . \quad . \quad 283$

Appendix H: Job Description for California

Community College Counselors for

the $1990^{\prime} \mathrm{s} \quad$. $\quad . \quad$. $\quad . \quad$. $\quad . \quad$. 288

Appendix I: Staff Development and Professional

Preparation Needs of California

Community Counselors for the 1990's,

Delphi Summary for Round 3. • . 290

$\mathrm{xi}$ 
Appendix J: Demographic Questionnaire Summary . 295 Appendix K: Cover Letters for Delphi Rounds One, Two and Three $\quad . \quad$. $\quad . \quad$. 299 
CHAPTER I

INTRODUCTION

\section{Background}

Since 1901, when the first junior college was established, the institution has undergone developmental changes in mission, philosophy, size, numbers and in the students it serves. The number of community colleges grew from 403 in 1929 to over 1,200 regionally accredited technical, community and junior colleges today. They enroll over five million college credit students and an additional four million students in non-credit adult and continuing education programs (Commission on the Future of Community Colleges, 1988).

The comprehensive community college has emerged as a major force in higher education. According to Schoenberg (1978) and Cohen (1982), community colleges have effected notable changes in American education, especially by expanding access. The community college is the most accessible institution of higher education. Community colleges have reached out to attract those who were not being served by the traditional higher education 
institutions. Today they are attracting and attempting to serve the low-income, part-time, ethnic minority, underprepared, underemployed, unemployed, physically handicapped, reentry adults and retired individuals. These new students have a pronounced effect on community colleges. Current trends indicate that most individuals will require continuing education in a postsecondary institution to prepare them for our rapidly changing society. No other higher education institution is as well prepared to respond to the changing demands as is the community college (Vaughan, 1983). The community colleges may well become even more essential to the well-being of America in the late twentieth century than they have been during the midtwentieth century.

Despite their contributions, community colleges also have been under scrutiny as have other segments of American education. There has been a public outcry for reform. The community colleges are faced with a great challenge and opportunity to help society cope with major changes. The purpose and mission of the community college have been questioned and debated especially in California where the growth has been the greatest. Community colleges in California now number 107 in 71 districts. The questions, the debates and the studies are magnified in California because of the state's rapid growth in population, diversity, and economic and societal changes. 
A recent examination of academic standards, student access and success and mission of community colleges has taken place in California. Between 1984 and 1988 the Commission for the Review of the Master Plan for Higher Education and the Joint Committee for the Review of the Master Plan in Higher Education reviewed and redefined the missions and responsibilities of the California community colleges. Their work was conducted with the constant awareness of the present and anticipated challenges facing the state and thus its community colleges. They were aware of the rapidly growing and diverse population. Their work culminated in legislation, Assembly Bill 1725, which was signed on September 19, 1988. This law has become the landmark statute for California community college reform.

The reform recommendations place a specific focus on college mission and function; academic excellence; access; assessment; counseling; student progress monitoring; student success; English as a second language; basic skills; faculty, administration and staff role and qualifications; staff development and renewal; affirmative action and finance (California Faces . . California's Future, 1988).

The reform bill with the 55 recommendations addresses the anticipated demographic changes in the next two decades for the State of California. California's population is 
changing and growing at a rapid rate. California is growing faster than the nation as a whole. The state's population will increase by one fifth by the year 2000 . California is becoming older and more ethnically diverse. There has been a rapid increase of female students during recent years in community colleges. Currently, the racial and ethnic groups account for 40 percent of California's population. A significant percentage of this latter group was born in another country. By the 21st century, California will be the first mainland state with a majority of non-white persons. Needless to say, these demographic changes will have a tremendous impact on California's community colleges. These changes will result in greater demand for postsecondary education and in substantially more variation of individual educational needs than ever before. For California community colleges, the demographic projections translate as an anticipated:

1. increase of part-time students,

2. increase of returning adults,

3. increase of underprepared students,

4. increase of Hispanic, Asian and Black students,

5. proportional decrease of Caucasian students,

6. proportional increase of female students,

7. decrease of recent high school graduates, 
8. increase of limited English proficient (LEP) students, and

9. increase of unskilled, unemployed and underemployed adults (Looking Ahead . . Data for Planning, 1987; California Faces - California's futures, 1988; Contours of Change, 1985; Hodgkinson, 1986).

Each of these students will bring, in addition to their numbers, their unique needs which may include assessment, remediation, English as a second language classes, child care, counseling and other curricular and student services.

The anticipated changes in the state and in potential student pools will have an impact on every facet of the community college. The way community colleges respond to the reforms of $A B 1725$ and to the state's demographics will affect the role of student services and most especially that of counseling services. The innovations that must take place in other segments of the college will require a need for parallel innovations in all of student services but especially in counseling services.

Matson (1972) stated that counseling is considered to be the "key student personnel service" (p. 173). Counseling must take into consideration the unique educational philosophy of the college and must address 
the unique needs of its diverse student body. The provision of counseling services is one of the major objectives of the community college (Jones, 1970; Miller, 1977; Schoenberg, 1978). The work of the Joint Committee for the Review of the Master Plan in Higher Education (1988) reemphasizes that student support services and the functions of counselors are "important and essential functions."

California's demographic changes and recent reform mandates will impact what counselors are expected to do at the community colleges. They will dictate, by necessity, the required competencies and staff development needs of currently employed counselors and the professional preparation needs of prospective California community college counselors. Counselors are still held accountable for their traditional functions of academic advising, career counseling and personal counseling (Jones, 1970; Warnath, 1972). But there will undoubtedly be changes and new facets to these responsibilities.

\section{Statement of the Problem}

Despite the noted importance of counseling services in community colleges, there is not an abundance of information in the literature about their responsibilities and competencies. An extensive review of the literature 
indicated that there have been studies on the functions of student personnel services as a whole profession including its various service areas. There are studies comparing counseling services needs of community college and university students; of counseling services at community colleges of varying sizes and there is one national study of counseling responsibilities (Jonasson and Stripling, 1977; Miller, 1979; Goodman, Beard and Martin, 1975; Hinko, 1971; Litwack, 1975).

In addition to these studies focusing on counselor and student services functions, the literature review revealed that there is disagreement about the role and function of community college counselors (Shertzer and Stone, 1974; Walz and Benjamin, 1979; Boy and Pine, 1979; Ciavarella and Doolittle, 1970; Kolveit, 1973; Lewis and Lewis, 1970; Blocker and Richardson, 1968; Warnath, 1972).

There was agreement in the literature on the importance of continual staff development and staff renewal (Walz and Benjamin, 1979; Walz and Leu, 1979; Maples, 1980; Creamer, 1983). Walz and Benjamin (1979) asserted, "No counselors prepared in one time will be adequately prepared to serve in another unless they have engaged in continuing attempts to renew their skills" (p. 27-28). The California reform bill AB 1725 places high emphasis on staff development. Funding is available for the staff development programs which community colleges must develop 
to revitalize the faculty (including counselors) so as to better prepare them to meet the needs of their diverse students.

Community college counselor training in the universities too often has been based on the assumption that counseling is counseling, regardless of the setting. In the literature review, Creamer (1983) was the only one to recognize and emphasize that community college counselor roles are sufficiently different from roles in other colleges to merit separate preparation. Creamer (1983) recognized the disagreement of role definition in community colleges but still stressed separate training for those commonly accepted roles.

The literature review, however, did not reveal any studies reporting on future community college counselor responsibilities and competencies that could contribute to meeting the demographic and reform change requirements in California community colleges. No study of staff development needs of currently employed counselors or of professional preparation needs of prospective community college counselors could be found. With the increasing significance of the community college role, California's demographic changes, the reforms mandated by legislation like Assembly Bill 1725, and the reaffirmed importance of counseling services, there is a need for comprehensive information about counselor responsibilities, competencies, 
staff development needs of those currently employed and professional preparation needs of prospective community college counselors.

In California, the chief student services administrators at the community colleges will be charged with shaping student services policies and decisions to face the demographic and reform challenges of the 1990's. They are the administrators who supervise all of the student services programs including counseling services. It is they who will be held responsible for the overall development and delivery of counseling services to ensure that they meet the changing needs of the students and of the institution. Thus, it seems prudent to assess the chief student services administrators' perceptions of counselor responsibilities, competencies and staff development needs of currently employed counselors as well as their perceptions regarding the professional preparation needs of prospective California community college counselors. This study addresses these areas critical to the future of community college counseling in California and is an original contribution to the literature. 
Purpose of the study

This study will determine the responsibilities and competencies of California Community College Counselors for the 1990's. The main objectives of the study are to:

1. identify the responsibilities that California Community College Counselors will have during the $1990^{\prime}$ 's as perceived by the chief student services administrators who are the decision and policy makers and

2. identify the competencies that California Community College Counselors will need to fulfill the responsibilities they will have during the 1990's.

\section{Research Questions}

The specific research questions to be answered by the study are:

1. What will be the responsibilities of California Community College Counselors during the 1990's? 
2. What competencies will California Community College Counselors need to fulfill their responsibilities during the $1990^{\circ}:$ ?

3. What will the 1990's job description for California Community College Counselors include?

4. What are the staff development needs of currently employed California Community College Counselors to prepare them to effectively fulfill their responsibilities in the 1990 's?

5. What course or seminar topics should counselor education programs include to prepare prospective California Community College Counselors to effectively fulfill their responsibilities in the 1990's?

\section{Significance of the Study}

In his book, Campus 1980, Eurich (1968) suggested that by examining the future, we can "speed changes toward a better future" (p. xviii). Toeffler (1974) also emphasized the need for examining the future by stating that:

no educational institution today can set sensible goals or do an effective job until 
its members. . . subject their own assumptions about tomorrow to critical analysis. For their shared or collective image of the future dominates the decisions made in the institution (p. 5) .

Toeffler's statement supports the purpose of this study. Such a study will not only contribute to the educational literature but will also contribute to the community college counseling profession.

The researcher both exerted leadership and enhanced her leadership skills by conducting this study. Leadership was demonstrated by doing research which will help create direction and vision for California Community College Counselors. As a student services administrator, the researcher enhanced her leadership skills by gaining insight on expert student services administrators' perspectives for future planning.

Since the mid-eighties, there has been major attention directed toward the improvement of California community colleges so that they can be better equipped to provide excellent education and services which address the needs of California's diverse staff and students. AB1725, the major reform bill for California's community colleges requires that many changes take place. It is imperative that analysis, planning and decision-making founded on good 
data, research and broad participation precede the specific implementation efforts of $A B 1725$. The results of this study provide useful information for long-range planning of counseling services in California's communty colleges. More specifically, the results of the study will serve as a foundation for:

1. the revision of the counselor job description at the campus level in California Community Colleges,

2. comprehensive planning for counseling services at California Community Colleges,

3. the planning of staff development and educational preparation programs for current and prospective California Community College Counselors,

4. the determination of minimum qualifications and standards for California Community College Counselors, and

5. the development of recommendations by the professional organizational groups to infiluence minimum stanäarảs, qualifications and requirements for California 
Community College Counseling Services as listed in Title $V$ and in the Education Code.

\section{Definition of Terms}

The following definition of terms will be used throughout this study.

California Community College Counselor: A professional holding a California Community College Counselor Credential to perform academic, vocational and personal counseling services.

California Chief Student Services Administrator: The highest ranking administrator having full responsibilities for all of the student services programs, including counseling services, at a community college. The specific title may be Dean or Vice President depending on the organizational structure of the college and the person in the position most commonly reports directly to the president of the college.

Community College: A post-secondary two-year college offering transfer, vocational, developmental and continuing education courses. In California, it is considered part of the system of higher education.

Competencies: The required set of abilities, expertise, masteries, proficiencies and skills necessary to fulfill the job responsibilities. 
Consensus: The agreement about each item on the Delphi Instrument. Since this study is gaining opinions about desired future conditions, the mode was used to indicate consensus (Rasp, 1973, p. 32). Consensus was reached if at least 50 percent of the respondents agreed on any given item.

Delphi Study: A rapid and efficient way to arrive at consensus of expert opinion about future states or conditions. It is a cirefully designed program of sequential individual interrogations interspersed with information and opinion feedback (Rasp, 1973, p. 29). Experts: The participants of the Delphi Study selected because of their recognized expertise in the field of study which, for this research, is student services.

Matriculation: A statewide mandated student services program including seven components: admissions, cognitive and affective domain assessment, new student orientation, academic advisement, student progress monitoring, staff development and institutional student follow-up and research.

Modal Response: The response which is selected most frequently.

Professional Preparation: The college credit course work and educational program completion from an accredited institution to become qualified for employment in a profession. 
Respondents: The experts who participated in the study.

Responsibilities: The required set of obligations or duties of the position.

Round: One complete cycle from researcher to respondent and back to researcher.

Staff Development: Credit or non-credit course work, workshops, seminars or field studies designed to enhance one's professional qualifications for one's current position.

\section{Limitations of the Research Methodology and Basic Assumptions}

The future cannot be predicted with absolute accuracy. This study used the Delphi technique to attempt to forecast and gain consensus about the probable responsibilities, competencies, staff development needs and professional preparation needs for California Community College Counselors. It has been documented throughout the literature that the Delphi technique is a strong consensus building and forecasting tool (Helmer, 1964, p. 3; Helmer, 1983, pp. 134-136; Wayschall, 1983, p. 43). Thus, although this study does not predict the future, it does, through Delphi, provide a consensus on a general forecast. 
The Delphi technique focuses on and relies heavily on the expertise and opinions of the experts and their willingness to participate in all phases of the study. These factors contribute potentially to both the strengths or weaknesses of Delphi. In this study every effort was made to identify participants that, in fact, had the expertise to contribute to the study. The demographic data gathered about the panel participants indicate their degree of expertise in the field. Despite all efforts to tap the best experts in the field and to keep them encouraged enough to complete all phases of the study, the study is limited by the degree of expertise and cooperation of the participants.

In addition there is always the possibility of researcher bias in the preparation of the summary. This may especially occur when the study is in a field to which the researcher is closely connected. The researcher in this study has served as a community college counselor and currently is a chief student services administrator. However, this researcher's 17 years of experience in the profession and her professional interest in seeing that the best thinking of the experts be studied and shared, to move the counseling profession in a direction to best address student needs, contribute objectivity in the reporting of the results. Furthermore, to assure against any potential 
bias, an independent party reviewed all the materials and results.

The following assumptions were made concerning this study:

1. The individuals nominated by their peers as "experts" are student services professionals who gave responses that are more knowledgeable than those of a random sample of student services administrators.

2. The Delphi technique is a useful research tool for forecasting and building consensus about future community college counselor responsibilities and competencies as well as staff development and professional preparation needs. 
CHAPTER II

REVIEW OF THE IITERATURE

\section{Introduction}

The review of the literature is divided into five sections to adequately establish the perspective for both the setting and the significance of the study. The first section provides a brief historical view of the development and role of the community college. The second section summarizes both the findings of the master plan commission and the reform demands for California community colleges. The third section reviews the demographic data available for the year 2000 for California and its community colleges. The fourth section focuses on the development of counseling services in the community colleges. The fifth and final section in the review of the literature provides information on the use of the Delphi technique. 


\section{The Community College}

"The community college is an innovation of the twentieth century" (Blocker, 1965).

Basically all institutions arise in response to certain needs that become evident within a society. In the late $1800^{\prime}$ 's, university leaders including William Rainey Harper, president of the University of Chicago, were striving for the establishment of upper division and graduate education as the ideal of higher education and thus they conceived the two-year college as a proper adjunct of secondary education. They envisioned the shifting of the first two years of college study from the university campus to the high school, thus separating the freshmen and sophomore years from the rest of the university program. A second force which impelled university leaders to encourage the development of the junior college was the fact that many secondary school graduates were inadequately prepared for the vigorous demands of college study. Harper attempted to find a satisfactory compromise between the American four-year college tradition and the German ideal by establishing a lower division called a junior college at the University of Chicago in 1896. As the idea began to be accepted, the first junior college was established at Joliet, Illinois in 
1901 (Blocker, 1965). The first Associate of Arts degree was offered in the program instituted by Harper. He saw the degree as a reward for students who had completed the initial two years of college, but who might not show potential to go further in the university (Zwerling, 1976).

On the west coast, two Californians, Alexis F. Lange, Dean of the School of Education at the University of California, Berkeley and David Starr Jordan, President of Leland Stanford University advocated the same educational concept. Lange went further than other university leaders in viewing the junior college as a fulfillment of the desire of universal education (Monroe, 1973).

In 1907, the California Legislature established the community college as part of the California state system of education (Thorton, 1966). For fifteen years prior to the 1907 legislation that allowed California high schools to offer post-graduate courses, Berkeley and stanford, prodded by Lange and Jordan, had been trying to reshape themselves by separating their upper and lower divisions. The reasoning was the same as that of those who wanted to create the "pure" university. Berkeleyites were even heard speaking of the "six-year high school" as the institution that was essential to the purification of the university. Jordan, however, used and made popular the name "junior college." The name conveyed a separate thought to the public and thus was received well. Unlike William Rainey 
Harper, Lange was unable to create his Joliet and had to settle for a separation between lower and upper division at Berkeley (Zwerling, 1976).

In 1910, Fresno, California became the site of the state's first and the nation's second public community college. Its presence was important not only to the higher education system in California but to the nation as California's community college system grew larger than any other in the country (Thornton, 1966; Zwerling, 1976).

Although the 1907 legislation establishing community colleges in California stipulated that such postgraduate. work should approximate the studies prescribed in the first two years of university courses, the Fresno Board added to their resolution that "technical work" should also be included. It is believed that this critical addition may have been the result of Lange's influence. He was the earliest advocate of adding vocational education to the junior college curriculum. The Fresno resolution is noteworthy for other reasons as well. It is the first document to stress anything other than theoretical, structural reasons for the establishment of separate, locally-based junior colleges (Zwerling, 1976). The reasons they stated in 1907 are as current as the recent reports on higher education which continue to call for low-tuition community colleges within commuting distance of 
all Americans. The Fresno Board expressed its resolution as follows:

\begin{abstract}
There is no institution of higher education within two hundred miles of Fresno where students may continue their studies beyond the regular high school course. Many of our high school graduates are but seventeen or eighteen years of age and parents are frequently loath to send these young people so far away from home. Many who desire to continue their studies cannot afford the expense necessary to college attendance where the items of room and board mean so much (Zwerling, 1976, p. 50).
\end{abstract}

Since 1901, the junior college has undergone developmental changes in mission and philosophy. One can identify four general developmental stages. The first stage was the junior college stage when it was considered a prep school for senior institutions. The junior college was an extension of the high school. During the next stage, the colleges were called people's colleges and a comprehensive curriculum began to emerge along with guidance services. After World War II, the colleges were called community colleges. Their goal was education for 
all and they provided a comprehensive curriculum including technical education. During the 1970's the colleges were still known as community colleges but began to place an emphasis on community-based learning and added community and continuing education to their.mission.

In addition to the comprehensive nature of the institution, other traits evolved that distinguished community colleges from other education systems. They were designed to be accessible to all people, a concept termed universal access in the Truman Report on Education (Parker and Vecchillo, 1973). As a result, the community colleges were labelled the open door college. Another factor that emerged in the development of the community college and its "open door" was the concept of low or no cost. The no tuition policy was mandated into law in California in 1907 and has been identified as a key factor of universal access (Wattenburger, Shafer and Zucher, 1973).

As the community colleges grew and developed, Blocker (1965) observed that:
comprehensive public education would be an essential part of the American system and the community college system could not escape its responsibility for providing those services necessary for the well being of its citizens (1965, p. 52). 
While the desire to educate the masses existed, a debate ensued over the role of the purpose and mission of the community college. This was especially true in California where the growth of the community college system was greatest. Much debate and consideration regarding mission followed. Blocker, Plummer and Richardson, Jr. (1965) pointed out that:

The educational purposes of the two year college as set forth in the early legislation, were originally based upon the concept that it was to provide either an extension of high school educational programs or a limited number of college level courses. Early laws did not spell out specifically that the two year college was a distinct entity, . . The language of the laws implied that the programs of the two year college were to serve as preparation for college--as a basis for further academic study--but there was no clear-cut indication as to whether the program was to be collegiate or secondary in nature and organization (p. 31).

The implementing legislation did not spell out a single mission or purpose for community colleges but rather 
identified many diverse programs. This diversity identified with the community college created confusion for its leaders, the public and members of the educational community (Gleazer, 1968).

In the late fifties an effort began in California to define the community college's role and clearly identify its purpose and mission. The first effort to define the community college role was made in 1960 when the Master Plan for Higher Education in California was accepted by the legislature. As the first state-wide Master Plan for education in the nation, the plan defined the role of the community college in providing educational services to Californians (Brown, 1965; Wilson, 1965; Glenny, 1965). It also created the Coordinating Council for Education. The Coordinating Council, which lasted until 1973 when the California Post Secondary Education Commission (CPEC) was formed, was designed to coordinate the institutions of higher education in California. In 1965, the Coordinating Council issued a staff report which stated that by their history and by their legal mandate, the California Junior Colleges were to complement, not mimic, the other segments of higher education (Gleazer, 1968).

Thus, as a complementary part to other educational systems, the junior/community college finally, during the sixties, attained full status as a member of the higher education establishment in the United States. Several 
states engaged in energetic efforts to develop systems of community colleges that would provide a campus within commuting distance of almost every high school graduate in the state (Thornton, 1972).

The community college has been the most rapidly developing educational institution in the United States (Carnegie Commission on Higher Education, 1974; Collins, 1967). This has been due to

- . their open admissions policies, their geographic distribution across the country and their unusually low tuition policies. They also offer more varied programs for a greater variety of students than any other segment of higher education, provide a chance for postsecondary education for many who are not fully committed to a four-year college career and appeal to students who are undecided about their future careers and unprepared to choose a field of specialization. In addition, they provide an opportunity for working adults to upgrade their skills and training (Carnegie Commission on Higher Education, 1974, p. 97). 
Growth in community colleges was favorable during the Depression and immediately afterward. The number of community colleges grew from 403 in 1929 to 584 in 1945 . By 1960 there were 678 community colleges (Monroe, 1973). In $1972 \mathrm{M}$. J. Cohen traced the relations among the number of community colleges in a state, the state's population density and its area. He found that community colleges tended to be built so that 90-95 percent of the state's population lived within reasonable commuting distance, about 25 miles. When the colleges reached this ratio, the state had a mature community college system and few additional colleges were built. Cohen identified seven states that in the early 1970's had mature systems: California, Florida, Illinois, New York, Ohio, Michigan, and Washington. Using his formula, Cohen found that 1,074 public community colleges would effectively serve the nation (Cohen, 1982). Today there are 1,224 regionally accredited, technical and junior colleges in the United States. They enroll over five million college credit students. An additional four million students are enrolled in non-credit adult and continuing education programs (Commission on the Future of Community Colleges, 1988). Community colleges have effected notable changes in American education, especially by expanding access. After World War II, college-going rates increased rapidly so that by the 1970 's three in every eight persons attended a 
community college. The increase in enrollments was accompanied by a major change in the composition of the student body. Community colleges were opened to ethnic minorities, to lower-income groups and to those whose prior academic performance had been marginal (Cohen, 1982). The community colleges reached out to attract those who were not being served by traditional higher education. They reached out to low-income, part-time, ethnic minority, underprepared, underemployed, unemployed, physically handicapped, reentry adults and retired individuals. More so than in the universities, the community college student population tends to reflect the ethnic composition of its surroundings. By 1977, minority group students formed more than 60 percent of the enrollment in the Los Angeles Community College District. Hispanic students made up 30 percent of the enrollment in Reedley College, located in a small California town (Cohen, 1982).

Astin (1982) points out, "it is probably true that, were it not for community colleges, many minority students would not attend college at all" (p. 152). He further states "students from all minority groups tend to be concentrated in two-year public colleges" (p. 132). Typically, community colleges have attracted the poor and minorities to their campuses. In 1978, 42 percent of all Black students and more than half of all Hispanic and American Indian students in higher education were enrolled 
in two-year colleges. In California more than 80 percent of all Blacks and Hispanics who went on to public higher education immediately after graduating from high school in 1979 did so at a community rellege (California Postsecondary Education Commission, 1981). People who, in the past, may not have considered higher education were greatly encouraged. Medsker (1960) related:

\begin{abstract}
The two year college was designed to play a special role in American higher education. This it does in a variety of ways: it is perhaps the most effective democratizing agent in higher education. It decentralizes post-high school opportunities by placing them within range of a large number of students. It makes higher education available at a low cost to the student--it offers a wide range of educational programs not found in other colleges (p. 4).
\end{abstract}

These new student groups have had a most pronounced effect on community colleges. Their success in enrolling these new students has affected what they can offer. As these students continue to become a sizeable portion of the college enrollment, the college's philosophy and mission will be affected. 
The community college has been referred to as the only truly American invention in the field of education (Collins, 1967). In establishing its role in education, it has developed its own unique identity (Cross, 1974; Matson, 1967). It may be best to characterize community colleges merely as untraditional. They do not follow the tradition of higher education as it developed from the colonial colleges through the universities. They do not typically provide the students with new value structures, as residential liberal arts colleges aspire to do. Nor do they further the frontiers of knowledge through research training. Community colleges do not even follow their own traditions. They change frequently, seeking ever-new programs and clients. As Cohen (1982) emphasized,

Community colleges are indeed untraditional, but they are truly American, at their best, they represent the United States at its best. They try new approaches--maintain open channels for individuals, enhancing the social mobility that has so characterized America. And they accept the idea that society can be better, just as individuals can better their lot within it (p. 28). 
The community college's stance has often been one of synthesizer and it has played this role well. It has encompassed a number of social, economic and educational. movements within its comprehensive philosophy. Community colleges serve unique communities and needs. And thus some observers caution against very specific, narrow missions for these open door institutions. Gleazer (1980) indicates:

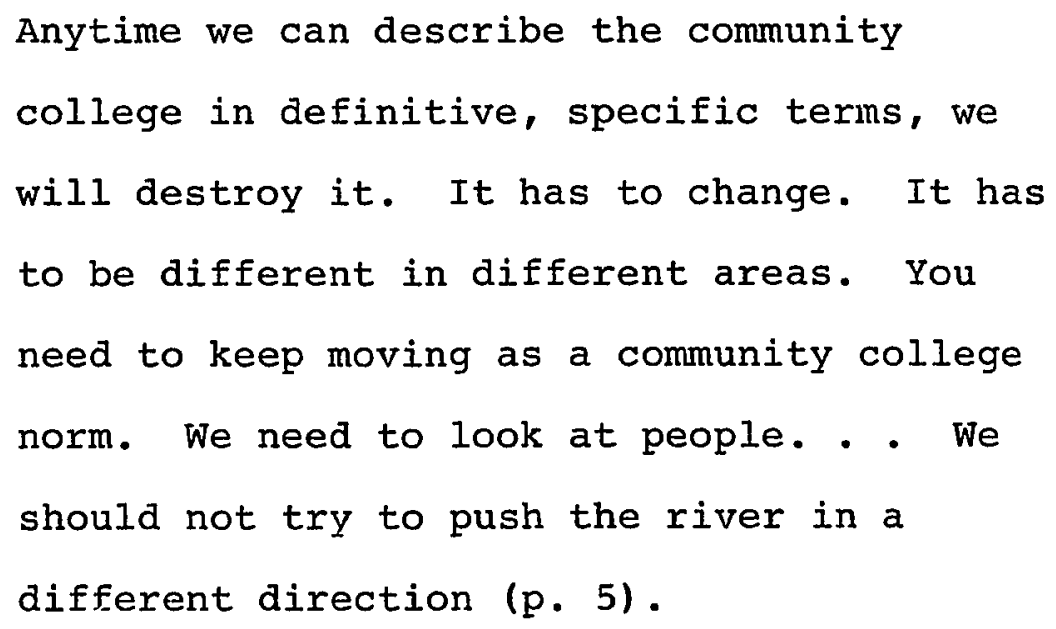

Mission statements of community colleges have been subject to change as demands of times change. While the basic purposes persist, the means by which the college carries out these purposes could be redefined as a result of changes in society. It is time to carefully examine the current environment and to forecast further needs as a basis for redesigning all segments of the educational system. There must be concentrated focus on our literacy crises and future occupational requirements. 
This examination has recently taken place in California. Between 1984 and 1988, in the state of California, the Commission for the Review of the Master Plan for Higher Education reviewed and, in some cases, redefined the missions and responsibilities, admissions to, governance, educational equity, educational quality and coordination of California's three postsecondary segments: the California Community Colleges, the California State University and University of Caiifornia. The Commission affirmed that:

The California Community Colleges shall offer academic and vocational instruction at the lower division level. . [primary function], provide remedial instruction for those in need of it. . ., English as a second language, adult non-credit instruction [important and essential function], and fee-supported community service instruction [authorized function] (Joint Committee for the Review of the Master Plan in Higher Education, 1988, p. 13) .

In essence the Commission supports the comprehensive mission of the community colleges. 
The American community college of the 1980's is a vital and dynamic institution whose mission can and should be more important to our nation than ever before. Since its inception, the fundamental qualities of the community college have been responsiveness and flexibility in meeting the educational needs of our society. For more than thirty years, its primary thrust was to expand access to higher education and to provide opportunity to new populations. Community colleges were eminently practical and without the binding traditions of universities, were able to react more quickly. Robert McCabe (1983), President of Miami-Dade Community College, has observed

Because of their adaptive flexibility, the community colleges made enormous contributions to changing American society and became the most important educational institution of the mid-twentieth century (p. 232).

Current trends clearly indicate that community colleges will become even more essential to the well-being of America in the late twentieth century than they have been during the mid-twentieth century. We have already entered a period in which most individuals will require continuing professional or occupational education in a postsecondary institution. With the current rapid growth 
of high technology and computer and information related occupations, jobs appropriate to the associate degree are rapidly expanding. No other institution is as well prepared to offer solutions to our national literacy problem. Through its continued commitment to the open door, the community college stands as the essential institution to assist individuals in making necessary transitions (Vaughan, 1983).

In summary, society needs community colleges to provide opportunities to young people in traditional programs and to adults with an awakening need for continuing education. The four-year institution, like the classical high school, cannot serve the needs of the heterogeneous populations that have come to view higher education as a necessity and a birthright. Consequently another institution, the two-year college evolved to attempt to meet this need. If community colleges did not exist, states would probably invent them (Knoell, 1983). The junior/community college movement was perhaps the most significant mass movement in education that this or any other country has seen in an equal period of time. Ray Lyman Wilber, Secretary of the Interior, stated in the late thirties:

The astounding growth and spread of the public and private junior college in the 
United States is evidence of a long overdue rentissance in the stereotyped and debilitated collegiate educational structure which has evolved from our traditional educational attitudes (Seashore, 1940, p. 1).

\section{Reform Recommendations for}

\section{California Community Colleges}

Social evolution has clearly outpaced advances in education in recent decades. This has resulted in a strong and justified public outcry for reform and revitalization throughout the total educational system. It is now the beginning of a new era in American society. Community colleges are faced with a great challenge and a great opportunity to help society cope with major changes. Community college leaders must shape their colleges to respond to the:

1. challenge of changing demographics,

2. growing negative feeling about public education academic standards,

3. limited government funding of student financial aid programs,

4. information age that Toeffler labelled "the third wave," and to the 
5. shrinking of the world which encourages more international students and limited English speaking students.

The community colleges must again rely on the major assets that made it so unique and important through the midtwentieth century--responsiveness and flexibility (McCabe and Skidmore, 1983; Gilley, 1983).

In the last 25 years, California has developed an extraordinary educational system from pre-school to postgraduate level. It has become the most comprehensive social institution in the state. The University of California, one of the world's top research universities consists of nine campuses. The California State University, renowned as a teaching institution, consists of nineteen campuses and many satellite centers. The California Community College system includes 107 colleges within 71 districts. This system has served, not only this country, but others as well, as the model for community-based lower division academic and vocational instruction.

This system, including private colleges and universities existed and worked harmoniously under the guidance of the 1960 Master Plan for Higher Education. The 1960 Master Plan sought to bring order and reason to the rapid growth that characterized not only the community colleges but also the state universities, the University of 
California and the independent colleges and universities. It delineated the primary functions of the community colleges which were: undergraduate education leading to transfer and vocatiosil and techical training leading to employment. There existed the underlying expectation that community colleges would remain accessible to all.

Since 1960, many demographic, societal and economic changes have occurred in the state and within the educational institutions. A cry for reform in higher education was heard. Academic standards were questioned and criticized and student success rates were scrutinized. Thus in 1985, work was begun by the Commission for the Review of the Master Plan for Higher Education. The Commission whose membership was broadly based, worked for two and one-half years reviewing the 1960 Master Plan for Higher Education in light of the present and anticipated challenges facing California. It completed its work with the adoption on July 22, 1987, of its report "The Master Plan Renewed: Unity, Equity, Quality and Efficiency in California Postsecondary Education" (Commission for the Review of the Master Plan for Higher Education, 1987). The Commission recognized that California's postsecondary education system was facing and would face new challenges in the future. It recognized that California is rapidly becoming a highly diverse society with all of its accompanying benefits and problems. It firmly believed 
California's increasingly diverse population is a great asset and that education should play a major role in developing that asset and in determining how to respond to the future challenges. To this end the Commission directed their recommendations toward the achievement of four possible goals:

Unity, to assure that all elements of the
system work together in pursuit of common
educational goals;

Equity, to assure that all Californians have unrestricted opportunity to fulfill their educational potential and aspirations;

Quality, to assure that excellence characterizes every aspect of the system; and

Efficiency, to assure the most productive use of finite financial and human resources (Commission for the Review of the Master Plan for Higher Education, 1987, pp. 2-4).

The reforms the Commission proposed were considered to be essential to meet the current and foreseeable future 
changes in California and in its higher education system. The Commission's report recognizes and supports community colleges as equal partners in the higher education enterprise and not part of the public school system. Thirty three recommendations were forwarded by the Commission. The recommendations that were of primary concern to the community colleges, addressed such issues as governance, mission, outreach/recruitment, affirmative action issues for students and all classifications of employees, articulation, admission requirements, assessment and counseling, remedial education, retention, student outcomes and an overall emphasis on student success. Some highlights include:

- Maintenance of lower division enrollment at University of California and California State University at no more than 40 percent of total undergraduate enroliment.

- A guarantee of future enrollment as upper division students at University of California or California State University to the campus of first choice for otherwise eligible students who elect to attend a community college, coupled with a guarantee of equal opportunity with continuing students for admission to programs. 
- The recognition of the California Education Round Table as the body responsible for necessary linkage for a unified system of higher education with the community colleges having a role equal to those of the other segments in addressing pressing issues relative to equity, admissions and curriculum.

- A requirement that students not regularly eligible for admission to University of California and California State University as freshmen complete an intersegmentally developed transfer core curriculum at a community college.

- The administration of a unified state-local system by the Board of Governors with broad policy making and management responsibilities in both academic and financial matters.

- Clarification and strengthening of the community colleges lead role in offering academic and vocational instruction at the lower division level, and in implementing minimum skill level requirements, mandatory assessilent and counseling.

- Elevation of the transfer function as a general institutional priority of all three public segments 
coupled with expectations that community college students will have access to courses that meet the lower division baccalaureate degree requirements of California's public universities.

- Guaranteed student financial aid for all qualified students in a manner that optimizes student choice.

- Improved recruitment in all three segments of minority and women faculty and administrators through a statewide program of early identification and training (Commission for the Review of the Master Plan for Higher Education, 1987).

The Commission's work was subsequently reviewed by Assembly and Senate members of the California Legislature who comprised the Joint Committee for Review of the Master Plan for Higher Education. The Joint Committee's full study and set of recommendations is included in their report: California Faces . . California's Future...Education for Citizenship in a Multicultural Democracy. The Joint Committee's recommendations resulting of more than four years of study, became the basis for Assembly Bill 1725. Assembly Bill 1725, Chapter 973, was signed into law on september 19, 1988, and became the landmark statute for community college reform. The result and 
potential impact of the Joint Committee recommendations could very likely be measured in the future by the adequate funding of and effective implementation of Assembly Bill 1725 .

In essence $A B 1725$ has become the major community college reform bill for the $1990^{\prime} \mathrm{s}$ and next century. It reaffirms the general direction of the community colleges and proposes to strengthen many facets of the colleges and the state system. It focuses particular attention to program improvement and faculty professionalization.

David Mertes, Chancellor of the California Community Colleges, in addressing the California Association of Community Colleges in November, 1988, exclaimed:

We are at a historic moment for the community colleges. The passage of $A B 1725$ signals closure to an era of scrutiny, self-study and reform. We have entered into a new era that is exemplified in the provisions of this legislation. I think of $A B 1725$ as a template for community colleges at the turn of the century. It addresses our role as part of California's society and our role in the state's economy (Mertes, 1989, p. 3). 
The bill's reform recommendations are extremely comprehensive and encompass eight major areas: mission, governance, finance, new programs and services, affirmative action, employment policies, accountability and conditions and appropriations for reform. A brief synopsis of each major portion of the bill follows (Board of Governors, 1988).

Mission: The mission of the colleges is clarified and, for the first time, priorities are established. Degree and certificated curricula in lower division arts and sciences and in vocational and occupational fields is the "primary mission." Remedial instruction, English as a Second Language and support services which help students succeed are "important and essential functions." Adult non-credit education curricula in areas defined as being in the state's interest is an "essential and important function." Community services courses and programs is an "authorized function" so long as their provision is compatible with an institution's ability to meet its obligations in its primary missions.

A common core curriculum for transfer students is to be developed and used by the University of California, the California State University and the California Community Colleges.

The Board of Governors is required, by January 1 , 1990, to adopt a specific regulation prohibiting students 
from acquiring more than 30 semester units of "remedial coursework."

The Board of Governors and the state Board of Education are required to assist school and community college districts in developing articulation agreements coordinating vocational education $(2+2$ programs $)$. In addition articulation efforts with universities are also stressed $(2+2+2$ programs).

The California Postsecondary Education Commission and the Department of Education are to conduct an English as a Second Language study to determine future needs for ESL programs.

Governance: The California community colleges are expressly designated as a postsecondary system of education, with a delineation of the respective roles of the Board of Governors and locally elected district governing boards. The composition of the Board of Governors is modified to require the Governor to appoint two current or former district trustees and a second faculty member. Up to six deputy or vice-chancellors exempt from State Civil Service are newly authorized for the Chancellor's office. The role of faculty, particularly that of academic senates in community college governance is strengthened. Throughout the bill, rights of faculty and roles for the academic senate are stressed. 
Finance: The major authority for developing and administering the community college finance mechanism is shifted from the legislature to the community college system. The use of average daily attendance (ADA) as the single workload measure for funding community colleges will be replaced by a more sophisticated and cost-based set of workload measures known as "program-based funding." A "program improvement" mechanism for major new funding is provided. It will provide funds to cover the cost of various state mandates contained in the bill; funds to enable districts to increase the employment of full-time instructors to reach the required 75 percent to 25 percent ratio of full-timers to part-timers and funds to be used at district discretion for various purposes outlined in the bil1.

New Programs and Services: In addition to providing for a major infusion of resources for various areas of program improvement, the bill creates or expands several specific programs and services. Among the major new programs and services are new programs for staff development. Through AB 1725, community colleges are the first educational segment to receive specific funding for staff development. This speaks loudly to the emphasis on improvement of skills of faculty, staff and administrators employed at the community colleges. Other programs and services include an expansion of the Community College Fund 
for Instructional Improvement, authorizing language to update and establish career resource and placement centers and the establishment of new service functions in the Chancellor's office to provide districts with information on economic trends and employment projections.

Affirmative Action: In the intent language accompanying $A B 1725$ the legislature recognizes that California is undergoing a major demographic, social and economic transformation and that community colleges are at the center of this change. It further recognizes the massive number of retirements that will occur in the community colleges during the next 15 years. Also recognized is the "window of opportunity" that exists to make the staff of the colleges more representative of the state's population diversity. Concerns about affirmative action and staff diversity are evident throughout the bill. Particular attention is paid to increasing the pool of qualified minorities and underrepresented group members from which community colleges will draw their new employees. Districts will be required to update their affirmative action plans and publish and distribute them. Assembly Bill 1725 creates the Faculty and Staff Diversity Fund to pursue two goals for the community college system: (1) by 2005 the cumulative workforce of the colleges should reflect proportionately the adult population of the state; and (2) by 1992-93, 30 percent 
of all new hires in the system should be ethnic minorities. This is an unprecedented step toward affirmative action. Courses and training to implement affirmative action programs are an authorized use of staff development money as are the costs of publishing and distributing affirmative action reports. Another way that affirmative action is stressed is by requiring districts to develop hiring criteria for faculty and administrators that include a sensitivity to and understanding of the diverse academic, socioeconomic, cultural, disability and ethnic backgrounds of community college students.

Employment Policies: Assembly Bill 1725 brings to an end an era of $\mathrm{k}-12$ employment policies that governed the hiring practices of colleges. Credentialing, with its standards for employment dictated by the legislature, is replaced by a structure that vests the Board of Governors and faculty with more authority to establish and apply policy. The systemwide governing board will be establishing minimum qualifications (standards) for employment of faculty members and administrators which are then applied by the local colleges. Both academic senates as well as exclusive representatives for collective bargaining will have roles in developing and administering this new structure. Credentials, thus will become inoperative when at least $\$ 70$ million in program 
improvement money is provided. This could happen as early as July 1, 1989 .

In addition to the repeal of credentials, and only after a third funding allocation of $\$ 70$ million, the probationary period for tenure is lengthened to four years as to be more consistent with those used in other postsecondary segments. Probationary employees must be evaluated at least once each academic year; tenured employees must be evaluated at least once every three academic years and part-time faculty must be evaluated within their first year and at least once every six semesters thereafter.

Accountability: Assembly Bill 1725 vests both the Board of Governors and district governing boards with significant authority to decide matters heretofore decided by the legislature. Assembly Bill 1725, however, also requires the Board of Governors, by July 1, 1990, to develop and recommend implementation of a comprehensive community college educational and fiscal accountability system. The contents of the system are generally described with a more specific instruction to define and measure, quantitatively and qualitatively, accountability information, including: student access; the extent to which the student body reflects proportionately the adult population of the state; student transfer rates; academic standards and student achievement; student goal 
satisfaction and success; adequacy of and student satisfaction with student services and completion rates of courses and programs. The implementation of the accountability system is dependent, in part, upon the development of adequate data collection and reporting system. Thus the Community College Management Information System (MIS) will be a critical priority in this effort to improve accountability.

Conditions and Appropriations: Initial implementation of $A B 1725$ would have cost, according to the estimates of the Board of Governors, at least $\$ 105$ million. The fiscal difficulties encountered by the state beginning the spring of 1988 made it impossible to fully fund the initial costs. As an alternative, various provisions of reform were drafted so as not to become operative until certain major new levels of funding are made available through the annual budget process. This option avoided what would have been a certain veto of a fully funded bill. It also enabled initial reform to commence with a small budget of $\$ 7.25$ million in January, 1989.

Assembly Bill 1725 provides that reform is to consist of two phases. Phase I focuses on improving community college programs to improve the subsequent professionalization of faculty. The repeal of credentials, the institution of the new structure for minimum qualifications and the new requirements for faculty and 
staff evaluation will become operative when $\$ 70$ million in program improvement funds are made available. Phase II follows initial program improvement and faculty professionalization and allows for more full-scale implementation of the act. Longer probationary periods for tenure and program-based funding will not become operative until a third funding allocation of $\$ 70$ million in program improvement funds is appropriated.

In summary, $A B 1725$ with its 55 total recommendations addresses many issues including: college mission and function, academic standards, transfer curriculum, progress monitoring, student success, English as a second language, basic skills, faculty, administration and staff role and qualifications, staff development and renewal, affirmative action and finance (California Faces. . California's Future, 1988).

Some of the challenges for California community colleges posed in $A B 1725$ seem familiar. However, what is new is the fact that a more diverse population and more rapid economic and social changes will make these challenges more difficult. Expected future conditions point to the need for strengthened and more diversified community colleges to ensure a literate, skilled and responsible California citizenry (California Community Colleges, 1985). In light of the AB 1725 challenges, 
McCabe's and Skidmore's (1983) comments are timely and relevant today.

It is time once again for community colleges to do what they do best--to design innovative and diversified programs to meet the rapidly changing needs of society. Traditional approaches must be abandoned and basic reform undertaken to permit continuation of the open door. Through such strengthening and growth, this institution will retain its position of central importance in the future evolution of American society (p. 248).

In summary, there is major attention being directed to the provision, in the community colleges, of an academically excellent education which addresses the needs of a diverse staff and students. To meet both the spirit and the requirements of Reform Bill $\mathrm{AB}$ 1725, many changes will take place in California's community colleges. Thus it is imperative that much analysis, planning and decisionmaking founded on good data, research and broad participation precede the specific implementation efforts of $\mathrm{AB}$ 1725. The way in which the community colleges will respond to $A B 1725$ will affect the role of student services. The innovations taking place in the academic 
segments of the colleges will require a need for parallel innovations in student services.

\title{
Demographics Affecting California
}

\section{Community Colleges 1990-2000}

\author{
"The evolving demographic revolution in our \\ society hits with the force of the \\ sledgehammer" (Miller, 1988, p. 25).
}

The heterogeneity of community college student populations has been a point of emphasis in the literature (Collins, 1967; Collins, 1972; Gleazer, 1973; Thurston, 1972). Collins (1967), in his summary of the McConnell Raines study, described the community college student as "almost as varied as humanity itself" (p. 12). There are indications that in the future the types of community college students will be even more varied. The present diversity and the predicted increase in types of students can be attributed to the open-door policy of community colleges as well as to rapidly changing demographics.

California's population is changing and growing at a rapid rate. The state's expected demographic changes are dramatic and relatively certain: 
California continues to grow faster than the nation as a whole.

The state's population will increase by one fifth by the year 2000 .

Among California adults, the 35-54-year old age cohort is the most rapidly growing.

The 18 to 24-year old traditional college going age cohort will decline until 1990; then increase, but not regain its 1980 level until near the end of the century (Contours of Change, p. 2).

Overall, California is becoming older and more ethnically diverse. The population is projected to grow by almost four million in the next ten years. The 14-24-year old group comprised 20 percent of the population in 1980 . The projections are that this group will represent 16 percent of the population in 1990; 15 percent in 2000 and 2010 and 13 percent by 2080. As this group declines, nationally the 25-54-year old group increases. (Demographics for the Eighties and Nineties, p. 1). This group which is increasing at the most rapid rate, will represent almost one-third of the state's population. Thus 
the proportion of older students at community colleges will increase over the next ten years. The percentage of females will remain slightly higher than the number of males (Looking Ahead: Data for Planning, 1987). It will be from this pool that colleges and universities will draw their major degree candidates.

Almost half of the projected growth of four million in the next decade will be due to natural causes (births minus deaths) and half to net in-migration. With the current uncertainties about Texas, and given the fact that in-migration to that state virtually halted at the end of 1985 due to the state's overwhelming dependence on world oil prices, California, with its diversified economy and population is the state that will absorb the growth. Two-thirds of the world's immigration is to the United States and California is now accepting almost one-third of that portion of immigrants. Since 1982, 30 percent of the new-arrival refugees to the United States chose California as their destination. Of these new refugees, 75 percent were from Southeast Asia. If it were not for immigration from other countries and in-migration from other states, the California population would actually be decreasing. Fifteen percent of California's population was born in another country while 55 percent was born in another state (Hodgkinson, 1986, p. 1). 
The nation's undocumented alien population is expected to number ten million by the early 1990's, half of whom are likely to reside in California. This represents a fivefold increase over 1980. This group will be composed primarily of young Hispanics. Passage of immigration legislation may make many of these individuals legal residents of California (Contours of Change, 1985). The Amnesty Program will be impacting English as a Second Language departments, admission and records offices and counseling departments as these students enroll in community colleges to improve their English language skills.

Currently, the racial and ethnic minority groups account for 40 percent of California's population. It is estimated that this will increase by 50 percent by 2005 . The number of Caucasions will decrease and be in the minority by the year 2000. California is first among all states in the numbers of foreign-born, primarily from the Pacific Basin including Asia, Mexico, Central and South America. Today, one of every six elementary students was born outside of the United States. The Hispanic population will increase at the most rapid rate, followed by Asians. The higher birth rate among the Hispanic populations will result in Hispanics becoming a larger percentage of the 14-24-year old age group, increasing from 24 percent in 1985 to over 34 percent in 2005. By the year 2000 more 
than one-third of all school age children will be Hispanic, one in eight will be Asian and one in twelve will be Black. It is estimated that sometime between 2000 and 2010 , Hispanics will constitute over 30 percent of the general population, Asians 13 percent, Blacks 8 percent and Whites less than 49 percent. Thus, by the 21st century, California will be the first mainland state with a majority of nonwhite persons (California Faces . . California's Future, Contours of Change, 1985).

There are two million children under the age of five in California. A majority of them are non-white and live in the southern part of the state. In the Fall of 1985 , only 15 percent of the Los Angeles school children were Caucasian. Although all the 28 largest United States cities now have a minority of Whites, the data for Los Angeles is particularly striking. During Fall 1985, non-Hispanic whites are only 15 percent of the early elementary enrollments while Hispanics are 60 percent, Blacks are 16 percent and Asians are about 4 percent. The total enrollment in the Los Angeles public schools for Fall 1985 was 547,233. That is larger by far than the combined total enrollments of the University of California $(147,500$ in 1985$)$ and the California State University (325,000 students). By 1990, a population as large as the Los Angeles school system will be added to the enrollment in California public schools. It will be even more diverse 
ethnically than the 1985 school population (Hodgkinson, 1986). With this kind of data, it is both evident and imperative that the higher education system in California must work very closely and effectively with the state's public schools.

\section{Implications for Community Colleges}

Future changes in the demographics and lifestyles of Californians will result in greater demand for postsecondary education and in substantially more variation of individual educational needs than ever before. The message is clear, "Community colleges should prepare for increasing and changing demands for their educational services over the rest of this century" (Contours of Change, 1985, p. 6).

Based on expected changes in the demography and social structure of California, potential community college students may be grouped into three general categories, "the traditional college-going, 18-24 year olds, the individuals with recurring educational needs and the new students" (Contours of Change, 1985, p. 7).

The traditional college-going student group consists of individuals who are enrolled in college for the first time and want to learn an occupational skill or prepare for transfer to a four-year institution. Currently this group represents 45 percent of comrunity college enrollments but 
is decreasing in absolute numbers and as a proportion of the total enrollment until the mid-1990s (Contours of Change, 1985; California Faces - . California's Future, 1988).

The group consisting of individuals with recurring educational needs includes those who are out of work and seek career or job skills or retooling for career changes; those with jobs who seek skills that will enable them to fully realize their potential and those who seek survival skills. This entire group and the needs it brings will increase dramatically during the rest of this century (Contours of Change, 1985). This group is generally older than the other groups. The needs of older students are different from those of the traditional 18-24 year old students. Many will be working and will have children. Frequently they will be coming back to school for education in a second or third career. In order to successfully accommodate job and children they will need flexible scheduling, child care and convenient class locations (Looking Ahead . . Data for Planning, 1987; Contours of Change, 1985).

The rapid increase in female students during recent years is expected to continue into the early 1990's. The most rapidly growing gender/age cohort among community college students has been that comprised of women aged 20 to 24. Many of these women have recurring educational 
needs. Increasing numbers of them are single and head of household and are pursuing training for their first entry into the labor market. Access for these students is dependent upon the time and location of classes, and often more important, the existence of special services such as child care, career counseling and financial aid (Contours of Change, 1985; Looking Ahead - . Data for Planning, 1987).

Many of the new student group are foreign-born and nearly all are from a minority racial and ethnic background. These students are often the first in their family to undertake postsecondary education; often possess limited English skills; typically come from low income circumstances and are underprepared for college and employment. Currently this is the smallest of the three student categories but it is the most rapidly growing group. This group will require special services in their educational endeavors. They will increase the demand for English as a Second Language and remedial coursework because of their limited English skills and their weak academic preparation. They may also be more dependent on financial aid because of their limited incomes (Looking Ahead . . Data for Planning, 1987; Contours of Change, 19851 .

These are but a few of the demographic projections. No attempt has been made here to address the anticipated 
changes in families, children, teenage pregnancies, technological changes, job growth and trends, personal income, employment and other economic, social and policy issues. However, the demographic information presented here is clear and compelling. For California community colleges, they translate as an anticipated:

1. increase of part-time students,

2. increase of returning adults,

3. increase of underprepared students,

4. increase of Hispanic, Asian and Black students,

5. proportional decrease of Caucasian students,

6. proportional increase of female students,

7. decrease of recent high school graduates,

8. increase of limited English proficient (LEP) students, and

9. increase of unskilied, unemployed and underemployed adults (Looking Ahead . . Data for Planning, 1987; California Faces . - California's Future, 1988; Contours of Change, 1985; Hodgkinson, 1986). 
The demographic changes addressed here and many others, not delved into here, will have a tremendous impact on the demand for curricular offerings and student services provided by California community colleges. These projections dictate the immediate need for selfevaluation, needs analysis, and program planning to be prepared to meet the challenges ahead for California community colleges.

\section{Counseling and Other student Services}

in Community Colleges

Both student personnel services and junior colleges have emerged in the twentieth century as distinguishing features of American education. Their development has been compared as being closely parallel with the founding of the first public junior college in Joliet, Illinois, in 1902 and with student personnel work beginning as an organized movement in 1900 . Both movements also reached mutually high points of development and recognition in the sixties (0'Banion, Thurston and Gulden, 1970). Student services, including counseling services were seen from the beginning of the two-year college movement as essential for student development and success. As early as 1921, California added provisions for guidance services to other existing laws. Nebraska passed a law providing such services in 
1931 and Wyoming took action in 1945. The most active changes have taken place since 1950 (Blocker, Plummer and Richardson, 1965).

Many of today's student services were originally performed by the college or university presidents. As these institutions grew and became more diversified, presidents delegated more responsibility to the faculty. The history of student services in higher education centers around three developments. First, student services functions were lodged in the area of discipline. In its loco parentis role, the college assumed responsibility for the conduct and moral well-being of its students. A second kind of student services function was often initiated by students themselves. Greek letter societies, intercollegiate athletics and other activities contributed to the quality of student life. A third set of student services grew out of the needs and demands of special interest groups. These are still evolving today though at a slower pace than during the sixties and early seventies. The most recent interest groups are women returning to school and handicapped students. The common thread in the history of student services is the importance of the special interest needs that motivate the establishment of new student services (Elsner, P. A. and Ames, W. C., 1983). As colleges and universities increased in numbers and complexity, student personnel work evolved as a group of 
loosely organized services. O'Banion, Thurston and Guldon (1970) stated that programs developed "as a series of services in reaction to forces within the college community rather than as an action program for shaping forces" (p. 7). Prior to 1930, student personnel services in the community college were mainly regulatory functions. In the 1940s, there was increased interest in providing guidance and counseling as well as testing programs for academic placement of students. By the 1950's, community colleges recognized the importance of a well-developed student services program. In recent years, the policy of serving an increasingly diverse population has emphasized even more the need for student personnel services (Collins, 1972; Medsker, 1972; Monroe, 1973; Thurston, 1972). Community colleges are charged with the responsibility of making the educational experience meaningful to these new students (Medsker, 1972).

Thus much of the early history of student personnel work has been reactive in nature as colleges attempted to meet both the needs of students and the institutions. However, in meeting the needs, services were established that would remain as basic functions in the years to come. A survey of the literature revealed a basic group of common functions or services which became essential to student personnel services programs. With few exceptions this same list of basic services has been repeated throughout the 
literature (Arbuckle, 1953; Fitzgerald, Johnson and Norris, 1970; Higgins and Thurston, 1966; Hinko, 1971; Hopkins, 1948; Mueller, 1961; O'Banion, 1970; Packwood, 1977; Williamson, 1961) and has included the following: selection for admission; registration and records; counseling; health services; housing and food services; student activities; financial aid; placement; discipline, special clinics (remedial reading, study habits, speech, and hearing and special services); student orientation, veterans advisory services; foreign student program and testing.

In light of the open-door policy, the Carnegie Commission has recommended that the community college provide counseling and guidance services to meet the needs of the new types of students (Carnegie Commission on Higher Education, 1974). Jones (1970) noted that junior college students even more than other groups of students can benefit from the help of professional counselors. Matson (1972) stated that counseling is considered to be the
key student personnel service. . it is the one function in which there are readily identifiable expertise and well-established training programs to provide the essential skills and knowledge. In this sense it is the most professionalized of all student 
personnel functions and thereby occupies

a central position in the total student personnel field (p. 173).

Both Jones (1970) and Collins (1965) stated, however, that the role of the junior college counselor is not that of a psychiatrist or psychologist. Collins (1965) emphasized that counselors should focus more on vocational and educational counseling. He also suggested that counselors should assist students with values clarification.

Blocker, Plummer and Richardson (1965) believed that counseling was the key feature of all student personnel work. They also believed that student initiated counseling was most likely to occur in response to a felt need or problem arising in one of four areas. The student may require assistance in selecting his educational program. Students are likely to seek assistance in choosing and planning for a transfer institution. They need assistance in clarifying their vocational classes. These general counseling functions are well recognized by administrators in two-year colleges and have their approval. The fourth area in which students may need assistance is subject to considerable controversy. This is the area of personal counseling. Some fail to recognize that problems in other areas are almost always related to personal difficulties 
and frequently are caused by them. Blocker, Plummer and Richardson (1965) recommend that professionally prepared counselors be available to provide this service.

In 1979 a California statewide task force was formed to respond to the Board of Governor's request that a comprehensive report be prepared on counseling in the California community colleges. The fifteen member task force studied counseling and formulated recommendations to the Board. Among one of their recommendations was the following mission and philosophy for community college counseling.

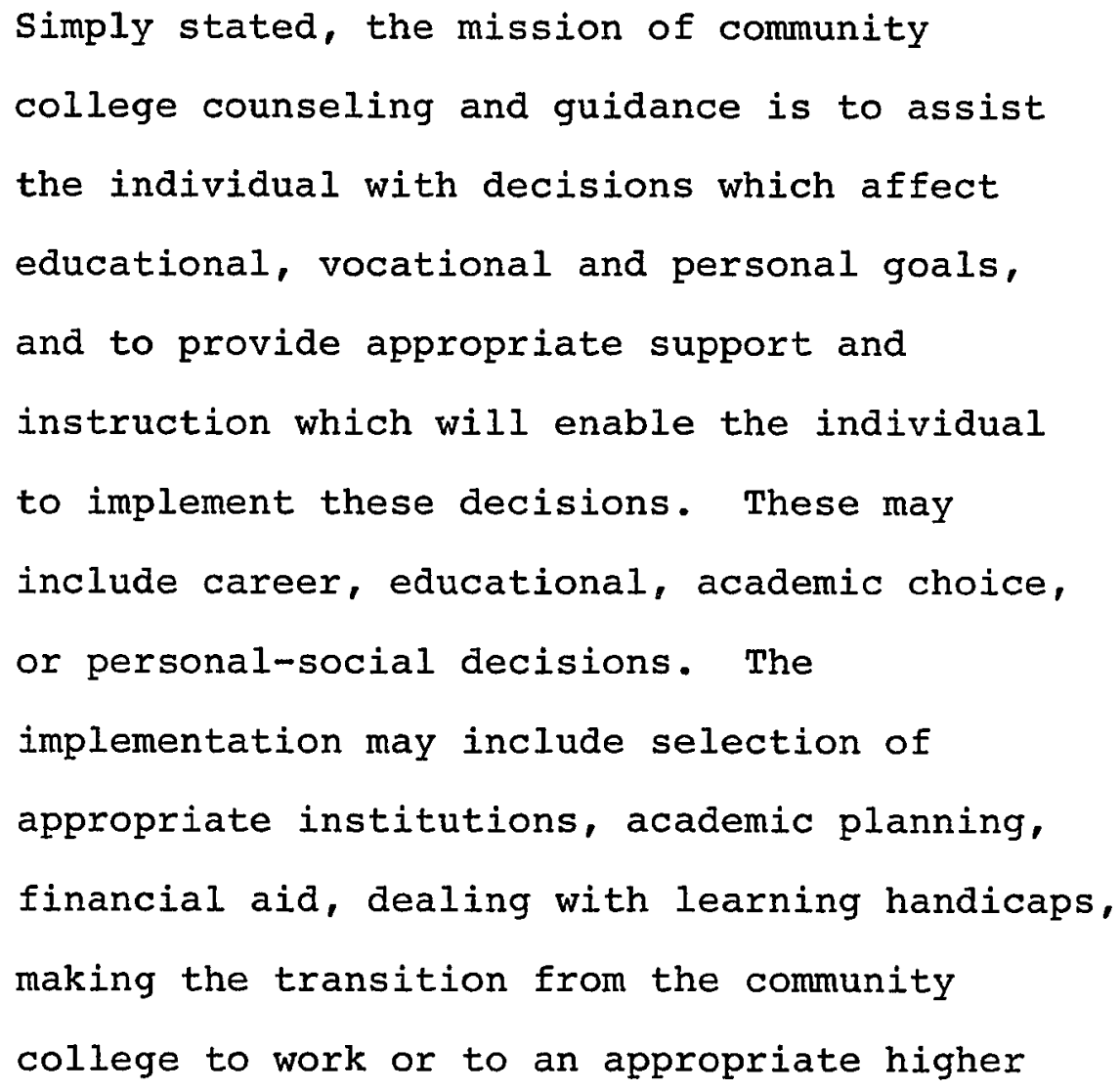


level college or university, and assistance in handling personal, family or social problems which may interfere with educational goal attainment (Task Force on Counseling, p. A43).

Counseling services in the community college must take into consideration the unique educational philosophy of the college. The philosophy centers on the students and their needs. The community college is student centered (Collins, $1970)$ and reflects a commitment to the personal as well as to the academic growth of the student (Miller, 1979).

The provision of counseling services is one of the major objectives of the community college (Jones, 1970; Miller, 1977; Schoenberg, 1978). Catalogs of the majority of community colleges, in describing the purpose of the institution, include some reference to guidance for counseling) as a major responsibility. There is substantial evidence that the role of counseling and guidance has been given much consideration and importance in the historical development of the two-year college (Matson, 1983).

The commitment by the community college, and recently by the Joint Committee for Review of the Master Plan in Higher Education, to the concept that student personnel services are an inherent part of its program has been emphasized (Blocker, Plummer and Richardson, 1965; Collins, 
1972; Monroe, 1973; O'Banion, 1970: Joint Committee for the Review of the Master Plan in Higher Education, 1988).

As stated by Yoder and Beals (1966), there is a relationship between the roles of the community college and student personnel services which mandates the need and commitment to these services.

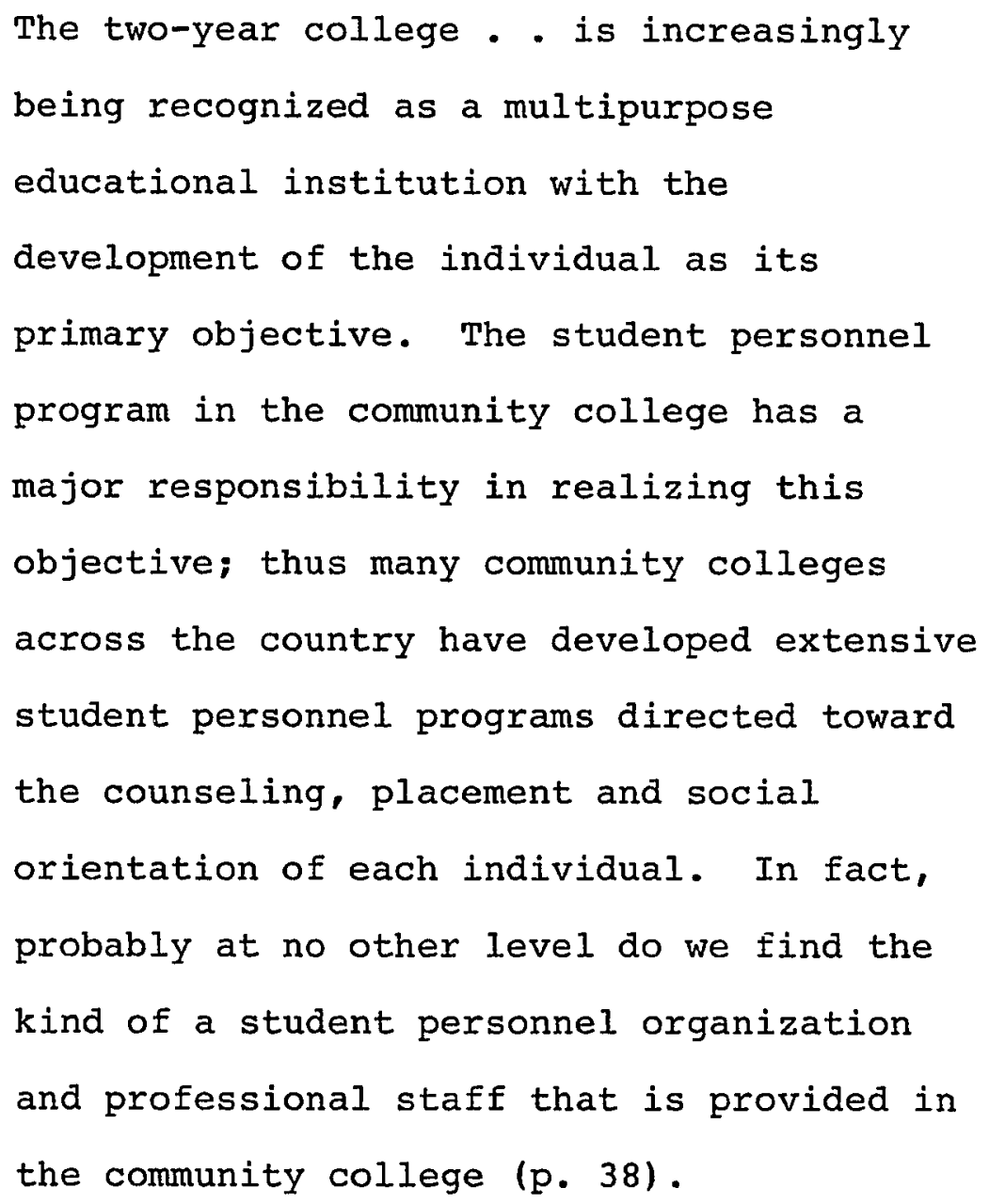

These comments are as appropriate today as they were in 1966. These comments are most fitting with California's 
recent mandate for community college reform including matriculation. In the past it has been advocated that student personnel services play a more active role in the mission of the community college (Mortvedt, 1972; Newton, 1974). In California in 1988 it is reemphasized in the work of the Joint Committee for the Review of the Master Plan in Higher Education. Mortvedt (1972) maintained that specialists in this area "should become active in the development of the philosophical, curricular and co-curricular experiences and activities of the community college" (p. 270-A). Thurston (1972) stated that "it is important for student personnel workers to realize that their work is an integral part of the total educational program of the college" (p. 221). O'Banion (1972) stated that the student personnel worker is no longer an interpreter of institutional philosophy, but rather a developer of institutional philosophy. Although these comments mention and include all student services workers, they are mainly focused toward the counseling staff of these service areas.

To summarize, the counseling services program is the most comprehensive and professionalized of all the student services areas. Counseling services grew with the assistance and support of the National Defense Education Act and in response to both student and institutional needs. In community colleges, counseling services are 
considered to be the most significant of all out-of-class services provided for students. It is usually the counselor that the student sees as the decision-making process is explored prior to and after enrollment in the college (Matson, 1972; Monroe, 1973).

\section{Studies of Community College Counseling Services}

Despite the noted importance of counseling services in two-year colleges, there is not an abundance of information about their functioning in the professional literature. Most studies focus on the counseling services of four-year colleges. There were a few studies addressing community college counseling services that were found and are summarized below.

Using a Delphi technique consisting of three rounds, Jonasson and Stripling (1977) did a survey of 435 student personnel service practitioners in community colleges in Florida to determine their perceptions of their future roles in the next decade. In round two, practitioners were asked to rate each of the 34 functions of student services, including counseling, on a five-point scale of importance and in round three they were to rank the functions in descending order of priority. The practitioners indicated a desire to become more involved in the total administrative organization and decision-making process of 
their respective college. More emphasis was placed on student development than on student regulation and social and academic regulations were rated near the bottom of the 1ist. The functions in rank order of priority were:

1. Administrative organization.

2. Student counseling.

3. Career information and decision-making.

4. Student advisement.

5. Faculty consultation.

6. Inservice education and staff development.

7. Change agents.

8. Student development.

9. Financial aid.

10. Pre-college information.

11. Program articulation.

12. Information center.

13. Personnel records.

14. Student registration.

15. Group orientation.

16. Paraprofessionals and peer group counseling.

17. Educational testing.

18. Services to special population groups.

19. Program evaluation.

20. Placement.

21. Curriculum development. 
22. Community services.

23. Applicant consultation.

24. Applicant appraisal.

25. Cooperative education.

26. Student induction.

27. Teaching.

28. Student self-government.

29. Cocurricular activities.

30. Academic regulation.

31. Health appraisal and services.

32. Athletics.

33. Social regulation.

34. Child care (Jonassen and Stripling, 1977, p. 85).

Although this study focused on all student services, several counseling functions were specifically identified and ranked in high priority. This may be due to the large number of counselors (40 percent) representing the student services practitioners who participated in the study (Jonassen and Stripling, 1977) .

Miller (1979) looked into counseling services at two-year colleges in the tri-state area of New York, New Jersey and Connecticut. Twelve colleges responded to her two page, sixteen-item questionnaire. Part-time students predominated in all colleges (p. 12). Miller found that the name most frequently used for the service 
was counseling center, followed by student services office and student development center. Counselors taught courses in all twelve of the colleges. They offered career workshops. In several of the colleges, counselors taught in academic areas. In rank order, the six most important problems presented by students in their requests for counseling assistance were (1) academic, (2) vocational, (3) interpersonal, (4) anxiety, (5) financial aid and (6) desire to drop out (p. 12). The counseling staffs in the colleges function cooperatively with instructional faculties in academic advisement, course placement and in remediation of academic deficiencies. The counselors assumed primary responsibility for vocational and career guidance, personal and emotional counseling and crisis intervention.

In 1975 Litwack attempted to survey all 1,203 community colleges in the United States, yet the return rate of 35 percent represented 426 colleges from all states except Rhode Island and South Dakota. Directors of Counseling were asked to rate 25 selected current and future counselor responsibilities on a six-point scale. Litwack (1978) found the following results: 


\section{Current and Future Community College}

\section{Counselor Responsibilities}

\section{Responsibility}

1. Vocational and career counseling

2. Personal-social counseling

3. Consulting with faculty and administration

4. Academic advising

5. Individual and group testing

6. Orientation

7. College and community liaison.

8. Admissions counseling

9. Pre-college counseling

10. Student advocate

11. Group counseling

12. Crisis intervention.

13. Providing in-service training programs

14. Drug counseling

15. Student recruitment . .

16. Establishing development programs

17. Marriage counseling .

18. Pregnancy counseling

19. Research on student characteristics

20. Job placement .

21. Teaching • . . .

22. Research on curriculum .

23. Foreign student advising.

24. Supervision of counseling interns

25. Training of paraprofessionals . (p.361). $\frac{\text { Now }}{\frac{8}{8} \operatorname{Rank}} \frac{\text { Future }}{\frac{8}{6} \operatorname{Rank}}$

$\begin{array}{rrrr}99 & 1 & 95 & 1 \\ 96 & 2 & 93 & 2 \\ 96 & 2 & 93 & 2 \\ 94 & 4 & 87 & 5 \\ 85 & 5 & 85 & 7 \\ 84 & 6 & 84 & 8 \\ 83 & 7 & 87 & 5 \\ 78 & 8 & 76 & 11 \\ 77 & 9 & 78 & 10 \\ 73 & 10 & 75 & 13 \\ 73 & 11 & 88 & 4 \\ 71 & 12 & 75 & 14\end{array}$

$\begin{array}{llll}65 & 13 & 82 & 9\end{array}$

$\begin{array}{llll}64 & 14 & 69 & 17\end{array}$

$\begin{array}{llll}64 & 15 & 76 & 11\end{array}$

$\begin{array}{llll}62 & 16 & 73 & 15\end{array}$

$\begin{array}{llll}62 & 16 & 67 & 18\end{array}$

$\begin{array}{llll}61 & 18 & 63 & 22\end{array}$

$\begin{array}{llll}60 & 19 & 76 & 11\end{array}$

$\begin{array}{llll}57 & 20 & 63 & 21\end{array}$

$\begin{array}{llll}55 & 21 & 61 & 23\end{array}$

$\begin{array}{llll}53 & 22 & 65 & 19\end{array}$

$\begin{array}{llll}45 & 24 & 58 & 24\end{array}$

$\begin{array}{llll}45 & 24 & 58 & 24\end{array}$

$\begin{array}{llll}44 & 25 & 71 & 16\end{array}$ 
Goodman, Beard and Martin (1975) reported results of a survey of counseling services in small, public, community/ junior colleges having enrollments of 5,000 or fewer students in eight southeastern states. The directors of counseling from 140 colleges responded. The study was directed toward ranking the order of importance of the principal counseling services offered. Educational counseling was judged to be the most important counseling service given to students. The order of importance placed upon the other principal counseling activities was: vocational counseling, (2) personal adjustment counseling, (3) college transfer counseling, (4) financial aid counseling, (5) testing, (6) job placement counseling and (7) research (p. 242).

In 1971 Paul Hinko conducted a national survey of counseling services. His study was limited to large community colleges. The survey included directors of counseling at 111 public community/junior colleges having total enroliments of 5,000 or more. Some highlights of Hinko's (1971) findings were:

1. Students were provided vocational, educational and personal social counseling, testing services and academic advisement. 
2. Group counseling services were offered primarily for personal growth and vocational decision-making.

3. Counselors assisted in the placement of students into appropriate course levels.

4. The director of counseling felt that lack of sufficient personnel and an adequate operating budget hindered the counseling program (pp. 21-24).

In addition to these studies focusing on counselor and student services functions, a review of the literature revealed that there is disagreement about the role and functions of community college counselors. Shertzer and Stone (1974) contended that clarification of the role of the counselor will lead to commitment to the tasks of the occupation. Counselors, individually and collectively, retain the responsibility for differentiating their services from those provided by others. Shertzer and stone (1974) reported:

One counselor's functions will differ from those of others in terms of the setting in which he works, his personality, and his training and experience. But despite 


\begin{abstract}
diversity of individual activities, commonalities do exist among counselors and make possible a generalized definition of function. If counselors themselves do not take primary responsibility for this definition, others, by default will do so. The definition must be firm enough to provide counselors a basis for professional identity, but at the same time sufficiently flexible to encourage growth and change within the profession (pp. 143-144).
\end{abstract}

Many authors cautioned that counselors must focus on and preserve counseling and their primary responsibility if the counseling profession is to have a clear identity (Boy and Pine, 1978, 1980; Arbuckle, 1972; Collins, 1970; Walz and Benjamin, 1979). When counseling is given priority over all other activities, the counselor is defined as a specialist (Shertzer and Stone, 1974).

Boy and Pine (1980) asserted that all counselors must resist time-consuming, non-counseling activities and "reinforce performance of important tasks and eliminate performance of the unimportant" (p. 163). Walz and Benjamin (1979) emphatically declared that the primary mission of counselors is to counsel and they maintained that "no matter what the time, present or future, or the 
occasion, personal or occupational, the counselor's sine qua non is the ability to provide counseling" (p. 25). Boy and Pine (1979) stated:

Counselors have become involved in administering institutional policies and programming nonacademic events, while neglecting their counseling . . . Counseling professionals have become overly involved in a myriad of quasiadministrative activities that, when evaluated, contribute more to keeping the institution running than to improving the human and behavioral conditions of clients who are supposed to be served by the institution. There is a strong tendency to institutionalize, formalize, complicate, paper-to-death the activities of counseling professionals. Now is the time for professional counselors to recommit themselves to the value and need of counseling in which the professional counselor should be involved . . Professional counselors - . must begin to resist institutional attempts to make them superclerks, Ioose-end coordinators and gatekeepers of institutional 
policies. Counselors should begin to dedicate themselves to clarifying their role so that counseling will be their primary responsibility. It will take a high level of commitment to do this in organizations that want them to do everything but counsel (pp. 527-528) .

Yet others (Ciavarella and Doolittle, 1970; Rolveit, 1973; Lewis and Lewis, 1970) believed that counselors should also assume the role of ombudsmen. Counselors would place themselves between students and the system, communicating the needs and problems of students to the school administration. Blocker and Richardson (1968), Miller (1977) and Schoenberg (1978) supported the dual role of counselor-teacher. Many advantages were cited for this dual role including improved relations and communications between student personnel professionals and teaching faculty. Wrenn and Leonard (1973) and Shertzer and Stone (1974) greatly supported the consultant role for counselors. They wanted to utilize counselors' facilitation skills. Another responsibility identified for counselors was conducting research (Wrenn, 1973; Goodman, Beard and Martin, 1975). They believed that counselors should be involved in research on the programs offered 
in student services and research on the changing characteristics of the student population.

Numerous authors proposed that the counselor should be involved as an active agent of change (Walz and Benjamin, 1978; Blocker, 1966; Warnath, 1972; Bradley, 1978).

Counselors should become actively involved and try to have an impact on the direction of the change process. They should identify and plan programs to address new needs. And finally, many recognized that when the role of the counselor is defined as that of a generalist, the counselor performs many functions (Shertzer and Stone, 1974; Goodman, Beard and Martin, 1975; Jonassen and Stripling, 1977; Schoenberg, 1978). These numerous functions may be orientation, group guidance, registration, class scheduling, course changes, testing, special class placement and scholarships. As a generalist the "counselor gives less time to counseling and more time to improving the relationships among teachers, administrators, parents, community resource personnel and students: (Shertzer and Stone, 1974, p. 146). Warnath (1972) acknowledged that short-term academicvocational counseling has been the predominate activity at colleges oriented toward preparing students primarily for occupational roles in society, while psychotherapy has been given legitimacy at liberal arts colleges and universities. Warnath (1972) stresses that "as counselors try to expand 
their services to meet student needs and establish new delivery systems, they must also be aware that they are still meeting institutional needs and goals (p. 236).

\section{Professional Development and Counselor Renewal}

Due to the diverse nature of the counselor's role, continual staff development and self renewal are crucial. Counselors must have time to involve themselves in further personal and professional training. Walz and Benjamin (1979) cited the critical need for counselor renewal, and asserted:
No counselors prepared in one time will be adequately prepared to serve in another unless they have engaged in continuing attempts to renew their skills. Counselors must feel that they have never completed their training, that lifelong learning and continuing renewal are vital aspects of their professional competence (pp. 27-28).

The need for ongoing skill development through inservice training is crucial. It is important for counselors regularly to refresh and update their skills, especially as society and technology change. One of the 
most frequently mentioned important and urgent needs facing counseling and student services personnel in the next five years is development of skills in counseling special populations. Student populations are increasing in diversity, with a concomitant increase in the need for counselors to develop new and more effective counseling approaches. Counselor education programs and inservice training programs should promote awareness of the special needs of ethnic minorities, women, returning students, older adults, working students, international students, gifted students and handicapped persons. Competency-based training modules need to be developed for training staff to work with these special populations. Counselors must be able to respond to societal changes. Inservice training should include ways of keeping counselors current with change (Walz and Leu, 1979).

Skill development is also needed in appropriate use of technology at all educational levels. Educational technology and information systems are changing rapidly. The computer is increasingly being used for student records, registration and career information (Walz and Leu, 1979) .

Community college counselor training in the universities too often has been based on the assumption that counseling is counseling, regardless of the setting. Creamer (1983) emphasizes that community college 
counselor roles are sufficiently different from roles in other colleges to merit separate preparation. Counselor education needs to respond to the special training requirements of counselors in community colleges, both during their initial training and in their continuing education. At present, counselor backgrounds are diverse. Counselors are: specialists in marriage and family counseling; clinical and counseling psychologists; graduates of programs focused on psychological counseling; and generalists from the classroom. To help counselors adopt new roles and sharpen their foci, community colleges must encourage counselors to participate in and must provide the resources for staff development. Counselors also need help in keeping up with the state of the art, including the use of new technology (Thurston, 1983).

Some educators and futurists suggest that we should move away from the traditional credentialing concept toward skill development. Individuals who wanted to be counselors would be required to demonstrate their level of mastery of the skills considered necessary for counseling in the desired setting (Walz and Leu, 1979).

"Although the guidance and counseling profession is still an adolescent, there are members of the profession who, once they are credentialed (usually meaning a minimum of a Master's degree) proceed to atrophy" (Maples, 1980, p. 11). These are individuals who are in desperate need of 
professional growth and renewal. Some professionals seek out and take advantage of available opportunities; but there are also those who ignore the need for professional renewal and who refuse to participate in professional associations. Perhaps the most significant challenge to the leadership and to every member of the counseling professional associations is to create a stir within those individuals.

\section{Examination of Counselor Responsibilities}

Frequent renewal and self-examination are necessities of any profession; especially during changing times. The evolution of both the community colleges and counseling services in these institutions has been adaptive in nature, changing to meet the new needs of students and society. As the mission of the community college continues to change to include new groups of students and provide new types of services, curriculum and programs, it is important that those in the field of student personnel services examine its role in regard to these changes (Carnegie Commission on Higher Education, 1974).

Thurston (1983) emphasized that,

to survive the decade ahead means taking on new roles and new points of view. The need 
for change is urgent; the need for effective counseling in community colleges is more critical than ever. Being a good generalist is not enough (p. 119).

The need to identify future alternatives for counseling services in the community college is obvious in the present educational context of knowledge explosion, technology change, demographic changes and demands for overall reform in community colleges. This would be supported by Harris (1968) today as it was when he stated in an article titled "Guidance and Counseling in the Year $2000: "$

If present practice is to become more meaningful, however, it is necessary for every discipline of man to examine its past and to project into the probable future. The field of personnel work, or guidance and counseling, is no exception (p. 262).

In addressing themselves directly to "Student Personnel in the Junior Colleges in the Years Ahead," Higgins and Thurston (1966) stated 
- . it is unlikely that student personnel

workers will perform the same functions in

the same ways as now. Unless we are able

to retrain and retool for a more creative

role, we will be as anachronistic as

comptometer operators and bookkeepers (p. 56).

Numerous educators have published articles suggesting future alternatives for student personnel services in community colleges. The same tone of urgency for selfexamination change and renewal can be observed from those authors of the sixties to those more recently. A thorough examination of the literature reveals one article directed specifically to the future of student personnel work in community colleges. Higgins and Thurston (1966) pointed out

In the years ahead, the junior colleges will be forever struggling with the problems of mounting enrollments, staff shortages, increasing student heterogeneity and community demands. At the same time, they will also face the crucial issues of gestation, birth, continued growth, and change - - For the junior colleges, there is little likelihood of 
stabilization--the future holds mostly innovation and change (p. 55).

Perhaps the strongest support for examining the future responsibilities of the counselor in the community college comes from Gleazer (1973). He stated

The community college assignment calls for a radical change in the usual concept of the work of the counselor. His role in institutions boasting of their counseling service has been uncertain. He has been described by presidents as "neither fish nor fowl," neither faculty nor administration. When the funds are cut, he is often the first to go. However, students and faculty are calling for services that suggest the need for a whole new approach to the "functions" commonly associated with the area of counseling (p. 90).

Basically what Gleazer (1973) offered as a future alternative was a reallocation of resources within student personnel services such that counseling would be perceived as a major opportunity to increase the effectiveness of the total educational program. California's state mandated 
matriculation program is today's vehicle to accomplish what Gleazer was promoting.

There was less urgency for change in the seventies. Counseling was a generally accepted function of the community college. With adequate financing, no aspect of the college was under close scrutiny. Thurston (1983) observed that counselors said, "Why should we change? We see lots of students and we help them" (p. 115). Thurston (1983) makes note of the increasingly diverse student populations. They include people of all ages at differing life stages, with differing needs and concerns; students with various disabilities; increasing numbers of disturbed students who reflect societal tensions and dislocations; and those with diverse cultural and ethnic backgrounds. There is no question that student growth needs to extend beyond the classroom. Yet at a time of greater need, counseling staffs are being reduced and administrative reorganizations made in which student personnel services are given low priority.

There is an urgency in getting on with the process of remodeling and rebuilding. Survival is the name of the game for every program and service. Counseling is no exception; to survive and meet the needs of the diverse students will require change.

The dynamic nature of the community college makes it essential that the roles of the counselor be conceptualized 
in such a way that, as the mission of the college is redefined and restructured to meet the needs of its constituents, the counselors can work within a flexible framework to identify appropriate tasks (Matson, 1983).

Since the counselors in community colleges work with diverse populations with a variety of needs, the scope of counseling services has broadened and is expected to continue doing so in the future. Broader responsibilities will be required to address the needs of the changing student population of the 1990's and the next century. The new roles required of counselors sometimes demand skills, time and energies that go beyond the traditional expectations. They are finding themselves under demands that exceed their resources (Trembly and Bishop, 1974). Boy and Pine (1980) commented:

Today's counselors, under more external pressures than ever before, are bombarded by role demands from a variety of sources. - . Culturally different clients demand the counselor become a social activist; institutions pressure the counselor to become more accountable by developing evidence attesting to the effectiveness of counseling; curriculum builders insist the counselor become more involved in the 
development and implementation of psychological education; career educators prod the counselor to become more sensitive to the importance of assisting clients in making accurate vocational decisions; computer advocates insist the counselor make expanded use of recent technological developments. The pressure for an expanded role increases from many sources (p. 161).

It is generally agreed that counselors will be needed more than ever but they must be ready to take on new roles. Historically, counseling in community colleges has been based on the voluntary, one-to-one, jack-of-all-trades, a theoretical model that Creamer (1983) calls the "educational generalist" (p. 88). The newer more promising but more complicated model is that of developmentalist in which counselors make use of developmental research on human growth. Robbins (1983) calls for incorporating this developmental perspective in the community college counselor's approach. Thurston (1983), too, supports this approach. She speaks of developmental counseling as being proactive and interventionist. It takes place in a systematic framework of consultation based on preassessment, advising and periodic evaluation. It is theory based. California's state-mandated matriculation 
program clearly is developmental counseling in that its focus is assessment, orientation, advisement, student program monitoring, institutional student follow-up and research, and staff development. Thurston (1983) asserted that transfer students, vocational education students and returnees seeking training for second careers and all those who look to the community college for upward mobility need this kind of specific structured ongoing assistance.

It would appear that the counseling function of the community college will become more important in the 1980's as the mix of students include higher percentages of the so-called nontraditional students and as more attention is attached to the retention of students (Cosand, 1979).

The counselor's role in helping students in their development is truly a crucial one for the 1980's. There have been several challenges to the work of the counselor within the last half century. The GIs in need of help in coping with a changed post-World War II America, the veterans of the Korean War and Vietnam, the minority groups, women, older students and handicapped who came to the community colleges in waves during the 1960's and $1970^{\prime}$ s found community college counselors seeking to meet their needs in different ways. The hope and challenge now is that, as the professional practice of community college counseling grows during the 1980's and 1990's, it will utilize more and more the new knowledge base of 
developmental theory. When the developmental perspective meshes with the eclectic activity of the community college counselor, then it is more likely that the college will cause intentional developmental change to occur in students. Within the world of a community college that takes seriously its mission, the counselor's contribution can thus be an immense one (Robbins, 1983).

"Do more with less" seems to be the new buzz phrase in community colleges. To implement this admonition by working harder and longer in order not to sacrifice present functions could be disastrous to students and staff alike. Counselors will be needed more than ever, but they must make some variations to their roles (Thurston, 1983). The California state reform expectations, state demographic changes and local campus needs combined with budgetary constraints make it imperative for community college counselors and their supervisors to identify priorities, define responsibilities and plan wisely for the future. During the 1990 's the fate of community college counseling will be determined not only by budgetary constraints, but also by actions of counselors and their supervisor: by the decisions they make regarding their mission and priorities, by the extent to which they broaden their competencies through staff development and by the professional working relationships they build (Thurston, 1983). The future, although influenced by outside forces, 
is, in the final analysis, determined by the choices we make.

Although the provision of counseling services is one of the major objectives of the community college (Miller, 1977; Jones, 1970; Schoenberg, 1978) an extensive review of the literature indicated that there is very limited investigation of counselor functions in the community college (Dameron and Wolf, 1975; Hinko, 1971; Goodman, Beard and Martin, 1975; Miller, 1979).

Though the literature shows that there have been studies on the functions of student personnel services (as a whole profession with various service areas); studies comparing counseling services needs of community college and university students and one national study, Litwack's, of counseling responsibilities, no studies in the literature report a future study of counselor responsibilities and competencies needed in California community colleges nor a study of staff development needs of currently employed counselors. The literature search could not reveal any study on professional preparation needs of prospective community college counselors.

The literature review presented here is a result of an ERIC search and a review of dissertation abstracts. Specific references were sought for community college counselor role, responsibilities, functions, competencies, staff development needs and professional preparation 
needs. Much of the literature addressing role and responsibilities was from the seventies referencing those, in the counseling profession, often thought to be the classic gurus. However, very little recent literature could be found addressing these topics. Many more recent references could be found about secondary school counseling. Iittle more than general statements could be found about community college counselor competencies, staff development needs and professional preparation requirements.

One can only hypothesize as to reasons for the dearth in the literature within the last five years. Very little focus of attention and very little hiring combined with an aging of professionals in the field during the last decade may play a part in the scarcity of studies or literary attention to community college counselors.

With the increasing importance of communit $\ddot{y}$ colleges and the associated reforms of legislation like $A B 1725$ in California, there is a critical need for comprehensive information about counselor responsibilities, competencies, staff development needs of those currently employed and professional preparation needs of prospective community college counselors. This study addresses these areas critical to the future of community college counseling in California and is an original contribution to the literature. 


\section{The Delphi Technique}

The Delphi technique was developed in the early fifties through the efforts of Dalky and Helmer (Dalky, 1969), employees of the Rand Corporation. Its innovators named the technique after the greatest of all Greek oracles, Apollo's Delphi Oracle. Delphi was originally used to forecast technological developments; thus, the name Delphi has been associated with forecasts of the future (Delbecq, Van de Ven and Gustafson, 1975, Uhl, 1983).

The Delphi technique is a "carefully designed program of sequential individual interrogations interspersed with information and opinion feedback" (Rasp, 1973, p. 29). Its goal is to collect judgments and establish consensus about future probabilities in terms of such variables as time, quantity and/or the desirability of some future state (Rasp, 1973). Dalky (1969) indicates that the Delphi technique is characterized by three major features:

1. Anonymous response--opinions of members of the group are obtained by formal questionnaires.

2. Interaction and controlled feedback-interaction is effected by a systematic 
exercise conducted in several interactions, with carefully controlled feedback rounds.

\section{Statistical group response--the group} opinion is defined as an appropriate aggregate of individual opinions on the first round (p. 4).

In its early form, the technique was used with small groups of about ten or twelve experts who were asked to estimate the probability of future events by engaging in an anonymous debate. Their opinions were exchanged through an intermediary who controlled the feedback of opinion in subsequent records of the inquiry. Anonymity existed at two levels: the participants were unknown to each other and the individual responses were never attributed to particular respondents. The process was basically aimed at trying to find consensus among members of a group while avoiding the problems arising from personal interaction where decisions may be swayed by strong and compelling personalities rather than by logical analysis of the situation being considered (Enzer, 1969; Gordon and Ament, 1969; Weaver, 1971).

The Delphi process is a procedure originally developed for obtaining greater consensus among experts regarding urgent defense problems without face-to-face discussion. 
The objective of eliminating the need for such meetings is achieved by having the participants complete a series of surveys interspersed with controlled opinion feedback. Each participant makes forecasts or submits his/her opinion individually on the survey. The results of each of the early rounds are collected and returned to the participants, who are then free to revise their original forecasts/opinions or to explain their divergent positions. The process (rounds) of collecting forecasts and distributing the results continues until each participant understands all other positions and all are satisfied with their individual positions (Phi Delta Kappa, 1984).

Uhl (1983) believed that this process of communication not only saved time and money but also, and more importantly, permitted independent thought among participants and assisted them in gradual formation of a considered opinion. It has the added advantage of anonymity. Direct dialogue at meetings often result in hasty offerings of opinions, the inclination to close one's mind to novel ideas, a tendency to be influenced by persuasively articulated opinions or by peer pressure.

Delbecq, Von de Ven and Gustafson (1975) identified three critical conditions for Delphi research: "1) adequate time, 2) participant skill in written communication and 3) high participant motivation" (p. 84). 
The technique is generally used to promote communication and thus obtain group consensus regarding possible future developments. Enger (1969) described the Delphi technique as:

a form of controlled conference accomplished in discreet steps. Judgments are elicited from a group, areas of consensus and disensus are identified, reasons for extreme positions are elaborated and judgments are re-examined in light of the earlier group consensus and the reason given for extreme positions. Delphi conferences typically maintain anonymity among the participants, elicit all inputs simultaneously and provide feedback to the participants at appropriate intervals (p. 10).

Weaver (1971) spoke of the Delphi technique as an "intuitive methodology for organizing and sharing expert forecasts about the future" (p. 267). Ezell and Rogers (1978) argued that the Delphi was not a technique for producing "truth" about the future but represented consensus of opinion about what might be (p. 125).

The traditional method for achieving consensus has been to conduct a round-table discussion among informed 
individuals and have them reach an agreed-upon position which is usually a compromise between divergent views. The compromise is often arrived at under the influence of time constraints and psychological factors such as loudest voice, persuasion and peer pressure. Some positive features of the Delphi technique address these concerns. Helmer and Rescher (1959) indicate that it

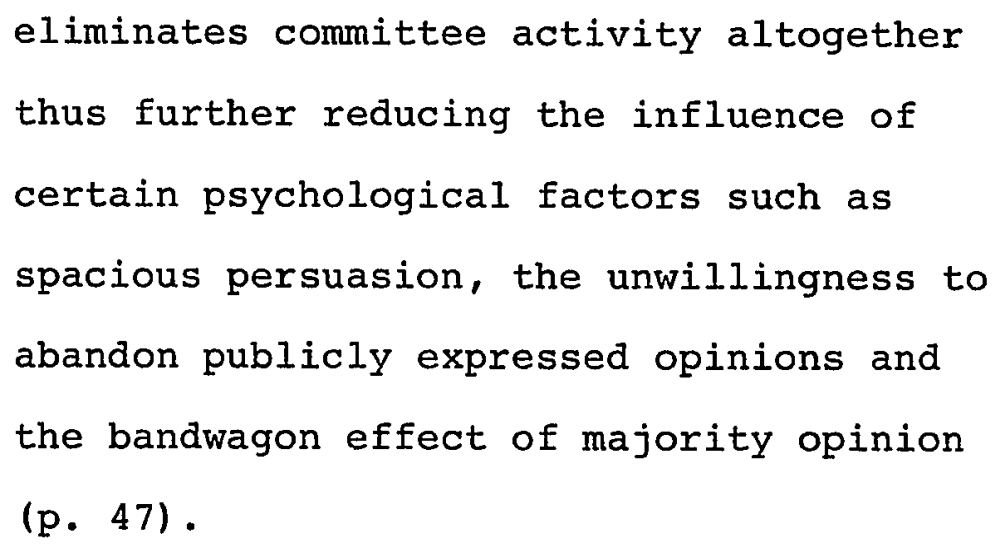

One of the first groups to use the Delphi, in the early fifties, was selected experts in the Air Force who simulated the viewpoint of a Soviet strategic planner by attempting to determine optimal industrial target systems and the number of atomic bombs required to destroy American productivity (Dalkey and Helmer, 1963). In an experiment by Rand, in 1968, one of the issues was to compare faceto-face discussion with controlled feedback interaction to determine which method most improved group estimates (Dalkey, 1969). In the experiment the groups responded to 
questions to which there were known answers. This was done so that the accuracy of the group estimates could be compared. The results of the study indicated that
more often than not, face-to-face discussions
tended to make the group estimates less
accurate, whereas more often than not, the
anonymous controlled feedback procedure made
the group estimates more accurate (p. vi).

These experiments produced a definite move toward a consensus of opinion by the participants. Anderson, Ball and Murphy (1975) stated that the Delphi
has proved so successful in producing
consensus that it has outgrown its use
solely in forecasting; it is now often
adopted in many different kinds of
situations where convergence of opinion
is advisable or desirable (p. 121).

Uhl (1973), too, recognized that although the Delphi technique was considered to be primarily a method for forecasting the future, its great potential for improving communication and generating consensus in solving complex problems is beginning to be realized. 
The Use of the Delphi Technique in Education

Although the Delphi technique was originally developed by the Rand Corporation over thirty years ago as a forecasting and consensus building tool about urgent defense problems, the method is recently but rapidly gaining recognition in higher education. This is evidenced by the growing number of articles and studies about varying educational issues using the Delphi technique.

The Delphi was suggested for use in education (Helmer, 1966). In a pilot study, Helmer explored the potentialities of applying the Delphi technique to educational planning. This study specifically explored ideas for possible educational innovations. As a result of their experience, the participants found the Delphi a helpful procedure and were encouraged to apply the Delphi to similar problems.

Weaver (1971) listed the promising educational application of the Delphi Technique in the following areas:

1. A method for studying the process of thinking about the future,

2. a pedagogical tool or teaching tool that forces people to think about the 
future in a more complex way than they ordinarily would, and

3. a planning tool that may aid in probing priorities held by members and constituencies of an organization (p. 271) .

Moreover, Helmer (1966) stated that the Delphi "can be applied to all phases of educational planning, at the federal, state, local or individual institutional level" (p. 6).

According to Judd (1972),

at least five major uses of the Delphi

method have emerged in higher education:

cost effectiveness; cost-benefit analysis;

curriculum and campus planning, college, university-wide and state-wide educational goals and objectives; consensus on rating scales, values and other evaluation elements and generalized educational goals and objectives for the future (p. 35).

Peterson (1971) cited the potential of the Delphi "for providing an institution with 1) a range of ideas about 
goals, 2) a priority ranking of the goals, and 3) a degree of consensus about goals" (p. 10). In another study, the Delphi was used by a school district to collect data from which goals for improving and building better programs could be developed (Rasp, 1973). Uhl (1971) found the technique helpful in assessing present and preferred goals of five colleges and universities. After participation in three rounds, the groups in the study reached a greater agreement in regard to present and preferred goals of the institution.

Gordon and Ament (1969) used the Delphi technique to develop a large set of specific technological and societal forecasts for the State of Connecticut. Hopkins (1972) also reported the use of the Delphi technique for a statelevel study of the future role of vocational and technical education in Oklahoma. Morrow (1972) employed Delphi to determine the probabilities that certain changes affecting the functions of management would occur by the years 1985 and 2000. Jonasson and Stripling (1977) used the Delphi technique surveying 435 student personnel service practitioners in community colleges in Florida to determine their perceptions of their future roles in the next decade. When faced with the decision as to whether a performance-based teacher-education program should be developed, the Department of Curriculum and Instruction at the University of Texas at Austin conducted a Delphi 
study and used the entire faculty as the panel of experts (Shepardson, 1972). At a liberal arts college the committee to develop the curriculum for a new branch campus used the Delphi method. Opinions were solicited from students, faculty, alumni and civic leaders. As a result of the study incorporating various opinions, a highly innovative and experimental type of curricular program was adopted by an extremely conservative faculty (Judd, 1970). Tiedemann (1985) completed a doctoral study using the Delphi technique to predict the nature of future higher education media services. The results of the study provided decision-making information for use in long-range planning by instructional technologists and academic administrators. Grauer (1989) conducted a Delphi study to research consensus in the emerging field of international resource development in the school community. He identified experts in the field of school-community relations and asked them to predict trends in global education.

During the Spring of 1988, the California Community Colleges Chancellor's Office conducted a Delphi project as one of several inputs in preparing the 1988-89 Board of Governors Basic Agenda for California Community Colleges. It was designed to have potential issues and solutions for the work of the community colleges ranked by a wide range of individuals concerned with the colleges: members of 
the Board of Governors, C'ancellor's Office staff, district and college Chief Exerutive officers and Chief Instructional Officers, A:ademic Senate Presidents and statewide participants (issues Confronting Community Colleges, 1988).

\section{Delphi Advantages}

The Delphi, as a research tool, offers many advantages :

1. The Delphi does not require face-to-face confrontation. Some of the undesirable aspects of group interaction are eliminated, especially the dominance of influential individuals in group dialogue (Helmer, 1966; Enzer, 1970; Weaver, 1971; Brooks, 1979).

2. In a Delphi study, the group decision is reached through each individual having the same opportunity for input. Every participant's input is considered (Dalkey and Helmer, 1963; Judd, 1970; Rasp, 1974; Brooks, 1979).

3. As the Delphi provides anonymity, many psychological barriers to communication are overcome, such as 
reluctance to state unpopular views, to disagree with one's associates or to modify previously stated positions (Enzer, 1970).

4. The Delphi provides a framework within which individuals with diverse backgrounds or in remote locations can work together on the same issue (Enzer, 1970)

5. The Delphi produces precise documented records. Since Delphis are conducted in writing, they produce concise written summaries of consensus and dissensus, together with agreements supporting alternative viewpoints (Enzer, 1970; Strauss and Zeigler, 1975).

6. The Delphi can be used effectively to bring together many expert opinions and complex issues to produce a group position that otherwise may be undetectable (Enzer, 1970; Strauss and Zeigler, 1975).

7. The Delphi technique is relatively simple. Advanced statistical skills are not necessary for design, implementation and analysis (Strauss and Zeigler, 1975) . 
8. The Delphi lends itself to more objectives than does either a group dialogue or individual interviews (Weaver, 1971).

9. A major strength in the technique is the flexible, but limited, time parameters that individuals have in which to respond at their convenience. This flexibility allows persons to participate who are not willing to share their time under other conditions (Brooks, 1979).

10. The Delphi is thought to be a valid and accurate future forecasting and consensus building technique (Dalkey, 1969; Judd, 1972; Strauss and Zeigler, 1975; Helmer, 1966; Uhl, 1983).

\section{Delphi Disadvantages}

The strengths of the Delphi technique are numerous as has been pointed out. Indeed it is considered a strong future-forecasting and consensus building technique. However, like all techniques, it has its limitations.

1. Delphis are slow and take a long period of time to execute (Judd, 1970; Strauss and Zeigler, 1975; Brooks, 1979). 
2. The capabilities and quality of the expert panel may be questionable (Juda, 1970; Brooks, 1979). The value of the results depends on the competency of the participants (Phi Delta Kappa, 1984) .

3. The results of this technique are intuitive rather than scientifically obtained (Phi Delta Kappa, 1984).

4. The Delphi offers few explanations except for dissenting opinions. There is no way of knowing exactly why one response was selected over another or why participants moved to consensus (Rasp, 1974; Sackman, 1975).

5. Consensus obtained by this technique may or may not represent a real shift in attitude or perceptions of a respondent. It may be easier to go along with the modal response than to write one's reason for a divergent opinion (Sackman, 1975).

6. There is considerable administrative work associated with the Delphi such as:

1) the maintenance of individual records for each respondent to determine changes and prior ratings, 2) the synthesizing of 
responses into communicable generalizations, 3) the preparation and mailing of several questionnaires and 4) the tabulation of the data (Cypert and Gant, 1970, p. 422).

7. Panelist dropout rates are high (Sachman, 1975).

Despite its weaknesses, the Delphi has been found by educators to be a useful technique in forecasting and gaining consensus and insight into a wide variety of areas. In summary, Thomas' (1981, p. 28) lay terms, although simple, are significant, "Delphi is a really quiet thoughtful conversation in which everyone gets a chance to listen." It is a relatively efficient way to arrive at convergence of expert consensus through feedback. It does not require that the expert panelists travel, meet in person or engage in verbal dialogue. More importantly, it can provide significant and useful data for future planning and that is the primary reason it is being used for this study.

According to Judd (1972),

an examination of the data presented suggests that higher education can benefit from employing the Delphi as a method of planning. Given the extent of education's 
need for more and better planning, this is as high a priority mission as any technique could wish for (p. 43). 


\section{CHAPTER III}

RESEARCH DESIGN AND METHODOLOGY

\section{Research Design}

The main purpose of this study was to gather the perceptions of chief student services administrators regarding the responsibilities and competencies of California community college counselors for the 1990's. The study attempted to provide planning and decisionmaking data to be used by chief student services administrators and community college counselors in addressing the challenges associated with California's changing demographics and reform mandates outlined in its landmark reform bill $\mathrm{AB}$ 1725. Consensus of expert opinion regarding the below listed questions was sought over that of random opinion because of the anticipated increased level of knowledge and experience. The specific research questions answered by the study were:

1. What will be the responsibilities of California community college counselors during the 1990's? 
2. What competencies will California community college counselors need to fulfill their responsibilities during the 1990 's?

3. What will the job description for California community college counselors include for the 1990's?

4. What are the staff development needs of currently employed California community college counselors to prepare them to effectively fulfill their responsibilities in the 1990 's?

5. What courses or seminars should counselor education programs include to prepare prospective California community college counselors to effectively fulfill their responsibilities in the $1990^{\prime} \mathrm{s}$ ?

Data, consensus about the data and planning were needed for future forecasting and for effective decisionmaking. Although there were numerous ways to gather data, one of the most widely used and accepted methods of forecasting future probabilities and of determining consensus was the Delphi method (Rasp, 1973; Uhl, 1973). The review of the literature indicated that the Delphi technique could be successfully applied to all phases of educational planning (Helmer, 1966; Peterson, 1971; Uh1, 
1971; Weaver, 1971; Judd, 1972; Hopkins, 1972; Rasp, 1973; Shepardson, 1972; Jonassen and Stripling, 1977). It could provide useful data for future planning. The Delphi technique attempted to make effective use of informed intuitive judgment (Helmer, 1967). For these reasons and because of its research strengths, a modified version of the Delphi technique was chosen for this study.

The design of this study included two phases and three Delphi rounds of questionnaires. Phase One dealt with counselor responsibilities and competencies. In Phase One, summaries of each round along with feedback and comments were mailed to the respondents for their review and consideration in responding to the subsequent rounds. Since this study was gaining opinion about desired future conditions, the modal response was used to indicate consensus (Rasp, 1973). The modal response was the response which was selected most frequently. To lend strength to the selected response and to the degree of consensus about that response, it was decided for this study that a minimum of 50 percent of the respondents had to select the modal response before consensus was considered to be reached. This guarded against the potentiality of consensus being identified on a minimal level in situations where opinion was widely dispersed over the response options. The respondents were given the percentage of those selecting the irodal response in the 
summary of the previous round so that they could consider that information in making subsequent response selections. Since consensus in Phase One of this study was readily reached to high degrees of 55-100 percent on all items, only two rounds were conducted.

Phase Two consisted of one round during which respondents were asked to reflect on their collective consensus of counselor responsibilities and competencies, resulting from Phase one of the study, and to address the staff development needs of currently employed counselors and the professional preparation needs of prospective community college counselors. Thus the research design used for this study was a modified version of the Delphi technique.

\section{The Delphi Methodology}

Ezell and Rogers (1978) argued that "the Delphi was not a technique for producing 'truth' about the future but represented consensus of opinion about what might be" (p. 125). Such forecasting and consensus information was gathered by the Delphi's process of repeated rounds of completed information-gathering instruments interspersed with feedback. Two to four rounds were usually needed to allow participants to review their responses and the adjoining feedback and to reconsider their responses before 
consensus was reached on the issues studied. An opportunity was provided for minority opinion on issues. Through this process, participants engaged in an anonymous debate which allowed for maximum input and involvement thus providing the researcher with more useful information (Dalky, 1969; Enzer, 1969; Gordon and Ament, 1969; Weaver, 1971).

Besides providing for selection of and communication with the cream of the incumbents of a profession, the Delphi required relatively little time of the panelists, motivated their involvement which it rewarded through feedback and finally enabled them to arrive at a consensus representative of their expertise. In the process, this technique lent objectivity, based on each respondent's knowledge, experience, philosophy and opinion. Delphi did not expect respondents to travel, do advance reading or research answers. It did require respondents to engage their thought processes by reflecting on the issues through the lens of their knowledge, skills and experience and to respond accordingly.

\section{Demographic Questionnaire and Delphi Instrument}

Judd (1972) maintained that there is no one method for conducting a Delphi study. He stated that the initial round may consist of a set of prepared statements in a 
structured format or it might use a set of open-ended questions. Judd (1972), Delbecq, Van de Ven and Gustafson (1975), Linstone and Turoff (1975) and Erdos (1983) cautioned against time consuming and lengthy questionnaires that might negatively impact the return rate. The advise about instrument development offered by Linstone and Turoff (1975), Erdos (1983) and Uhl (1983) was considered in the development of the instruments used in this study. The feedback received from the pilot study, described in the next section, contributed to the final draft of the instruments.

A demographic questionnaire and the Delphi instrument were developed and used. The demographic questionnaire, Appendix B, provided personal, professional and site location information about each of the expert participants. The specific questions were designed to provide general information about the respondents and their colleges to demonstrate an overall profile of the participants. The responses to the professional background questions substantiate the expertise and qualifications of the panel. Some of the questions specifically address the level of past experience in the field and also the amount of future involvement in the field. The responses identify the experts as stakeholders in the future of counseling and the probability of their future leadership involvement. 
The Delphi instrument used in the entire study consists of four parts. The Delphi instrument used in Phase One (Appendix B) consists of two parts called Part One and Part Two. Part One focused on California Community College Counselors' responsibilities. Approximately 50 current (1987 and 1988) job descriptions and job announcements were reviewed by the researcher to compile a list of current responsibilities. The researcher requested the job descriptions and job announcements from California community colleges. Fifty different documents were received. Some of them represented more than one college in the case of multi-college districts. Those received were representative of small, large, urban and rural community colleges. Identical responsibility listings were common indicating little if any difference due to size or location of the college. Part one of the Delphi instrument consists of the 35 distinct counselor responsibilities identified through the job descriptions and job announcements, and additional space for respondents' additions.

Part Two of Phase One of the study focused on California Community College Counselors' competencies. All 32 competencies, as listed in the collected job descriptions and job announcements, were included in this part of the instrument. Space for additional competencies 
and respondent comments was designed in this part of the instrument as well as in Part One.

In addition to the specific responsibility and competency item listing, a brief synopsis of California's demographic changes and of the reform demands in Assembly Bill 1725 was included in a section of each part of the instrument called "Background Information." This was specifically included to direct the respondent's attention to these major forces on community colleges and counselors. It was crucial that they have the "Background Information" in mind, as they responded to the questionnaire, so as to influence their response since this study sought a response to these issues by counselors via their work during the 1990 's.

The Delphi instrument used in Phase Two (Appendix E) also consists of two parts called Part Three and Part Four. Part Three addressed the staff development needs of currently employed California community college counselors as identified through the review of the literature and by the researcher's 17 years of observation and experience in the field. Sixteen topics that could be addressed in staff development programs were listed. Additional space was designed for respondents' additions.

Part Four addressed the professional preparation needs of prospective California community college counselors. The list of topics and courses to which the expert panel 
was asked to respond included those most commonly offered in counselor education programs with additions from the researcher's experience in the field. Additional space was also designed in this part of the instrument for respondents' additions.

The same brief synopsis of California's demographic changes and of the reform mandates in $A B$ 1725, used in Phase One of the study, was included in Parts Three and Four of the instrument used for Phase Two of the study. During Phase One of the study, the respondents were asked to rate the importance level of each responsibility and competency statement with the perspective of the anticipated circumstances for California community college counselors in the $1990^{\prime} \mathrm{s}$. They were encouraged to keep the "Background Information" in mind as they responded. The importance level scale gave the respondent five, Likert-like, choices from which to select: No Importance, Little Importance, Important, Very Important and Extremely Important. Two rounds during Phase One were needed to arrive at consensus. During Phase Two of the study the respondents were asked to rate the importance level of each staff development and professional preparation need for the 1990's, keeping the counselor responsibilities and competencies agreed to during Phase One of the study in mind. They were encouraged to add items and to Rank order the top ten staff development and professional preparation 
needs from their completed list. Each part of the Delphi instrument allowed space for and strongly encouraged the participants to add items. Thus, this Delphi instrument combines open-ended and structured formats. This decision was made after preliminary consultation with professionals in the field who suggested that the combined format with emphasis on structure would assure a higher return rate. They believed that the structure would stimulate thought and would also help keep the overall time required to complete the rounds within a reasonable limit. The return rates in this study of 96 percent, 87 percent and 96 percent, respectively for each round, substantiated their belief.

Uhl (1983) found that by leaving space for the participants to modify statements or add items they believed were important, the researcher could elicit additional items from the participants. He found that not only was the structured procedure less frustrating for the participants but a wider range of items would be considered thus increasing the potential of gathering more useful data. The review of the literature substantiated that researchers can expect a much higher dropout rate with the unstructured questionnaire than with the structured format (Linstone and Turoff, 1975; Uhl, 1983; Erdos, 1983). 


\section{Pilot Study Description}

According to Borg and Gall (1983) and Erdos (1983), a final but critical step in the development of the demographic questionnaire and Delphi instrument is pretesting for validity, conciseness, clarity of instructions, language use, bias, logical and attractive format and rate of return. A pilot study of the demographic questionnaire and a pretest validation of the Delphi instrument were conducted shortly after the expert panel was nominated. Chief student services administrators, other than those on the expert panel, were asked to pretest and complete the instruments. They were given an overview of the objectives of the study, background demographic and Assembly Bill 1725 information and were asked to complete the forms. They were also given an outline form on which to include their comments and recommendations regarding the instruments. They confirmed the validity of the instruments in that they reported that the instruments measured what they intended to measure. Content validity is further demonstrated by the direct relationship that exists between the items on the Delphi instrument and the research questions. Their comments and recommendations in reference to the other guidelines of questionnaire construction presented by Borg and Gall (1983) and Erdos (1983) were also solicited. The decision to use a structured format 
for the Delphi instrument was greatly influenced by the pilot study feedback. Revisions in format layout and clarity of questions were made as a result of their suggestions. Their comments about the value and timeliness of the study, in light of recent changes impacting California's community colleges, contributed to the researcher's motivation and persistence with the study.

\section{Expert Panel Selection}

Most Delphi studies use a panel of experts. One of the key elements in the successful accomplishment of a Delphi study is the identification of appropriate and willing respondents. The value of the results depends largely on the excellence and cooperation of the participants (Gordon and Ament, 1989; Harmon, 1975; Linstone and Turoff, 1975).

Enzer and de Brigard (1970 indicated that the:

The composition of the panel is crucial to the success of any Delphi study since the quality of the output is entirely dependent upon the arguments presented by the panel. The key factors considered in selecting a Delphi panel are the kind of expertise required for the subject being discussed 
and the identity and availability of the most appropriate people to provide the needed coverage. For a Delphi panel, "most appropriate" implies not only knowledge and recognized achievement in the area of question, but also a broad knowledge of many related aspects and an open-minded and communicative attitude (p. 62).

Linstone and Turoff (1975) speak of the "ingredients" for creating a successful mix of panelists. They identity three kinds of panelists:

Stakeholders, those who are or will be directly affected; experts, those who have an applicable specialty or relevant experience; and facilitators, those who have skills in clarifying, organizing, synthesizing and in contributing alternative global views of the culture and society (p. 68).

The participants on the expert panel used for this study met the qualifications and represent the three kinds of panelists. These qualifications were considered in the identification and selection of the participants and later 
were substantiated with the personal and professional data gathered through the demographic questionnaire.

The expert panel for the study consisted of California Community College Chief Student Services Administrators who were identified as experts by the leadership of their professional organization; the California Community College Chief Student Services Administrators Association (CCCCSSAA). Specifically, two past presidents, the current president and the president elect were asked to identify the expert panel. The criteria used by them for identification of "expert" included: service on task forces/advisory committees, presenters at conferences, service as region representatives, service as executive officers of the CCCCSSAA, doers and innovators and respected veterans of the profession. This was in agreement with Harmon's (1975) considerations of identification of experts. He stated:
A reasonable definition of expertise involves recognition and approbation of peer groups; to wit, someone is an expert in his field if others in his field consider him to be an expert. Some measures of expertise, by this definition, are the holding of office in the national organization, the holding of a position, 


\begin{abstract}
- . and awards. . . such measures taken
jointly, rather than singly, would very

likely serve as useful identifiers of

expertise. When a variety of professionals

in a field are polled about whom they regard

as an expert, and the same individuals keep

being mentioned, those individuals must be

considered experts (p. 5).
\end{abstract}

Although not necessary in a Delphi study, an attempt was made to provide for statewide representation in the selection of the expert panel. The state of California is divided into ten geographical regions for the purpose of communication and consultation among and between the professionals in the field and the State Chancellor's office for California Community Colleges. Since the leadership of CCCSSAA did not initially identify minimally one expert from one of the ten regions, the researcher asked them to identify an expert from the region not represented. Broad representation of the expert panel is not a critical issue in Delphi studies as it is in other studies. Murray (1968) stated that

\footnotetext{
in this kind of survey of expert opinion and estimates, since it is not a statistical survey of the Gallup type,
} 
it is immaterial whether the experts be a representational sample (p. 30) .

It was expected that there would be a minimum of ten to fifteen panel members. However 23 experts were identified. All individuals mentioned by three of the four nominators were included on the panel. Most of the individuals were mentioned by all four nominators. A panel size of fifteen is acceptable for a Delphi study. Delphi studies conducted by Ted Gordon and olaf Helmer (Helmer, 1964) used panels of fifteen respondents.

The decision to use an expert panel as opposed to all 107 chief student services administrators in California was primarily made to enhance the probability of tapping the most experienced, knowledgeable and expert administrators. There has been some turnover in this level position during the last two years. Due to the potential applicability of the results of this study, it was important to get the opinions of those people who had enough experience to have a historical perspective and a professionally mature and information-founded future perspective. Although the researcher recognized that those holding their positions within the last two to three years may very well have matched this profile, the researcher believed it was more likely that those with more professional seniority in their 
positions would have a greater degree of expertise to offer this study.

\section{Data Collection}

Three rounds of the modified Delphi method were used to collect the data. Each nominated expert received a call from the researcher to inform him/her of the study and their nomination and to request a commitment of their full participation in each phase and round of the study. The panel of experts then received a cover letter, co-signed by the president of CCCCSSAA verifying and encouraging their participation as well as background information (Appendix A) for the study.

During round one, the respondents were asked to complete both the demographic questionnaire and parts one and two of the Delphi instrument. They received self-addressed, stamped envelopes for returning their materials. The intent of round one was to gather demographic data about the panel and to develop a comprehensive list of responsibilities and competencies. The respondents were given a list of items in each area to stimulate their thinking but were strongly encouraged to add items in each area that they believed would be very important to meet the challenges of the 1990 's. They were asked to rate each item using a five-point importance level 
scale. Two weeks were allowed for responding before reminder letters were sent to non-responders.

Round one materials were then tabulated and summarized. Round two materials, with instructions and self-addressed, stamped envelopes, were mailed to the panel. During round two, the panel received parts one and two of the Delphi instrument with the modal response of all the participants' ratings gathered from round one, for each item listed. In addition, they received their individual priority rating for each item if the response was different from the modal consensus. The materials they received also included all comments and added responsibility and competency statements submitted by respondents during round one. The panel was asked to either join the consensus or to state the primary reason for remaining outside the consensus. They were also asked to rate and comment on the items which were added during round one. They were encouraged to submit any comments and feedback that they believed were important for consideration by the researcher and other panel members. The primary function of round two was to increase consensus on the responsibilities and competencies for counselors for the 1990's and to define minority opinion more clearly. Round two materials were summarized, using the responsibility and competency items receiving importance level ratings of four and five, to develop a draft of a 
job description for California community college counselors to meet the challenges of the 1990's. An independent reader reviewed all the materials to insure against researcher bias in the development of the job description draft. During round three, the panel received the job description draft, minority opinions on the items, additional feedback gathered during round two and parts three and four of the Delphi instrument. Respondents were asked to take the job description, drafted from their input, the additional information provided and their best planning and forecasting judgment to make their ratings of parts three and four using the five-point importance level scale. They were encouraged to add items and were then asked to submit, in rank order, the top ten staff development and professional preparation needs. The primary function of round three was to gather the respondents' opinions and rankings of staff development and professional preparation needs of counselors who would have to meet the specifications of the proposed job description. They were also asked to submit whatever other final input they had specifically for the job description and generally for the entire study. The researcher sent reminder letters and called to follow-up respondent progress to ensure maximum return prior to completion and analysis of all the data. 


\section{Data Analysis}

The data was compiled and summarized after the cutoff date for each round to prepare the materials for the subsequent round and to determine the modal response of the group to each item in the Delphi instrument. One of the purposes of the Delphi method was to encourage consensus. The measures of central tendency which generally are used to indicate consensus on questionnaires are either the mode or the median, since the mean would not give information in regard to consensus. In this study, consensus was considered to be reached when a minimum of 50 percent of the respondents selected the same response for the item. The percentage of those selecting the mode illustrated the degree of consensus. Rasp (1973) stated that "median is often used in surveys focusing on judgments about time or quantity, and the mode is frequently used in efforts to gain opinion about desired conditions" (p. 32). Furthermore, Isaac and Michael (1972) have stated that the mode is used when, "we wish to know what is the most typical case" (p. 117).

Dalky (1969) noted that one of the characteristics of the Delphi is to assure that the opinion of every participant in the study is requested in the final response. Therefore, all additions recommended by the panel for each part of the instrument was included in the 
subsequent round for consideration by all. Comments and other feedback were summarized or included verbatim in the Delphi summaries (Appendices D, F and G) mailed to the respondents. A job description draft (Appendix H) was prepared from round two results and returned to the respondents, along with the Delphi instrument Parts Three and Four, for use in round three.

A summary of the Demographic Questionnaire (Appendix J) was prepared after round one. At the conclusion of the study, the researcher mailed the respondents a copy of: the summary of the Demographic Questionnaire, the job description for California community college counselors for the 1990's and the summary, in rank order, of staff development needs for currently employed counselors and professional preparation needs of prospective community college counselors (Appendices H, I and $J$ ).

A final analysis using descriptive statistics was made of the data gathered through the study. The information was used by the researcher to present at the general session of the 1989 annual CCCCSSAA conference. The researcher was also asked to serve on a panel at a workshop addressing the Student Services Profession's response to the reform mandates of Assembly Bill 1725. In addition the researcher was requested to serve as a consultant by several community colleges to discuss the study and to assist them in addressing the future of counseling services 
at their respective colleges. A summary of the findings and recommendations from the results were prepared and disseminated to all the community college chief student services administrators in California. The summary and recommendations can be found in Chapter $V$.

Weaknesses of the Delphi Methodology

Many of the strengths and advantages of the Delphi technique were observed in this study. The methodology allowed for wide representative and consistent participation in the study. Difference of opinion as well as comments and recommendations are all documented. The flexibility of the technique contributed to the high degree of participation.

Some of the disadvantages of the Delphi as previously stated were not evident in this study. Panelist drop-out rates were not high. The return rates of 96 percent, 87 percent and 96 percent per each round were exceptionally good. The capabilities and quality of the expert panel were also very strong which lends to the credibility of the study's results.

However, the Delphi technique is not without its problems and weaknesses. The thinking, attitudes and perceptions about the experts' consensus is not explained with this methodology. The degree of consensus in this 
study is not only clear but very strong as evidenced by the 80 percent rating and higher. However, the Delphi technique does not totally help reveal why the experts believe the specific responsibilities and competencies are extremely important for the $1990^{\prime}$ 's or why they changed their ratings to join the consensus. Thus the interpretation and summation of responses is an educated estimate at best and is never complete, because as Iindstone and Turoff (1975) expressed, "the panelists do not send in their 'heads' but only their responses" (p. 70). Combining an interview research technique with the Delphi process would give more insights to both the questions and the results.

Because the results of a study using the Delphi technique are intuitive rather than scientifically obtained and because we can't predict the future, the results of this study, at best, give us trends and indications for the future. Whether or not actual change will result from the experts' opinions can only be determined by a subsequent study after passage of a few years.

Despite some drawbacks with the Delphi methodology, it was the best research method to fit the problem of obtaining consensus about a future state. So long as the results are viewed and understood in their appropriate context, they make a useful contribution to both the literature and field of community college counseling. 
CHAPTER IV

FINDINGS OF THE STUDY

\section{Introduction}

The purpose of this study was to provide comprehensive information about California community college counselor responsibilities and associated competencies for the 1990 's, keeping in mind both California's rapid growth and diversity and the reform mandates in Assembly Bill 1725. The study also sought information about staff development needs of currently employed counselors and professional preparation needs of prospective community college counselors. The information is useful in planning, decision-making and policy formulation related to community college counselors and the services they provide.

This chapter presents and analyzes the data gathered regarding these critical counselor issues for the 1990's as perceived by the chief student services administrators. The data presented answers the following research questions: 
1. What will be the responsibilities of California Community College Counselors during the 1990's?

2. What competencies will California Community College Counselors need to fulfill their responsibilities during the 1990's?

3. What will the 1990's job description for California Community College Counselors include?

4. What are the staff development needs of currently employed California Community College Counselors to prepare them to effectively fulfill their responsibilities in the 1990 's?

5. What course or seminar topics should counselor education programs include to prepare prospective California Community College Counselors to effectively fulfill their responsibilities in the 1990 's?

\section{Demographic Questionnaire Analysis}

The Demographic Questionnaire was designed to elicit personal, professional and site location information about each of the expert participants and their colleges. Twenty two of the twenty three nominated chief student services administrators completed the questionnaire. These twenty two comprised the panel and became the active participants of the study. Most participants completed 
all the items on the questionnaire. The Demographic Questionnaire Summary, Appendix J, includes a complete listing of all the responses. The responses are grouped into categories and presented with greater detail in the following pages.

\section{Expert Panel Characteristics}

\section{Position Titles}

Table 1 demonstrates the variety and distribution of titles that the respondents hold.

Insert Table 1 about here

The Superintendent/President who participated in the study had just acquired this position at the beginning of this study and had previously served as a chief student services administrator for eleven years. This respondent had been nominated as an expert by all four of the nominators and agreed to participate in the study. One of the Assistant Superintendents/Vice Presidents of Student Services retired at the beginning of the study but agreed to participate in the entire study. All the other 20 
Table 1

Job Titles of Respondents

Job Title

Responses

Dean of Student Services

6

Vice President, Student Services

Assistant Superintendent/Vice President

of Student Services 2

$\begin{array}{ll}\text { Superintendent/President } & 1\end{array}$

Vice Chancellor, Student Affairs and

Community Services

Vice President, Student Development

and Student Services 1

Vice President, Community and Student Services 1

Vice President, Educational Services 1

Vice President 1

Dean of Student Personnel Services 1

Dean of Student and Enrollment Services 1

Dean of Academic Affairs 1

Note: $\mathrm{N}=22$ respondents. 
respondents currently hold chief student services administrator positions.

\section{Direct Supervisor's Position Titles}

Table 2 indicates the panelists' supervisor's position titles.

Table 2

Direct Supervisor's Job Title

Job Title

Responses

President

12

Superintendent/President

6

Board of Trustees

1

Chancellor

1

Vice President, Academic Services

Vice President, Instruction and Student

Services

1

Note: $\mathrm{N}=22$ respondents.

Except for the Superintendent/President, who reports directly to the Board of Trustees, the supervisors of 19 of the respondents are the chief executive officers of the colleges. Only two of the respondents do not report 
to the chief executive officer. Nonetheless, all but the Superintendent/President have direct supervisory responsibilities for student services under which counseling services is included.

Years in Present Position

Table 3 lists the total, average and range of years that the respondents have held their current positions.

Table 3

Years in Present Position

\begin{tabular}{lcc}
\hline Total & Average & Range \\
\hline 143 Years & 6.5 Years & $1-17$ Years
\end{tabular}

Note: $\mathrm{N}=22$ respondents.

Previous Position

Table 4 illustrates the variety of immediately previously held positions of the respondents. 
Table 4

Immediate Previous Position

Position Title

Responses

Dean of Students 3

Assistant to the President 1

Vice President, Student Services 1

Vice President of Instruction 1

Dean of Admissions and Records 1

Dean of Counseling 1

Dean of Counseling and Student Services 1

Dean of Special Programs 1

Dean of Student Personnel 1

Associate Dean 1

Associate Dean of Admissions and Records 1

Associate Dean, Instruction 1

Associate Dean, Student Affairs 1

Assistant Dean, Student Services 1

Department Chairperson, Counseling 1

Director, Advising Services 1

Director, Learning Center 1

Counselor, Affirmative Action officer 1

Admissions Officer and Registrar 1

$\begin{array}{ll}\text { Blank } & 1\end{array}$

Note: $\mathrm{N}=22$ respondents. 
Eighteen of the 21 respondents who answered this item held an immediate previous position directly related to student services. One respondent left this item blank.

\section{Years in Immediate Previous Position}

Table 5 lists the total, average and range of years that the respondents held their immediate previous position.

Table 5

Years in Previous Position

\begin{tabular}{llc}
\hline Total & Average & Range \\
\hline 124 Years & 5.6 Years & $1-20$ Years \\
\hline
\end{tabular}

Note: $N=22$ respondents.

\section{Community College Counseling Experience}

Table 6 lists the total, average and range of years of counseling experience for those respondents who have been community college counselors. 
Table 6

Community College Counseling Experience

\begin{tabular}{|c|c|c|c|c|}
\hline $\begin{array}{l}\text { Respondents } \\
\text { Without } \\
\text { Counseling } \\
\text { Experience }\end{array}$ & $\begin{array}{l}\text { Respondents } \\
\text { With } \\
\text { Counseling } \\
\text { Experience }\end{array}$ & Total & Average & Range \\
\hline 7 & 15 & $\begin{array}{c}80 \\
\text { Years }\end{array}$ & $\begin{array}{c}5.7 \\
\text { Years }\end{array}$ & $\begin{array}{l}1-10 \\
\text { Years }\end{array}$ \\
\hline
\end{tabular}

Note: $\mathbf{N}$ of 22 to question of whether or not respondent had previous community college counseling experience.

$\mathbf{N}$ of 21 to question of number of years of counseling experience.

Student Services Profession Experience

Table 7 lists the total, average and range of years that the respondents have had in the student services profession. 
Table 7

Student Services Profession Experience

\begin{tabular}{lcc}
\hline Total & Average & Range \\
\hline 395 Years & 18.8 Years & $7-28$ Years \\
\hline
\end{tabular}

Note: $\mathbf{N}=21$ respondents.

Responsibility Areas of Current Position

Seventeen of the respondents are responsible for all the student services areas at their college and four are responsible for both the student services and instruction areas/divisions of their college. The latter four hold their positions at smaller colleges which tend to have one vice president/dean responsible to the President for both areas. One respondent is currently the superintendent/ President.

Age and Gender

Table 8 shows the gender and age distribution of the panelists. 
Table 8

Age and Gender Distribution

\begin{tabular}{lcc}
\hline Gender & Age Range & Responses \\
\hline 7 Female & $20-30$ & 0 \\
15 Male & $31-40$ & 1 \\
& $41-50$ & 10 \\
& $51-60$ & 9 \\
& $61-70$ & 2 \\
\hline
\end{tabular}

Note: $\mathrm{N}=22$ respondents.

\section{$\underline{\text { Academic Degrees }}$}

Each of the 22 respondents have earned both a bachelor's and master's degree. Fifteen or 68 percent have at least one doctoral degree. Six participants indicated that, in addition to their bachelor's and master's degrees, they hold an associates degree, specialist certificate, second master's or a second doctorate. 
Conferences Related to Community College Counseling Attended by Respondents

Nineteen of the 22 respondents have attended a local, state or national conference related to community college counseling during the last two years. All 22 respondents have attended the annual California Community College Chief Student Services Administrators Association Conference at which some counseling-related workshops were offered. All also have attended the regional CCCCSSAA Conference. Five respondents have attended the annual Association of California Community College Administrators Conference and five had attended matriculation conferences. Four have attended the annual Learning, Assessment, Retention, Consortium (IARC) Conference and four have attended the annual California Association of Community Colleges Conference. Two respondents indicated they have attended the National League of Innovations Conference. Each of the other 16 conferences, listed in Appendix J, item 4, page 3 , have been attended by one respondent.

\section{Presentations Related to Counseling Made by Respondents}

Eighteen of the 22 respondents made counseling-related presentations at local, state or national conferences during the last two years. At least half of the 
respondents made at least two and as many as ten presentations. Thirty one separate topics were addressed. Some topics including assessment, matriculation, student services program review and student retention were covered by several of the respondents. A complete listing of topics and titles of these presentations is found in Appendix J, item 5, page 3 .

\section{Panelist Profile}

From the data presented above, a profile of the average panelist in this study has been developed. The typical panelist is a 50 year old male, vice president with a doctorate degree who has been in his current position about seven years. He has worked an average of 19 years in the student services profession including about six years as a community college counselor. He has responsibility for all of the student services programs and reports directly to the chief executive officer of the college. His immediate previous position was a midmanagement position in student services which he held an average of six years. He is a member of the California Community College Chief Student Services Administrators Association and has attended the annual conference in 1988 and several matriculation and other counseling-related conferences. He has made at least two and as many as ten 
presentations related to counseling at local, state and national conferences during the last two years. His prompt and persistent participation in this study speaks to his degree of professionalism and interest in the community college counseling profession.

The information gathered from the Demographic Questionnaire, listed in its entirety in Appendix $\mathrm{J}$, demonstrates that the average respondent is an expert in the student services profession and has extensive experience as a community college counselor. Collectively, the respondents have had 395 years of experience in the student services profession, with 143 of those years in their present positions as chief student services administrators, and 20 percent or 80 years have been spent directly as community college counselors. A total of 65 academic degrees have been earned collectively by the 22 respondents. A11 22 hold both bachelors and masters degrees and 15 or 68 percent hold doctorate degrees. The remaining degrees earned include associate degrees, specialist certificates, second masters and second doctorate degrees. Finally, their conference attendance and number of presentations made during the last two years is testimony to their professional involvement. They collectively have attended 54 local, state or national conferences and each participant has attended the annual California Community College Chief 
Student Services Administrators Association Conference. A total of 39 presentations have been made on 31 separate topics by 18 of the 22 respondents.

\section{Institutional Characteristics}

Respondents were assured anonymity and thus specific information received on the Demographic Questionnaire from item 1 is not included in this summary. Details of college enrollment and ethnic breakdown of enrollment are given in Tables 9 and 10 which follow.

\section{Enrollment}

Small, medium and large community colleges are represented by this study. Responses to item 6, "Student Enrollment at Your Institution," are fairly evenly distributed. Table 9 demonstrates the distribution pattern of enrollment, by headcount, of the community colleges. 
Table 9

Student Enrollment

\begin{tabular}{lcc}
\hline Enrollment Range & Responses & Percentages \\
\hline 5,000 or Less & 3 & 13.6 \\
$5,001-10,000$ & 6 & 27.3 \\
$10,001-15,000$ & 5 & 22.7 \\
$15,001-20,000$ & 4 & 18.2 \\
$20,001-25,000$ & 2 & 9.1 \\
More Than 25,000 & 2 & 9.1 \\
\hline
\end{tabular}

Note: $\mathrm{N}=22$ respondents. Mode $=5,000-10,000$.

Ethnic Breakdown of Enrollment

Table 10 indicates the degree of ethnic diversity in the collective enrollment of all 22 community colleges. The figures represent an average of percentages of enroliment per ethnic category as reported by 19 of the 22 respondents. The categories are those currently most commonly used on community college admissions applications. The range of the percentages reported is also included to direct the reader's attention to the high percentage of Hispanics, Blacks and Asians at some of the community colleges. 
Table 10

Ethnic Breakdown of Enrollment

\begin{tabular}{lcr}
\hline Ethnic Category & $\begin{array}{c}\text { Percentage } \\
\text { Average }\end{array}$ & $\begin{array}{c}\text { Percentage } \\
\text { Range }\end{array}$ \\
\hline American Indian or & 1.45 & $.6-2.4$ \\
$\quad$ Alaskan Native & 5.93 & $.0-16.0$ \\
Asian or Pacific & 5.20 & $1.0-20.0$ \\
Islander & 13.62 & $32.7-90.0$ \\
Black & 1.45 & $.0-5.8$ \\
Caucasian (Not & 2.05 & $.0-50.2$ \\
Hispanic) & & $.0-9$ \\
Filipino & 136 & \\
Hispanic & &
\end{tabular}

Note: $N=19$ respondents.

\section{Institutional Profile}

Al1 22 respondents work at California community colleges. An attempt was made to provide for statewide representation in the selection of the expert panel and thus of community colleges. Each of the ten geographical regions, determined by the State Chancellor's office for California Community Colleges, is represented in this 
study by at least one community college. The northern and southern community colleges are evenly represented as are small, medium and large colleges. The average of percentages of enrollment by ethnic category is reflective of the changing demographics in the state of California. Hispanics represent the largest non-caucasian enrollment group followed by Asians and Blacks. While there is no typical institution, the 22 institutions in this study are representative and reflective of the 107 community colleges in California.

\section{Delphi Analysis}

The Delphi instrument for this study was divided into four parts: Counselor Responsibilities, Counselor Competencies, Staff Development Needs and Professional Preparation Needs. On the first and second part, the respondents were asked to indicate the level of importance, from 1 to 5 , of each responsibility and competency listed, or added by them, for counselors for the 1990's. They were asked to complete their rating with the perspective of the anticipated demographic changes in California and the reform demands in Assembly Bill 1725. On parts three and four, the panelists were asked to rate the importance level, from 1 to 5 , of the staff development and professional preparation topics/courses 
listed or added by them. They were asked to rank order the top ten staff development and professional preparation topics/courses. As they completed parts three and four, they were asked to keep in mind the job description, formulated from their responses to parts one and two, for California community college counselors in the 1990's. An analysis and summary of each of the rounds of this study follows. However, more detailed information, including respondents' comments per item, can be found for each round in Appendices D, F, H and I. Appendices D, F and I were Delphi summaries sent to panelists after each round. Appendix $\mathrm{H}$, which was mailed with round three materials, is the job description for California community college counselors for the 1990's developed directly from the panel's round two responses.

\section{Round One Results}

Prior to round one materials being sent out, the researcher called each of the 23 nominated panel experts and requested their participation in the study. All 23 expressed interest in the study and agreed to participate. Round one materials included a cover letter (Appendix K), co-signed by the researcher and the president of the California Community College Chief Student Services Administrators Association, a Demographic Questionnaire 
(Appendix B), a synopsis of the demographic and AB 1725 information and parts one and two of the Delphi instrument (Appendix C). These materials were mailed out on October 18, 1988 to all 23 nominated panelists who were asked to return the materials no later than November 1 , 1988. On November 7, 1988, a follow-up letter was mailed to those who had not yet responded. Round one was completed by 22 of the 23 panelists yielding a return rate of 96 percent.

Round one respondents rated the importance level, for the $1990^{\prime} \mathrm{s}$, of 35 community college counselor responsibilities and 32 competencies. The list of responsibilities and competencies was compiled from data found in current (1987-1988) job descriptions of California community college counselors. The respondents were asked to make comments about each of the responsibilities and competencies and were also encouraged to be futuristic and add what they believed would be important responsibilities and competencies for counselors in the 1990's. The respondents took this first part of the study very seriously as is evidenced by the number of comments submitted. All the comments for each item are listed in the Delphi Summary for Round One (Appendix D), which was mailed to the respondents after round one. A total of eight different responsibilities and eleven competencies were added by the respondents. 
The data generated from round one have been listed, categorized and analyzed in the round two analysis which is discussed later in this text and is included in the Delphi Summary for Round One (Appendix D). The summary of the Demographic Questionnaire, also completed during round one is included in Appendix $J$. Since the main purpose of round one was to gather demographic data about the panel and to develop a comprehensive list of responsibilities and competencies, very little data were actually analyzed following round one. The ratings submitted by the respondents for the listed responsibilities and competencies were analyzed to determine the modal response. This information along with respondent comments was returned in the summary during round two for the respondents' review. The added responsibilities and competencies were also included for round two respondents to rate.

\section{Round Two Results}

Round two materials were mailed to all 23 of the originally nominated experts including the one who had not participated in round one. The participants received parts one and two of the Delphi instrument with the modal response of all the respondents' ratings, gathered from round one, for each item listed. In addition, they 
received their individual importance-level rating for each item if their response was different from the modal consensus. The materials (see Appendix D) they received also included all comments and added responsibility and competency statements submitted by the panel during round one. The respondents were asked to either join the consensus or to state the primary reason for remaining outside the consensus. They were also asked to rate and comment on the items which were added during round one. Participants were encouraged to submit comments and feedback which they believed were important for consideration by the researcher and other panelists. They were informed that the primary function of round two was to both increase consensus on the responsibilities and competencies for counselors for the 1990's and to define minority opinion more clearly. The panel was also informed that the results of this round would comprise the job description for California community college counselors for the 1990's. Round two materials were mailed on November 22, 1988. On December 7,1988 , a reminder was mailed to the nonrespondents. Round two was completed by 20 of the 23 nominated experts yielding a return rate of 87 percent. During round one, respondents had added eight different responsibilities and eleven competencies to the list they were given. In addition they had submitted numerous comments regarding many of the responsibilities 
and competencies. Thus, during round two, they reconsidered these ratings and changed some of them. They also rated the added items. Figure 1 summarizes the rating information and illustrates the degree of movement, which for some items was substantial, toward the consensus.

Figure 1 reveals that a very high degree of consensus occurred for the ratings of both responsibility and competency items after only two rounds. The degree of consensus ranged from 55 percent to 100 percent with more than two thirds of the items receiving 80 percent consensus or higher. Thus, no attempt was made to conduct a third round of the Delphi technique to study counselor responsibilities and competencies.

Insert Figure 1 about here

Community College Counselor Responsibilities for the 1990's: Consensus Items

It is interesting to note that there were no changes in the modal response for the importance-level rating for the counselor responsibilities. A substantial amount of change, however, is evident between rounds in the degree of consensus about the importance level of counselor 
Figure 1

Delphi Summary of Ratings for Rounds One and Two

\section{Part 1: Responsibilities}

Definition of Responsibility: A trust, obligation, or duty; that for which one is responsible.

Importance-Level Scale:

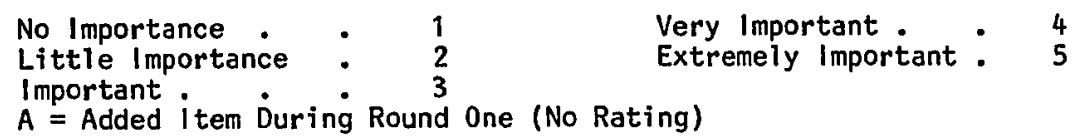

1. Academic advising (course selection assistance)

2. Educational planning (goal selection assistance)

3. Personal counseling (assistance in personal adjustment and problem areas)

4. Career counseling (career exploration and selection)

5. Life planning (goal, decisionmaking, lifestyle assistance)

6. Conduct new student orientation sessions

7. Prepare written handouts, handbooks, brochures, video and slide presentations

8. Participate in outreach/recruiting functions

9. Devel op and teach traditional academic discipline classes

10. Administer and interpret academic placement tests

11. Administer and interpret tests of interests, values, personalities and career planning

12. Program approval and assistance during registration

13. Assist student with college forms and applications

14. Provide information about schol arships and financial aid services

15. Work with instructors to establish test data to determine student placement

16. Assist instructors in monitoring student progress (early warning system)

17. Counsel provisional/probationary or di squalified students

18. Coordinate, develop and assist

in the implementation of the Matriculation Plan

\begin{tabular}{|c|c|c|}
\hline 5 & 5 & 59 \\
\hline 5 & 5 & 82 \\
\hline 3 & 3 & 41 \\
\hline 5 & 5 & 55 \\
\hline 5 & 5 & 41 \\
\hline 4 & 4 & 41 \\
\hline 2 & 2 & 41 \\
\hline 4 & 4 & 32 \\
\hline 2 & 2 & 64 \\
\hline 3 & 3 & 55 \\
\hline 3 & 3 & 45 \\
\hline 3 & 3 & 32 \\
\hline 2 & 2 & 27 \\
\hline 3 & 3 & 36 \\
\hline 3 & 3 & 32 \\
\hline 4 & 4 & 41 \\
\hline 5 & 5 & 77 \\
\hline 5 & 5 & 45 \\
\hline
\end{tabular}

(figure continued) 
19. Develop effective liaison relationships with instructors to facilitate communication and staff development

20. Develop and teach counseling/personal development ciasses

21. Initiate, plan, develop, implement and evaluate programs and services to meet student needs

22. Meet the special counseling needs of:

(a) international students

(b) re-entering adults

(c) veterans

(d) displaced workers

(e) limited English-speaking students

(f) transfer students

(g) EOP students

23. Facilitate crisis intervention

24. Develop and work with network of community resources

25. Refer students to appropriate onand off-campus services

26. Develop liaison and articulation relationships with high schools

27. Develop $1 i$ aison and articulation relationships with colleges and universities

28. Keep current with labor market trends and local employment opportunities

29. Develop, update and maintain records of accountability and documentation

30. Assist in grant writing

31. Work with counseling related computer assisted systems

32. Plan and conduct relevant research in student personnel areas

33. Prepare written reports and data analysis

34. Provide work direction and supervision to paraprofessionals

35. Participate in the college governance process and curriculum development

36. In-service training for teaching staff

37. Provide learning consultation for staff

38. Own personal development

39. Take a leadership role in student retention activities

40. Take a leadership role in meeting the challenge of the "new" student populations

41. Evaluate student services frequently

42. Attend state conferences to keep informed

43. Participate in teaching teams

\begin{tabular}{|c|c|c|}
\hline 5 & 5 & 50 \\
\hline 4 & 4 & 45 \\
\hline 3 & 3 & 36 \\
\hline $\begin{array}{l}3 \\
4 \\
3 \\
4\end{array}$ & $\begin{array}{l}3 \\
4 \\
3 \\
4\end{array}$ & $\begin{array}{l}32 \\
41 \\
27 \\
41\end{array}$ \\
\hline $\begin{array}{l}5 \\
5 \\
A \\
4\end{array}$ & $\begin{array}{l}5 \\
5 \\
5 \\
4\end{array}$ & $\begin{array}{r}50 \\
59 \\
\mathrm{~A} \\
32\end{array}$ \\
\hline 4 & 4 & 41 \\
\hline 4 & 4 & 45 \\
\hline 5 & 5 & 55 \\
\hline 5 & 5 & 59 \\
\hline 4 & 4 & 32 \\
\hline $\begin{array}{l}3 \\
2\end{array}$ & $\begin{array}{l}3 \\
2\end{array}$ & $\begin{array}{l}32 \\
64\end{array}$ \\
\hline 5 & 5 & 45 \\
\hline 2 & 2 & 41 \\
\hline 3 & 3 & 55 \\
\hline 4 & 4 & 36 \\
\hline 4 & 4 & 45 \\
\hline A & 4 & A \\
\hline $\begin{array}{l}A \\
A\end{array}$ & $\begin{array}{l}4 \\
4\end{array}$ & $\begin{array}{l}A \\
A\end{array}$ \\
\hline A & 5 & A \\
\hline $\begin{array}{l}A \\
A\end{array}$ & $\begin{array}{l}5 \\
5\end{array}$ & $\begin{array}{l}A \\
A\end{array}$ \\
\hline $\begin{array}{l}\mathrm{A} \\
\mathrm{A}\end{array}$ & $\begin{array}{l}4 \\
4\end{array}$ & $\begin{array}{l}A \\
A\end{array}$ \\
\hline
\end{tabular}

(figure continused) 
Part 2: Competencies

Definition of Competency: Ability, expertise, mastery, proficiency or skill.

\begin{tabular}{lll}
\hline & & Percent Choosing \\
Listed in the Order of Appearance & Modal Response & $\begin{array}{c}\text { Modal Response } \\
\text { in the Delphi Instrument }\end{array}$ \\
\hline
\end{tabular}

1. Educational planning skills

2. Career counseling skills

3. Life planning and counseling skills

4. Personal counseling skills

5. Group dynamics/process skil1s

6. Teaching skills

7. Knowledge of assessment tests and test interpretation

8. Knowledge of study skills

9. Knowledge of learning theory

10. Knowl edge of adult development theory

11. Knowledge of human motivation and behavior

12. Ability to work effectively with underprepared students

13. Ability to work effectively with a diverse age group

14. Ability to interact effectively with persons of diverse socio-economic and ethnic backgrounds

15. Ability to work effectively with re-entry adults

16. Ability to assimilate large volumes of changing academic information

17. Ability to assimilate large volumes of changing career information

18. Ability to interpret, apply and explain policies and procedures

19. Ability to analyze a situation correctly and adopt effective course of action

20. Knowledge of the Matriculation Plan for community colleges

21. Knowl edge of community college mission and philosophy

22. Understanding of applicable sections of the State Education Code

23. Knowledge of articulation

24. Knowledge of admissions, financial aid and veterans affairs

25. Ability to communicate effectively in written and verbal form

26. Organizational and program development skills

27. Skills with counseling-related computer-assisted systems

28. Knowledge of community social agencies, services and resources

29. Knowledge of basic research principles

30. Previous paid community college counseling experience

31. Internship or practicum at a community college setting

32. California Community College Counseling Credential

\begin{tabular}{|c|c|c|}
\hline $\begin{array}{l}5 \\
5 \\
5 \\
5 \\
5 \\
3\end{array}$ & $\begin{array}{l}5 \\
5 \\
5 \\
5 \\
5 \\
3\end{array}$ & $\begin{array}{l}82 \\
73 \\
63 \\
32 \\
36 \\
55\end{array}$ \\
\hline $\begin{array}{l}5 \\
4 \\
4 \\
3\end{array}$ & $\begin{array}{l}5 \\
4 \\
4 \\
3\end{array}$ & $\begin{array}{l}50 \\
41 \\
50 \\
41\end{array}$ \\
\hline 4 & 4 & 50 \\
\hline 5 & 5 & 68 \\
\hline 5 & 5 & 82 \\
\hline 5 & 5 & 86 \\
\hline 5 & 5 & 55 \\
\hline 5 & 5 & 50 \\
\hline 3 & 3 & 32 \\
\hline 4 & 4 & 36 \\
\hline 4 & 4 & 36 \\
\hline 5 & 5 & 50 \\
\hline 5 & 5 & 32 \\
\hline $\begin{array}{l}3 \\
4\end{array}$ & $\begin{array}{l}3 \\
4\end{array}$ & $\begin{array}{l}36 \\
36\end{array}$ \\
\hline 3 & 3 & 36 \\
\hline 5 & 5 & 55 \\
\hline 3 & 3 & 45 \\
\hline 5 & 5 & 45 \\
\hline 3 & 3 & 36 \\
\hline 2 & 2 & 36 \\
\hline 3 & 3 & 50 \\
\hline 3 & 3 & 41 \\
\hline 5 & 5 & 36 \\
\hline
\end{tabular}

(figure continued) 
Listed in the Order of Appearance

Modal Response

Percent Choosing

in the Delphi instrument

33. Teaching experience (prior)

34. Integrity

35. Free from mental problems

36. Sensitivity to cultures

37. Possibly bilingual (depending on location)

38. Flexibility and tolerance

39. Understand and provide linkage between counseling and

instruction

$\begin{array}{llll}\text { A } & \text { 5 } & \text { A } & 75 \\ \text { A } & 5 & \text { A } & 95 \\ \text { A } & 4 & \text { A } & 70 \\ \text { A } & 4 & \text { A } & 60 \\ \text { A } & 4 & \text { A } & 75 \\ \text { A } & 4 & \text { A } & 60\end{array}$

40. Be able to fulfill variety of functions but with one or two specializations

41. Be active in professional

organizations

42. Knowledge and participatory skills in program review

43. Masters degree in counseling

$\begin{array}{lll}\text { A } & 5 & \text { A }\end{array}$

$\begin{array}{lll}\text { A } & 4 & \text { A }\end{array}$

$\begin{array}{llll}\text { A } & 4 & \text { A } & 70\end{array}$

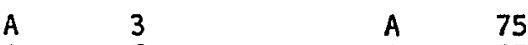

Note: $N=22$ respondents for Round One and 20 respondents for Round Two. 
responsibilities for the 1990 's. The degree of consensus changed anywhere between 8 and 64 percentage points between round one and round two. Although one cannot specifically identify all the determining factors for such change in consensus, one can safely assume that at least one of the influencing factors was the opportunity to consider other respondents' ratings and comments. This illustrates why the Delphi technique is considered to be a strong consensus building tool. Anywhere between 55 percent and 100 percent degree of consensus was reached for each item. Over two thirds of the items received an 80 percent or higher degree of consensus on the importance-level rating. The main objective of this round, to increase consensus about future counselor responsibilities, was reached.

All counselor responsibility items receiving an importance-level rating of 4 (Very Important) or 5 (Extremely Important) were identified and placed into one of six categories: Counseling, Instruction, Evaluation, Professional Development, Institutional and Other. These categories were found on several of the job descriptions reviewed by the researcher. The format of the descriptions including these categories was used in this study. Each responsibility was then ranked according to importancelevel rating and degree of consensus under each category. The resulting list identified the California community 
college counselor responsibilities for the 1990's in rank order per category. Figure 2 displays this list. The ranking results of studies of similar counselor responsibilities found in the literature have been added to the listing. It is hoped that the figure facilitates the reader's comparison of the studies' results.

Insert Figure 2 about here

Although Litwack (1978) identified 25 counselor responsibilities, only 12 were the same responsibilities identified by high importance level ratings in this study. Litwack's responsibilities of drug, marriage and pregnancy counseling could be subsumed under the "Personal Counseling" responsibility listing of this study, but the latter did not receive a high enough rating to be included as a top priority responsibility. "Life Planning" including goal, decision-making and lifestyle assistance was ranked eight of 17 responsibilities under the counseling category. Based on comments submitted, some of the respondents saw a close link between Personal Counseling and Life Planning. Other responsibilities in Litwack's study such as group counseling, job placement, research on curriculum and supervision of counseling interns were not identified in this study and thus no ranking comparison can be made. 
Figure 2

Community College Counselor Responsibilites for the 1990's

\begin{tabular}{|c|c|c|c|c|}
\hline$\frac{\text { Specific Responsibilities }}{\text { (Vela, 1989, } 33 \text { Responsibilities) }}$ & $\begin{array}{l}\text { (Litwack } \\
\text { 1975-25) }\end{array}$ & $\begin{array}{l}\text { (Goodman, } \\
\text { et al, } \\
1975-8 \text { ) }\end{array}$ & $\begin{array}{l}\text { (Hinko, } \\
\text { 1971-6) }\end{array}$ & $\begin{array}{l}\text { (Miller, } \\
\text { 1979-6) }\end{array}$ \\
\hline
\end{tabular}

A. Counseling (in order of importance)

*1. Meet the special counseling needs of EOP students

*2. Counsel provisional/probationary

or disqualified students

*3. Meet the special counseling needs of transfer students

*4. Provide educational planning (goal selection assistance)

5. Work with counseling-related computer-assisted systems

*6. Take a leadership role in meeting the challenge of the "new" student

7. Provide academic advising course selection assistance)

8. Provide life planning (goal, decision-making, lifestyle assistance)

*9. Meet the special counseling needs of limited Englishspeaking students

*10. Provide career counseling

11. Refer students to appropriate on- and off-campus services

12. Develop and work with network of community resources

13. Neet the special counseling needs of di splaced workers

14. Maintain currency with 1 abor market trends and local employment

*15. Assist instructors in monitoring student progress (eariy warning system)

16. Facilitate "crisis" intervention

*17. Meet the special counseling needs of re-entering adults

B. Instruction (in order of importance)

*1. Develop effective liaison relationships with instructors to facilitate communication and staff development

2. Develop and teach counseling/ personal development classes

3. Participate in teaching teams

4. Conduct new student orientation sessions

C. Evaluation

*1. Evaluate student services frequentiy

(figure continued) 


\begin{tabular}{|c|c|c|c|c|}
\hline $\begin{array}{l}\text { Specific Responsibilities } \\
\text { (Vela, 1989, } 33 \text { Responsibilities) }\end{array}$ & $\begin{array}{l}\text { (Litwack } \\
\text { 1975-25) }\end{array}$ & $\begin{array}{l}\text { (Goodman, } \\
\text { et al, } \\
\text { 1975-8) }\end{array}$ & $\begin{array}{l}\text { (Hinko, } \\
\text { 1971-6) }\end{array}$ & $\begin{array}{l}\text { (Mil1er, } \\
\text { (979-6) }\end{array}$ \\
\hline
\end{tabular}

D. Professional Development (in order of importance)

*1. Provide in-service training for teaching staff

2. Provide learning consultation for staff

3. Participate in own personal development

*4. Attend state conferences to keep informed

E. Institutional (in order of importance)

*1. Take a leadership role in student retention activities

*2. Develop liaison and articulation relationships with high schools

*3. Develop liaison and articulation relationships with colleges and universities

*4. Coordinate, develop and assist

in the implementation of the Matriculation Plan

*5. Participate in the college governance process and curricul um development

6. Participate in outreach/ recruiting functions

5

7

6 5

F. Other

1. Provide work direction

and supervision to paraprofessionals

Note: $*$ Responsibilities in direct response to the demographic changes and the reform mandates in Assembly Bill 1725. 
The rankings of five of the eight responsibilities researched by Goodman, et al (1975) can be directly compared to those of this study. Counselors in their study were involved in job placement services. A review of California community college counselor job descriptions did not find job placement to be a counselor responsibility. Financial aid counseling and research ranked fifth and eighth in their study but in this study these responsibilities did not receive high enough ratings to be listed as top priority responsibilities. The comments submitted by the respondents suggest that these are responsibilities of other employees.

Hinko (1971) identified six responsibilities in his study of counseling services. All but one can be compared to the responsibilities found in this study. Group counseling was not a distinctly listed responsibility of this study. However, due to the high ratings by the respondents for group counseling competencies, one can safely assume that the respondents see group counseling as a delivery mode for other counseling services. Miller (1979) identified the six most important problems for which students sought counselors' assistance. Three of the six are specifically listed as counselor responsibilities of this study. However, the respondents of this study suggested that financial aid counseling was the responsibility of the financial aid 
staff. Neither "anxiety" nor "desire to drop out" were specifically addressed by this study but could be subsumed under various other categories.

In this study, the 16 responsibility items receiving an importance-level rating of 1 (No Importance), 2 (Little Importance) or 3 (Important) are not included in Figure 2 but can be found by reviewing Figure 1 .

All eight of the responsibilities added by respondents during round one received, during round two, importancelevel ratings of 4 (Very Important) and 5 (Extremely Important) with consensus degrees of 60 percent to 90 percent. Thus these eight responsibilities, listed in Table 11, superseded some of those identified from the original job descriptions and all were included in Figure 2. They include:

Insert Table 11 about here

A strong relationship between these eight added responsibilities and the demographic information and implications of the reform mandates in Assembly Bill 1725, given to the panel as background information, can be seen. In essence, the panel followed the directions of the researcher to be futuristic and respond to the Delphi instrument keeping the background information in mind. 
Table 11

\section{Responsibilities Added During Round One}

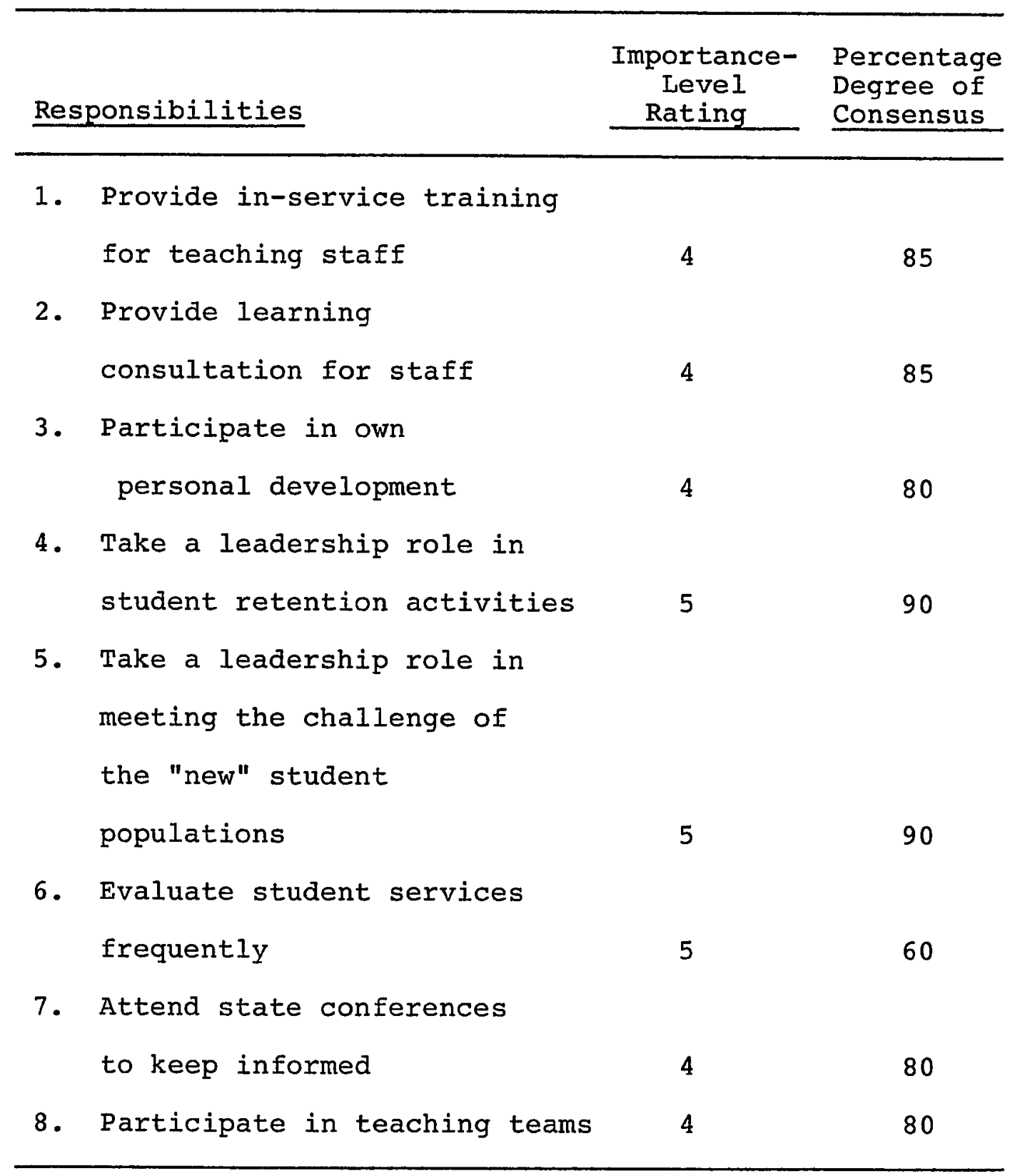

Note: $\mathrm{N}=22$ respondents 
In fact, 18 of the 33 counselor responsibilities listed in Figure 2 are in response to the state's demographic changes and reform mandates in $A B$ 1725. They are shown with an asterisk on the table for easy identification. During round three, respondents were given a final opportunity to add responsibility items and submit comments relating to the responsibilities or the study in general. Ten responsibility items were submitted, but nine of the ten already had been included, with different wording, and rated in the study. The only distinctly new addition to the responsibility listing was "meet the special needs of disabled students." While there is no disagreement that this student population has special needs, it is not often the generalist community college counselor's responsibility to meet those needs that are directly related to the disability. State legislation found in Administrative Code Title $\mathrm{V}$ requires that counselors with special credentials serve these students. Thus, this responsibility is not included in the list of community college counselor responsibilities. The detailed listing of the ten added responsibilities can be found in Appendix I. 
Community College Counselor Competencies for the 1990's: Consensus Items

Just as there were no changes of the modal response for counselor responsibilities between round one and round two, there were no changes, as illustrated in Figure 1, for the counselor competencies either. However, there were as many as 63 percentage points difference between rounds on the degree of consensus about the rating for some of the competencies. The Delphi technique worked well in gathering consensus about counselor competencies.

All counselor competency items receiving an importance-level rating of 4 (Very Important) or 5 (Extremely Important) were identified and placed into one of three categories: Skills and Abilities Required, Knowledge Required and Other Requirements. These categories are found in the format of several job descriptions reviewed by the researcher. Each competency was then ranked according to the importance-level rating and degree of consensus it received from the panel. Figure 3 displays the specific California communty college counselor competencies for the 1990 's. 
Figure 3

Community College Counselor Competencies for the 1990's

\section{Specific Competencies}

A. Skills and Abilities Required (in order of importance)

*1. Ability to work effectively with underprepared students.

*2. Ability to interact effectively with persons of diverse socio-economic and ethnic backgrounds.

*3. Educational planning skills.

*4. Career counseling skills.

5. Group dynamics/process skills.

*6. Ability to work effectively with a diverse age group.

*7. Ability to work effectively with re-entry adults.

8. Ability to communicate effectively in written and verbal form.

9. Skills with counseling-related computer-assisted systems.

10. Life planning and counseling skills.

11. Personal counseling skills.

12. Ability to assimilate large volumes of changing academic information.

13. Ability to analyze a situation correctly and adopt effective course of action.

14. Ability to fulfill variety of functions but with one or two specializations.

15. Ability to interpret, apply and explain policies and procedures.

*16. Bitingual (depending on location).

B. Knowledge Required (in order of importance)

*1. Knowledge of community college mission and philosophy.

*2. Knowledge of assessment tests and test interpretation.

*3. Knowledge of the Matriculation Plan for community colleges.

*4. Knowledge of learning theory.

*5. Knowledge of study skills.

6. Knowledge of human motivation and behavior.

*7. Knowledge of articulation.

C. Other Requirements (in order of importance)

1. Integrity.

*2. Understand and provide linkage between counseling and instruction.

3. Masters degree in counseling.

4. Teaching experience.

5. California Community College Counseling Credential.

6. Free from mental problems.

*7. Be active in professional organizations.

*8. Sensitivity to cultures.

9. Flexibility and tolerance.

Note: $*=$ Competency in response to demographic changes and the reform mandates in Assembly Bill 1725. 
During round one, the panel was given 32 competencies to rate and they were encouraged to submit comments and add competencies. Eleven different competencies were added to the list by the respondents. All but one of the added competencies received an importance-level rating of either 4 (Very Important) or 5 (Extremely Important) with corresponding consensus percentages of $60-95$ percent. All but one of these 11 added competencies displaced competencies on the original list and thus were listed in Figure 3. The added competencies are listed in Table 12.

Insert Table 12 about here

One can note that some of these added competencies $(4,5,6,7,9,10$ and 11$)$ relate directly to the anticipated demographic changes and to the reform mandates of California's Assembly Bill 1725. The panel indeed followed the researcher's instructions to respond with these factors in mind. The 16 competencies listed with asterisks on Figure 3 are those which are in direct response to these key factors impacting California's community colleges.

However, it is also interesting to note the inclusion of some personality characteristics and qualities not usually found in job descriptions. Although only one 
Table 12

Competencies Added During Round One

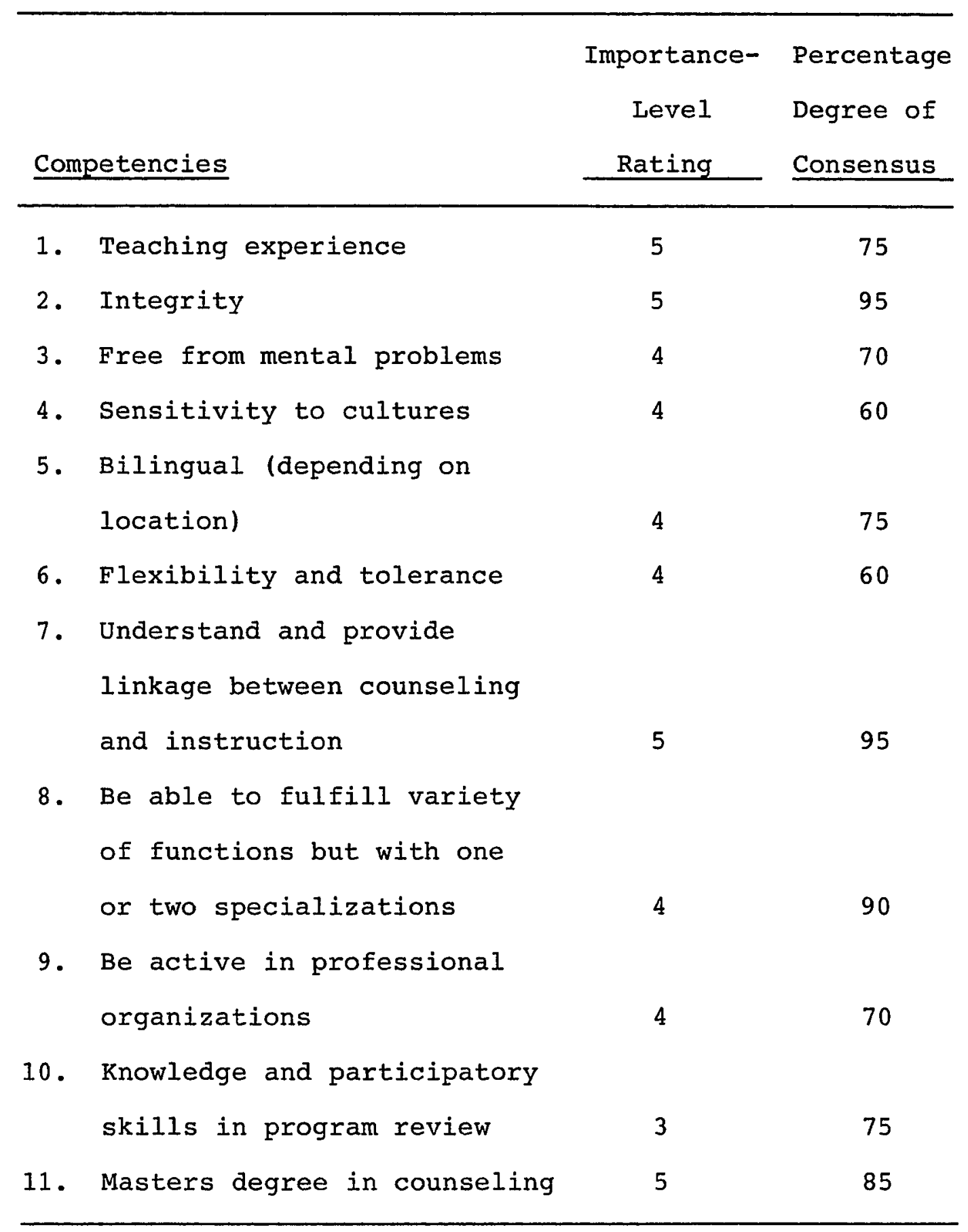

Note: $N=22$ respondents 
respondent each added "integrity," "free from mental problems," or "flexibility and tolerance," the importancelevel rating and the degree of consensus, reached after round two, speaks to the importance of these qualities from the perspective of the respondents. There is no question that the qualities of flexibility and tolerance will be necessary assets for counselors being asked to meet the varying needs of an increasingly diverse student population.

A final opportunity was given to each respondent, during round three, to add any competencies they believed were important. Six competencies were submitted. One had already been included in the study with slightly different language. However, the other five were distinct and merit recognition.

1. Be abie to intervene, take leadership.

2. Friendly, open and caring.

3. Ability to develop and implement student flow models and activities.

4. Ability to: detect learning difficulties, be sensitive to students with learning disabilities and refer students to appropriate services.

5. Knowledge of wellness concepts and preventions of diseases, particularly AIDS and of substance abuse to 
not only enhance retention but also to enhance wellness.

Some colleges have learning disabilities specialists and health specialists on their staff who have among their responsibilities responsibility 4 and 5 respectively. However, that is not to say that counselors could not better serve students with these skills. Since these were submitted during the last round of the study, the entire panel did not assess the importance level of these competencies. However, they are included as findings of this study.

Job Description for California Community College Counselors for the $1990^{\prime} \mathrm{s}$

Round two materials were summarized using the responsibility and competency items which received importance-level ratings of 4 and 5 with a high degree of consensus, to develop a draft of a job description for California community college counselors to meet the challenges of the $1990^{\prime} \mathrm{s}$. It should be noted that despite the high degree of consensus (approximately 85 percent) on most responsibilities and competencies, the results of this study indicate future directions and trends towards a California community college 
counselors' job description but do not necessarily predict the future. However, since the results of this study reflect the thinking of those who are in the position to influence the job description, one can feel a comfortable level of confidence that the job description for California community college counselors for the 1990 's will resemble the one that follows in Figure 4. An independent reader reviewed all the materials to insure against researcher bias in the development of the job description.

Insert Figure 4 about here

Round Three Results

Round three materials included: the job description (Appendix H), drafted from round two results; a summary of round two (Appendix G), including minority opinions on the items and additional feedback gathered during round two; and parts three and four of the Delphi instrument (Appendix E). The materials were mailed on January 6 , 1989, to all 23 original expert panel nominees. They were asked to take the job description, additional information and their best planning and forecasting judgment to rate the staff development and professional preparation 
Figure 4

Job Description for California Community College Counselors for the 1990's

\section{General Responsibilities}

It is the responsibility of all counselors to participate in development, implementation and evaluation of counseling services that will result in educationa1, vocational and personal development of students.

\section{Specific Responsibilities}

\section{A. Counseling (in order of importance)}

1. Meet the special counseling needs of EOP (Extended Opportunity Program) students.

2. Counsel provisional/probationary or di squalified students.

3. Meet the special counseling needs of transfer students.

4. Provide educational planning (goal selection assistance).

5. Work with counseling-related computer-assisted systems.

6. Take a leadership role in meeting the challenge of the "new" student.

7. Provide academic advising (course selection assistance).

8. Provide life planning (goal, decision-making, lifestyle assistance).

9. Meet the special counseling needs of limited English-speaking students.

10. Provide career counseling.

11. Refer students to appropriate on- and off-campus services.

12. Develop and work with network of community resources.

13. Meet the special counseling needs of displaced workers.

14. Maintain currency with labor market trends and local employment.

15. Assist instructors in monitoring student progress (early warning system).

16. Facilitate "crisis" intervention.

17. Meet the special counseling needs of re-entering adults.

B. Instruction (in order of importance)

1. Develop effective liaison relationships with instructors to facilitate communication and staff development.

2. Develop and teach counseling/personal development classes.

3. Participate in teaching teams.

4. Conduct new student orientation sessions.

C. Evaluation

1. Evaluate student services frequently.

D. Professional Development (in order of importance)

1. Provide in-service training for teaching staff.

2. Provide learning consultation for staff.

3. Participate in own personal development.

4. Attend state conferences to keep informed.

E. Institutional (in order of importance)

1. Take a leadership role in student retention activities.

2. Develop liaison and articulation relationships with high schools.

3. Develop liaison and articulation relationships with colleges and universities.

4. Coordinate, develop and assist in the implementation of the Matriculation Plan.

5. Participate in the college governance process and curriculum development.

6. Participate in outreach/recruiting functions.

F. Other

1. Provide work direction and supervision to paraprofessionals.

(figure continued) 
Specific Competencies

A. Skills and Abilities Required (in order of importance)

1. Ability to work effectively with underprepared students.

2. Ability to interact effectively with persons of diverse socio-economic and ethnic backgrounds.

3. Educational planning skills.

4. Career counseling skills.

5. Group dynamics/process skil's.

6. Ability to work effectively with a diverse age group.

7. Ability to work effectively with re-entry adults.

8. Ability to communicate effectively in written and verbal form.

9. Skills with counseling-related computer-assisted systems.

10. Life planning and counseling skills.

11. Personal counseling skills.

12. Ability to assimilate large volumes of changing academic information.

13. Ability to analyze a situation correctiy and adopt effective course of action.

14. Ability to fulfill variety of functions but with one or two specializations.

15. Ability to interpret, apply and explain policies and procedures.

16. Bilingual (depending on location).

B. Knowledge Required (in order of importance)

1. Knowledge of community college mission and philosophy.

2. Knowledge of assessment tests and test interpretation.

3. Knowledge of the Matriculation Plan for community colleges.

4. Knowledge of learning theory.

5. Knowledge of study skills.

6. Knowledge of human motivation and behavior.

7. Knowledge of articulation.

C. Other Requirements (in order of importance)

1. Integrity.

2. Understand and provide linkage between counseling and instruction.

3. Masters degree in counseling.

4. Teaching experience.

5. California Community College Counseling Credential.

6. Free from mental problems.

7. Be active in professional organizations.

8. Sensitivity to cultures.

9. Flexibility and tolerance. 
topics/courses, listed in parts three and four of the Delphi instrument, using the same five-point importancelevel scale. The respondents were encouraged to add items and were instructed to rank order the top ten staff development and professional preparation needs of counselors who are expected to meet the challenges of the 1990's. The main function of round three was to gather the panel's opinions about staff development and professional preparation needs. Panelists were also invited to submit comments about the job description or the study in general. Reminder letters were sent to the non-respondents on January 18, 1989. Round three of the study was completed by 22 of the 23 nominated experts, yielding a return rate for the final round of 96 percent.

Staff Development Needs of Currently Employed California Community College Counselors

California's rapidly changing demographics and the reform mandates included in Assembly Bill 1725 will trigger changes in the responsibilities and thus, in the needed competencies of the currently employed community college counselors. The changes in responsibilities and competencies can already be seen in the listing of responsibilities and competencies for the 1990's on Figures 2 and 3. As stated earlier, the experts in the 
field identified new responsibilities and competencies in response to the anticipated changes and gave them a high level of importance.

The same experts were asked to consider the following, "Do today's counselors have the needed competencies to meet the job description demands of the 1990's? What is missing?" They were asked to identify key topics that addressed the staff development needs of currently employed counselors to prepare them for the 1990's. The respondents were given a list of 16 staff development topics and were asked to add others. They were then asked to submit their top ten ranked staff development recommended topics.

A great deal of interest was expressed in staff development as is evidenced by the number of staff development topics added to the list. Eighteen additional topics were added and rated by several respondents. Some respondents suggested the same additional topics which points to the agreement of thought in this area. These 18 additions were included in the top ten ranked topics of several respondents. Ten other topics were also added by respondents and were given an importance-level rating but were not included in the top ten ranked topics.

A complete listing of ranked and unranked staff development topics can be found in Figure 5. A complete listing of the ranking points per topic can be found in Appendix I . 
Figure 5

Ranked and Unranked Staff Development Topics

Ranked Staff Development Topics

Topic

Rank Order

* Cultura1 Awareness, Understanding and Sensitivity

* State Matriculation Plan

* Cognitive Assessment Principles

* Learning Needs of ESL Students

Computer Skills for Counselors

*Aduit Development Theory

Affective Domain Assessment

*Learning Theory

Substance Abuse

*Affirmative Action

Sexual Harassment

State Codes (Education and Title V)

*Second Language Skills

Teaching Skills

Higher Education Laws

Grievance Policies and Procedures

* Career Development Theory, Career Trends and Changes

Interpersonal Relationship Ski11s--Counseling Methods

Transfer Requirements

Academic Advising Principles and Topics

*Articulation with Transfer Institutions

Career and Personal Development Assessment Instruments

*Effective Intervention Skills with Probationary Students

Effective Change Agent Skills

Listening Skills

Student Services Relationships

Group Dynamics

* Local Matriculation Plans

*Study Skills

*Articulation with High Schools

Career Intervention

Financial Aid Skills

Community Resources

Facilitation of Faculty/Staff Relations

Rank Orde

2

3
4

5

6

7

8

9
10

12

13

14

15

34

Note: $*=$ Staff development topic in direct response to the demographic changes and the reform mandates in Assembly Bill 1725.

Unranked Staff Development Topics

This list includes topics that: were added to the original list by the participants, were given an importance level rating but were not included in any participant's list of the top ten ranked topics. They are presented here in alphabetical order.

Topic

AIDS Awareness

$2+2+2$ Articulation

Budget Development

Coping with Stress

Disabled Student Awareness, Understanding and Sensitivity
Economic Development

Global Society and Impact on Jobs

Learning Needs of Handicapped

Team Building

Vocational Curriculum Development 
As is noted on Figure 5, 14 of the 34 ranked staff development topics are in direct response to the anticipated demographic changes and to the reform demands in Assembly Bill 1725. Half of the top 17 ranked topics are directly related to the anticipated changes. It is evident that members of the expert panel believe that participation in staff development opportunities addressing these topics will enable currently employed California community college counselors to fulfill their responsibilities effectively during the 1990's.

Professional Preparation Needs of Prospective California Community College Counselors

The anticipated demographic changes discussed in this study are quickly being realized and their impact will be profound. The reform mandates in Assembly Bill 1725 are included in the California State Education Code. This information, coupled with the anticipated retirement projections of community college faculty, including counselors, should direct us to think about prospective community college counselors and the skills they will need to effectively fulfill the challenges of their jobs in the $1990^{\prime}$ 's and beyond.

Members of the expert panel in this study were asked to reflect on the counselor job description they developed 
for the 1990's and to identify topics/courses that should be included in the professional preparation program of prospective California community college counselors. They were given a list of 13 topics/courses and were encouraged to add others they believed were important. Panel members were then asked to rank their top ten professional preparation topic recommendations.

As with staff development needs, an impressive amount of interest was demonstrated in professional preparation needs. Twelve additional topics were added and given an importance-level rating. Some of the additions were also included in some of the respondents' top ten ranked recommendations thus displacing some of the original 13 listed topics. Fourteen other topics were also submitted and rated but were not included in the top ten ranked recommendations. Figure 6 displays a complete listing of the data gathered on professional preparation needs. The listing of the ranking points per topic can be found in Appendix I. 
Figure 6

Ranked and Unranked Professional Preparation Topics

Ranked Professional Preparation Topics/Courses

Topic

Rank Order

$\begin{array}{lr}\text { Career Development Theories } & 1 \\ \text { Counseling Theories } & 2 \\ \text { *Community College Mission and Philosophy } & 3 \\ \text { *Cultures in American Society } & 4 \\ \text { Assessment of Cognitive and Affective Domain } & 5 \\ \text { *Community College Counsel ing Practicum } & 6 \\ \text { *Adult Development Theory } & 7 \\ \text { Group Dynamics } & 9 \\ \text { *Learning Theory } & 8 \\ \text { Personality Theory } & 10 \\ \text { Teaching Methodology } & 11 \\ \text { Abnormal Psychology } & 13 \\ \text { Higher Education Law } & 15 \\ \text { Counseling Practicum } & 12 \\ \text { Integration of Student Services and Instruction } & 14 \\ \text { Student Services Mission and Coals and Concept of Student } & 16 \\ \text { Services as a Team } & 17 \\ \text { Goal Setting } & 18 \\ \text { Intervention Techniques for College Counselors (Study } & 19 \\ \text { Skills, Crises, Drugs, etc.) } & 20 \\ \text { Academic Advising Techniques--Assessment, Planning and Follow-up } \\ \text { *Participating in Institutional Planning, Decision and Policymaking } \\ \text { Practicum in Careers } & 21 \\ \text { Single Economics/Personal Finance } & 22 \\ \text { Know Your Community } & 23 \\ \text { Computer Skills } & 24 \\ \text { Higher Education Structure and Interrelationships } & 25\end{array}$

Note: $*=$ Professional preparation topic in direct response to the demographic changes and the reform mandates in Assembly Bill 1725.

\section{Unranked Professional Preparation Topics/Courses}

This list includes topics that: were added to the original list by the participants, were given an importance level rating but were not included in any participant's list of the top ten ranked topics. They are presented here in alphabetical order.

Topic

*Articulation

Conflict Resolution

Curricul um Theories

Development/Training of

Paraprofessionals

Effective Use of Community Resources

Finance/Budget Development

Grant Writing Skills

\author{
Integration of Instruction to \\ Student Services \\ Mental Heal th and Wellness \\ Orientation Issues and Skills \\ Research Methodology \\ Strategic Planning \\ Substance Abuse \\ Time Management/Stress Management
}

Note: * = Professional preparation topic in direct response to the demographic changes and the reform mandates in Assembly Bill 1725. 
Half of the top ten ranked professional preparation needs, listed in Figure 6, relate directly to the anticipated demographic changes and to the reform mandates in Assembly Bill 1725. These five topics are listed with an asterisk and include: Community College Mission and Philosophy, Cultures in American Society, Community College Counseling Practicum, Adult Development Theory and Learning Theory. Although others may also relate, these five topics traditionally have not been included in counselor preparation programs to the degree that the other topics have. Emphasis on the need for "Community College Counseling Practicum" which ranked sixth is evident especially as this is compared to a general "Counseling Practicum" which ranked twelfth. The others in the top ten are classic courses traditionally included in most counselor preparation programs. Their inclusion, by the panel, in the top ten substantiate their continued value as counselor preparation topics. Members of the expert panel believe that participation in professional preparation programs that include these topics will enable prospective California community college counselors to effectively meet the professional challenges of their responsibilities during the $1990^{\prime} \mathrm{s}$. 


\author{
CHAPTER V \\ SUMMARY AND RECOMMENDATIONS
}

\title{
Background Issues
}

California community colleges have been under study during the $1980^{\prime} \mathrm{s}$. Major reforms have been recommended by the Commission for the Review of the Master Plan for Higher Education and the Joint Committee for the Review of the Master Plan in Higher Education. The members' work was conducted with the constant awareness of the present and anticipated challenges facing California and its community colleges. The challenges included an increasing diversity in the age, ethnic background and academic preparation of students. The reform recommendations placed a specific focus on college mission, academic excellence, access, counseling, English as a second language, staff development and affirmative action (California Faces. . .California's Future, 1988) .

The work of the Commission and the Committee culminated in legislation, Assembly Bill 1725, which 
was signed on September 19, 1988. This law has become the landmark statute for California community college reform. Both the legislative and anticipated demographic changes in the state will have an impact on every facet of the community college. The response of community colleges to the reforms of $A B 1725$ and to the state's demographics will affect the role of student services, especially that of counseling services. Counselors' responsibilities and competencies will be affected by these changes which will result in an immediate need for staff development of those community college counselors currently employed. Likewise, the proessional preparation courses and seminars that prospective community college counselors pursue must be adapted to these changing demographics and mandates. Change in counseling services to better meet the challenges of the future is inevitable. The direction of such changes must come from those in positions to influence policy and decisions. It must come from those in the student services profession who have experience with the colleges, the counselors and the students so that they can project change recommendations with the current and anticipated needs in mind. The impetus and direction for the changes should come from the chief student services administrators. As Toeffler (1974) said, "their shared or collective image of the future dominates the decisions made in the institution" (p. 5). 


\section{Objectives of the Study}

The purpose of the study was to determine the responsibilities and competencies of California community college counselors for the 1990's as perceived by the chief student services administrators. The specific objectives of this research were:

1. To identify the responsibilities of California community college counselors for the 1990's;

2. To identify the competencies of California community college counselors for the 1990's;

3. To identify the staff development needs of currently employed California community college counselors to prepare them to effectively fulfill their responsibilities in the $1990^{\prime} \mathrm{s}$; and

4. To identify course or seminar topics that should be included in counselor education programs to prepare prospective California community college counselors for the 1990's and beyond.

\section{Methodology}

This study sought to elicit the opinions and consensus of experts regarding a future condition. Because of its strengths as a consensus building and 
forecasting tool, the Delphi technique was used for this study.

The Delphi instruments were designed and pilot tested in August, 1988. The expert panel was identified in July, 1988, and consisted of 23 California Community College Chief Student Services Administrators who represent both northern and southern community colleges. Small, medium and large community colleges are represented and each of the ten geographical regions, as determined by the State Chancellor's Office for California Community Colleges, is represented in this study.

Three rounds of the modified Delphi method were completed by the expert panel between October, 1988, and January, 1989. A high degree of interest in this study was immediately observed as a result of the number of comments submitted on the Delphi instruments, the personal notes of interest and encouragement, and most importantly, by the high rates of return. Round one was completed by 22 of 23 panelists yielding a return rate of 96 percent. Round two yielded an 87 percent return rate and round three was returned by 96 percent of the original 23 panelists.

A Demographic Questionnaire was designed to provide personal, professional and site location information about the panel. A panelist profile as well as an institutional profile were completed from the questionnaire. 
Descriptive statistics were used to analyze and summarize the data gathered in this Delphi study. The results of this study are presented in three forms:

1. A job description, including responsibilities and competencies (Appendix H), for California community college counselors for the 1990's;

2. A comprehensive list of staff development topics for currently employed counselors (Appendix I); and

3. A list of professional preparation topics for prospective community college counselors (Appendix I).

\section{Findings and Conclusions}

As stated earlier, Peterson (1971) noted the potential of the Delphi technique "for providing an institution with 1) a range of ideas about goals, 2) a priority ranking of the goals and 3) a degree of consensus about goals" (p. 10). The potential of the Delphi has also been demonstrated in this study. The final data of the study have provided:

1. a range of ideas about counselor responsibilities, competencies, staff development needs and professional preparation work;

2. a priorty ranking of these issues; and 
3. a degree of consensus about the importance level of these issues.

Helmer (1966), Uhl (1971), Weaver (1971), Judd (1972), Tiedemann (1985), and Grauer (1989) cited the beneficial use of the Delphi in educational planning. It is hoped that the data derived from this Delphi Study will be used for planning future directions of community college counseling services.

Community College Counselor Responsibilities for the $1990^{\prime} \mathrm{s}$

As they did in the seventies (Jones, 1970; Warnath, 1972), counselors will still have responsibilities for their traditional functions of academic advising, career counseling and personal counseling. However, this study reveals that there will be new facets to those responsibilities in the $1990^{\prime} \mathrm{s}$.

For this study, academic advising (course selection assistance) was distinguished from educational planning (goal selection assistance). As such, educational planning received a higher importance-level rating than did academic advising. The respondents believe that counseling process-oriented activities are more important responsibilities for credentialed counselors than are 
information dissemination activities and thus rated the former much higher than the latter. The following comment from one of the respondents emphasizes this point, "Welldefined graduation requirements and articulation agreements can be interpreted and disseminated more cost effectively by well-trained paraprofessionals. Counselors are needed for goal clarification--not programming." Other respondents submitted similar comments and further recommended that the academic advising functions be computerized. Chief student services administrators are now saying what community college counselors have been saying about these functions since the mid-seventies. Counselors have emphasized, for years, that their counseling skills are not really being utilized to their maximum potential because of the job demands and expectations that they provide information dissemination services.

Career counseling still appears on the responsibilities list but so does a new related responsibility, "Keep current with labor market trends and local employment." Personal counseling was on the list of responsibilities to be rated but did not receive a high enough rating of 4 (Very Important) or 5 (Extremely Important) to be included in the job description for the 1990 's. Fourteen of the 20 respondents in Round two rated this as a 3 (Important). In comparison to the 
rating of other responsibilities, this is a low rating. However, several comments were submitted for this item (see Appendix F, p. 2) that suggest different thinking. One such comment was, "Current and future students are bringing more personal problems to the academic environment. Counselors must address short-term problems that will interfere with educational success." Perhaps the key here is the "short term" personal counseling. In the past, counselors have been criticized for trying to be psychotherapists in an educational setting. It can be assumed here that the respondents support short-term personal counseling but not psychotherapeutic counseling as a responsibility for community college counselors. The literature indicates academic advising, career counseling and personal counseling, in this order, are the key counselor responsibilities at community colleges. In this study academic advising ranked seventh of seventeen counseling responsibilities; career counseling ranked tenth and personal counseling did not rank among the top seventeen.

Several observations can be made from the respondents' comments, ratings and degree of consensus regarding the ratings. The key observation is that the respondents are, indeed, sensitive to the anticipated demographic changes in California and in its colleges and to the reform mandates in $A B$ 1725. This is evidenced by the 
fact that 18 of the 33 counselor responsibilities listed in the job description in Appendix $\mathrm{H}$ relate directly to these changes. The following eight responsibilities from the various categories on the job description illustrate this point.

1. Meet the special counseling needs of EOP (Extended Opportunity Program for low income) students;

2. Take a leadership role in meeting the challenge of the "new" student;

3. Meet the counseling needs of limited English-speaking students ;

4. Counsel provisional/probationery or disqualified students;

5. Meet the special counseling needs of re-entering adults;

6. Participate in own personal development;

7. Take a leadership role in student retention activities; and

8. Coordinate, develop and assist in the implementation of the Matriculation Plan (statewide-mandated program to enhance student access and success).

Furthermore, four of the above listed responsibilities (1, 2, 6 and 7) were added by respondents during round one. 
These four received, during round two, high enough ratings to be included in the job description for the 1990's.

Respondents indicated a preference for identifying some responsibilities that really belong to a paraprofessional and not to a credentialed counselor. These include academic advising, orientation, career information dissemination and outreach/recruiting functions. The reader will note that all of these appear on the job description of community college counselors for the 1990's. However, the respondents' comments (see Appendix F) indicate that although they believe the function to be important, they also believe that paraprofessionals are not only more cost efficient but are also more effective in providing these services. It is also important to note that the responsibility "Provide work direction and supervision to paraprofessionals" received a rating of 4 (Very Important) with 100 percent consensus. This is noteworthy because not all community colleges in California currently employ paraprofessionals in the counseling centers.

This study revealed a trend towards counselor involvement in what could be considered indirect counseling service to students. The responsibilities supporting this trend include: 
1. Initiate, plan, develop, implement and evaluate programs and services to meet student needs. One of the comments received with this responsibility was, "More need than ever for this emphasis. This is a vital new role."

2. Develop, update and maintain records of accountability and documentation--evaluate student services frequently. One of the comments submitted with this was, "Have a responsibility for the quality of services."

3. Participate in the college governance process and curriculum development. Of this responsibility, a respondent commented, "Counselors are the main focus for student input and need to be heard--AB 1725 mandates."

4. Participate in own personal development.

5. Take a leadership role in student retention activities.

6. Take a leadership role in meeting the challenge of the "new" student.

Responsibilities 4,5 and 6 were added by respondents in the course of this study. These responsibilities also are directly responsive to both the anticipated demographic changes and the reform mandates of $\mathrm{AB}$ 1725. Thus, it seems that in the future community college counselors will be 
serving students by providing both direct and indirect services.

The researcher directs the reader's attention to not only the responsibilities that have been included but also to those that have been excluded from the future job description. The following responsibilities which appeared on current job descriptions (1987-1988) did not receive high enough ratings to be included in the job description for the 1990's.

1. Prepare written handouts, handbooks, brochures, video and slide presentations;

2. Develop and teach traditional academic discipline classes;

3. Program approval and assistance during registration;

4. Assist students with college forms and applications;

5. Provide information about scholarships and financial aid services;

6. Assist in grant writing; and

7. Plan and conduct relevant research in student personnel areas.

All but responsibilities 3 and 6 received a rating of 2 (Little Importance) while 3 and 6 received ratings of 3 (Important). The rating of "Little Importance" related to the degree of importance of the responsibility for a 
credentialed counselor. The comments indeed acknowledge the importance of the service but the respondents recommended that paraprofessionals be used to provide some of the services while some of the other responsibilities should be assigned to administrators or specialists. In response to the question, "What will be the responsibilities of California community college counselors during the 1990's?," one can assume that they will have some of the traditional counselor responsibilities but also will be required to focus on the special needs of the new student who will be older, underprepared, underemployed and who may speak English as a second language. In addition, counselors in the $1990^{\prime} \mathrm{s}$ will be more involved in providing indirect service to students through program development and institutional policy development. Counselors will be expected to evaluate their services and to participate in their own professional and personal development. They will be more involved in process-oriented counseling activities which will better utilize their counselor training, and be less involved in those information dissemination activities which can be performed by paraprofessionals. 


\section{California Community College Competencies for} the $1990^{\prime} \mathrm{s}$

Other than skills in personal counseling, career counseling and group dynamics, no mention of other community college counselor competencies could be found in the review of the literature. The review of the literature addressed some responsibilities from which one could assess what the corresponding competencies might be. However, the literature review did not reveal a list of competencies for community college counselors. A 1 ist of 32 competency statements was developed by the researcher after reviewing numerous current (1987-1988) job descriptions of California community college counselors. The respondents added 11 more competencies and rated all of them. A listing of specific competencies (Appendix H), grouped into three categories was developed by the researcher using the results of the study. Ten of the 11 added competencies received higher ratings than those listed in current job descriptions. It is noteworthy that 16 of the 32 competencies are in direct response to the demographic changes and the reform mandates listed in $A B$ 1725. This is not surprising, however, since 18 of the 33 responsibilities shared this relationship. 
Several observations can be made in response to the question, "What competencies will California community college counselors need to fulfill their responsibilities during the 1990's?" First, the traditional counselor competency requirements in personal counseling, career counseling, group dynamics and educational planning will continue to be needed by counselors in the future but they will be given medium priority. The top ranking skill requirements for counselors in the 1990's will be those that enable them to meet the needs of the anticipated new student population. Specifically they include:

1. Ability to work effectively with underprepared students;

2. Ability to interact effectively with persons of diverse socio-economic and ethnic backgrounds;

3. Ability to work effectively with a diverse age group;

4. Bilingual ability (depending on location); and

5. Sensitivity to cultures.

A second observation is that a very specific knowledge base will be required of counselors during the 1990 's. California community college counselors will be expected to know and understand the community college mission and philosophy; the state-mandated Matriculation Plan; learning theory; study skills; computer skills and 
articulation. Community college mission and philosophy and learning theory represent new cognitive areas of study for counselors. Computer skills will enable them to use computer-assisted counseling tools.

Another new direction is an emphasis on the counselors' personal qualities of integrity, freedom from mental problems, flexibility and tolerance. While these qualities may have been desired or even required in the past, no specific mention of them was found on the job description. However, there is no doubt that the respondents in this study believe these to be very important.

In summary, community college counselors in the 1990 's will be expected to have some of the traditional counseling skills as well as new counseling and cognitive skills to effectively serve underprepared and culturally and age diverse students. Also, it is likely that some counselors will be expected to be bilingual.

\section{Job Description for Community College Counselors} for the 1990's

The research question, "What will the job description for California community college counselors include for the 1990's?" can best be addressed by first referring the reader to Appendix $\mathrm{H}$. A copy of the job description 
developed through this study appears in Appendix $H$. Next the reader is asked to review the two previous sections that discuss the future counselor responsibilities and competencies. In the researcher's opinion, the job description represents the best of the traditional community college counselor role and lays out the blueprint for a new community college counseling era that will serve the new community college student of the twenty first century.

Staff Development Needs of Currently Employed Counselors

In 1979, Walz and Benjamin cited the critical need for counselor renewal and asserted:

No counselors prepared in one time will be adequately prepared to serve in another unless they have engaged in continuing attempts to renew their skills (pp. 27-28).

This is equally true today and will continue to be applicable so long as change occurs. As we move toward the 1990's counselors in California community colleges are experiencing change that will have a significant impact on their future role. The respondents of this 
study are quite cognizant of the need for staff development for currently employed counselors.

The study of the topic of staff development is timely in that California's reform mandates in Assembly Bill 1725 stress the need for staff development. Legislators approved funds to provide staff development opportunities for community college faculty, staff and administrators. The reader is asked to review Appendix I to obtain the response to the following research question: "What are the staff development needs of currently employed California community college counselors to prepare them to effectively fulfill their responsibilities in the 1990's?"

The key staff development needs are those that are directly related to the most recent changes; California's demographics and reforms mandated in AB 1725. All 22 participants of the study identified, "Cultural awareness, understanding and sensitivity" as one of the top ten staff development needs of currently employed counselors. Fifty percent ranked this as the number one staff development need. Most of the counselors in the field received their training at a time when cultural studies courses were not offered as part of their counselor training program. Until recently, community college students were predominantly Caucasian. With the rapid changes in the demography of California the need for cultural understanding is keen. 
Other identified staff development needs relate to today's community college key issues of matriculation, cultural and language diversity, adult development, learning styles, affirmative action, human rights, health issues, articulation, college governance and traditional counseling issues. The extensive list of 34 ranked and 10 unranked staff development topics is evidence that the staff development needs of currently employed community college counselors are numerous, diverse and timely. The list speaks also to the external pressures and role demands on California's community college counselors during the $1990^{\prime} \mathrm{s}$.

\section{Professional Preparation Needs of Prospective Counselors}

Creamer (1983) emphasized that community college counselor roles are sufficiently different from roles in other colleges to merit separate preparation. Professional preparation programs must respond to the unique requirements of community college counselors. The expert panel in this study provided several recommendations to answer the final research question of this study, "What course or seminar topics should counselor education programs include to prepare prospective California community college counselors to effectively fulfill their responsibilities in the 1990's?" 
To respond to this question, the participants reviewed the job description for the 1990's that they, in essence, developed and they also used their best judgment and forecasting skills. As with the topic of staff development needs, much interest and information were generated regarding professional preparation needs. The list of topics generated by the respondents is included in Appendix I. Twenty five ranked and 14 unranked topics were submitted.

Five professional preparation topics/courses identified for prospective community college counselors are: Community College Mission and Philosophy, Cultures in American Society, Community College Counseling Practicum, Adult Development Theory and Learning Theory. These five relate to the identified counseling responsibilities and competencies for the 1990's. While some mention of these topics already may be included in counselor preparation programs, the importance of these to prospective community college counselors merit that entire courses on some of these topics be included in their professional preparation.

Emphasis should be placed on the Community College Counseling Practicum experience which ranked sixth of twenty five topics/courses. The more common course of "Counseling Practicum" ranked twelfth of twenty five. The respondents understand and acknowledge, through their 
ratings, the value of a practicum experience. However, they make it quite clear that a community college counseling practicum experience is, by far, more preferable. Such an experience would provide prospective counselors an opportunity to apply theories learned in class, under a supervised situation, at a community college. It provides them an opportunity to work with and experience the "new" student at an educational institution which differs significantly from community agencies, high schools or universities. The Community College Counseling Practicum experience rounds out the prospective community college counselor's preparation.

The key issues of personality theory, counseling theories and group dynamics are usually addressed in the classic courses traditionally included in most counselor preparation programs. Other issues such as intervention techniques, mental health and wellness and goal setting can best be addressed via workshops or seminars.

Participation in professional preparation programs that include these key topics will enable prospective California community college counselors to meet the demanding, numerous and varied professional challenges they will face during the 1990's. 


\section{Recommendations for Chief Student}

\section{Services Administrators}

The significance of this study lies in the data gathered and in its use and application. The primary purpose of this study was to provide information for long-range and comprehensive planning for counseling services at California community colleges. To that end, the following recommendations are made to chief student services administrators:

1. That information from this study be used as a basis for discussion between the chief student services administrator and the counseling staff about counseling services;

2. That local assessment of the issues addressed in this study be conducted to assist in future local planning;

3. That job descriptions of counselors at the individual colleges be reviewed and revised as appropriate to assure that they reflect future responsibility and competency requirements for counselors;

4. That information from this study, along with that gathered from the local assessment, be used in planning for future counseling services and new hires. This is critical in that a high rate of retirement is expected in the next few years. The 
counselors hired within the next three to five years will weave the fabric of the philosophy and values which will envelop and lend strength to community college counseling services for the 1990's and beyond;

5. That a comprehensive and relevant staff development program for currently employed community college counselors be developed utilizing the results of this study;

6. That a strong and persistent request for staff development funds, provided through Assembly Bill 1725, be made locally to support the counseling staff development program; and

7. Finally, that the results of this study and that of the local assessment be used to determine the minimum qualifications and standards for community college counselors as required by Assembly Bill 1725 .

\section{Recommendations for the California Community College}

\section{Chief Student Services Administrators' Association}

Just as chief student services administrators can use the results of this study on a local college basis, so too can they use the results on a statewide basis via their professional organization, CCCCSSAA. Thus, the following 
recommendations are made for the California Community College Chief Student Services Administrators' Association:

1. That a draft of minimum qualifications and standards for California community college counselors be prepared, using the results of this study, and other pertinent data, shared with the California Community College Counselors Association and adopted by both organizations.

2. That the leadership of CCCCSSAA should communicate with the leadership of California Community College Counselors' Association (CCCCA) to share the findings of this study and to recommend that staff development opportunities for currently employed counselors be provided by CCCCA.

3. That dialogue occur between the Association and the Chief Executive Officers' group requesting their support of $\mathrm{AB} 1725$ dollars for staff development opportunities for currently employed counselors. It should be stressed to the chief executive officers that such staff development opportunities enhance the counselors' skills so as to enable them to better meet the challenges of their job in the 1990's.

4. That a list of recommendations of professional preparation requirements for prospective community college counselors be developed and shared with 
counselor education program directors throughout the state.

\section{Recommendations for Further Research}

On the basis of the foregoing study, the following recommendations for further studies are made:

1. That a similar study be completed to gather California community college counselors' perspectives regarding responsibility, competency, staff development and professional preparation issues of community college counselors.

2. That an additional round of the staff development and professional preparation sections be conducted to arrive at a more conclusive consensus of opinion regarding these two critical issues.

3. That a study be completed within the next five years to examine the job descriptions of California community college counselors to see if the counselor responsibilities and competencies, identified and projected in this study for the 1990's, have been realized and appear on the job description.

4. That a study be conducted to define the responsibilities and competencies of paraprofessional staff assigned to the counseling center. 
In summary, since 50 percent of the chief student services administrators who participated in this study are in the 31-50 age group, these individuals will continue, in all probability, in leadership roles well into the $1990^{\prime}$ 's and beyond. Therefore, they can and probably will have significant influence on the definition and expectation of responsibilities and associated competencies of California community college counselors for the 1990 's and beyond. Thus, the data presented in this study reflect some of the trends that are likely to occur in the foreseeable future. 
REFERENCES

Anderson, S. B., Ball, S. and Murphay, R. T. (1975).

Encyclopedia of educational evaluation. San

Francisco, California: Jossey-Bass, Inc. Publishers.

Arbuckle, D. S. (1953). Student personnel services in

higher education. New York: McGraw-Hill.

Arbuckle, D. S. (1972). The counselor: who? what?

Personnel and Guidance Journal, I , 785-790.

Astin, A. W. (1982). Minorities in American higher

education: Recent trends, current prospects and

recommendations. San Francisco, California:

Jossey-Bass, Inc., Publishers.

Blocker, C. E., Plummer, R. H., and Richardson, R. C., Jr.

(1965). The two-year college: A social synthesis.

Englewood Cliffs, New Jersey: Prentice-Hall

International, Inc.

Blocker, C. E. and Richardson, R. C., Jr. (1968).

Teaching and guidance go together. Junior College

Journal, XXXIX, 14-16.

Blocker, D. H. (1966). Can the counselor function as an

effective agent of change? The School Counselor,

XIII, 202-205. 
Board of Governors. (1988). AB 1725 Comprehensive

Analysis. Sacramento, California: California

Community Colleges.

Borg, W. R. and Gall, M. D. (1983). Educational

research: An introduction. New York: Longman.

Boy, A. V. and Pine, G. P. (1979). Needed: A rededication to the counselor's primary commitment. Personnel and Guidance Journal, LVII, 527-528.

Boy, A. V. and Pine, G. P. (1980). "Avoiding counselor burnout through role renewal." Personnel and Guidance Journal, XLIX, 161-63.

Bradley, M. K. (1978). Counseling past and present:

Is there a future? Personnel and Guidance Journal, LVII, 42-45.

Brooks, K. W. (1979). Delphi technique: Expanding applications. North Central Association Quarterly, LIII, $377-385$.

Brown, E. G. (1965). Public higher education in California. In Logan Wilson (ed.), Emerging Patterns in American Higher Education. Washington, D.C.: American Council on Education.

California Community Colleges. (1985). Contours of change: A working vision for the California community colleges to the year 2000. Sacramento, California: California Community Colleges. 
California Community Colleges. (1987). Looking ahead-Data for planning (Report No. 887). Sacramento, California: California Community Colleges. California Community Colleges. (1988). Issues confronting community colleges. (Report on a Delphi project, 88-5). Sacramento, California: Chancellor's Office, California Community Colleges. California Postsecondary Education Commission. (1980) . Missions and functions of the California community colleges. Sacramento, California: California Postsecondary Education Commission.

Carnegie Commission on Higher Education. (1973). The purposes and the performance of higher education in the United States approaching the year 2000 . New York: McGraw-Hill.

Carnegie Commission on Higher Education. (1974). A digest of the report of the Carnegie Commission on Higher Education. New York: McGraw-Hill. Ciavarella, M. A. and Doolittle, L. W. (1970). The ombudsman: Relevant role model for the counselor. School Counselor, XVII, 331-336.

Cohen, A. M. Hispanic students and transfer in the community college. Paper read at Hispanic Roundtable Talk, American Association of Community and Junior Colleges, Phoenix, Arizona, May 1984. 
Cohen, A. M. and Brawer, F. B. (1982). The American community college. San Francisco, California: Jossey-Bass, Inc.

Collins, C. C. (1965). Junior college counseling: A critical view. Personnel and Guidance Journal, 43, 546-550.

Collins, C. C. (1967). Junior college student personnel programs. What they are and what they should be. Washington, D.C.: American Association of Junior Colleges.

Collins, C. C. (1970). Giving the counselor a helping hand. Junior College Journal, $\mathrm{XL}_{1}, 17-20$. Collins, C. C. (1972). Student characteristics and their implications for student personnel work. In T. O'Banion and A. Thurston (eds.), Student Development Program in the Community Junior College. Englewood Cliffs, New Jersey: Prentice-Hall. Commission on the Future of Community Colleges. (1988). Building communities--a vision for a new century. Washington, D.C.: American Association of Community and Junior Colleges.

Commission for the Review of the Master Plan for Higher Education. (1987). The master plan reviewed: Unity, equity, quality and efficiency in California postsecondary education. Sacramento, California: California Legislature. 
Cosand, J. P. (1979). Perspective: community colleges in the 1980's. Washington, D.C.: American Association of Community and Junior Colleges. Creamer, D. G. (1983). Preparing and nurturing professional counselors. New Directions for Community Colleges, $\underline{43}$. San Francisco: Jossey-Bass, Inc. Publishers.

Cross, K. P. (1974). Beyond the open door. San Francisco, California: Jossey-Bass, Inc. Publishers. Cyphert, F. R. and Gant, W. L. (1970). The Delphi technique: A tool for collecting opinions in teacher education. Phi Delta Kappon, 21, 417-425.

Dalky, N. C. (1969). The Delphi method: An experimental study of group opinion. Santa Monica, California: RAND Corporation.

Dalky, N. and Helmer, O. (1963). An experimental application of the Delphi method to the use of experts. Management Service, 9 , 458-467.

Dameron, J. D. and Wolf, J. C. (1975). Counseling center functions in two-year and four-year colleges. Journal of College Student Personnel, XVI, 482-485. de los Santos, A. G., Jr. (1980). Hispanics and community colleges. (Topical Paper No. 18). Tucson: University of Arizona, Center for the Study of Higher Education. 
Delbecq, A. L., Van de Ven, A. H., and Gustavson, D. H. (1975). Group techniques for programming planning:

A guide to nominal and group Delphi processes. Glenview, Illinois: Scott Foresman.

Demographics for the eighties and nineties. (1988).

National Association of College Stores-Campus Focus,

1, p. 1 .

Eckert, M. A. (1974). Development of a functional model for a community-junior college financial aid office by the Delphi technique (Doctoral dissertation, East

Texas State University, 1973). Dissertation

Abstracts International, 35, 5624A (University Microfilms No. 74-5754).

Eells, W. C. (1931). The junior college. Boston, Massachusetts: Houghton-Mifflin Company. Elsner, P. A. and Ames, W. C. (1983). Redirecting student services. In G. B. Vaughn and Associates, Issues for Community College Leaders in a New Era.

San Francisco, California: Jossey-Bass, Inc. Publishers.

Enzer, S. (1969). A case study using forecasting as a decision-making aid. Madison, Wisconsin: The Institute for the Future.

Enzer, S. and de Brigard, R. (1970). Issues and opportunities in the state of Connecticut: 1970-2000. Middleton, Connecticut: Institute for the Future. 
Erdos, P. L. (1983). Professional mail surveys. Malabar, Florida: Robert E. Krieger Publishing Company. Eurich, A. C. (ed.) (1968). Campus 1980. New York: Delacorto Press.

Ezell, A. S. and Rogers, J. K. (1978). Futuring technologies in education; Delphi technique. College Student Journal, XIII, 122-26.

Fitzgerald, L. E. Johnson, W. F. and Norris, W. (eds.). (1970). College student personnel. Boston, Massachusetts: Houghton-Mifflin Company. Fox, A. M. and Brookshire, W. F. (1971). Defining effective college teaching. Journal of Experimental Education, XL, 37-40.

Gilley, J. W. (1983). Population trends and need for diversity. In Vaughan and Associates, Issues for Community College Leaders in a New Era. San Francisco, California: Jossey-Bass, Inc. Publishers. Gleazer, E. I., Jr. (1968). This is the community college. Boston, Massachusetts: Houghton-Mifflin Company.

Gleazer, E. L., Jr. (1973). Project focus: A forecast study of community colleges. New York: McGraw-Hill. Gleazer, E. L., Jr. (1980). The community college: values, vision and vitality. Washington, D.C.: American Association of Community and Junior Colleges. 
Glenny, L. A. State systems and plans of higher education. In Logan Wilson (ed.), Emerging Patterns in American Higher Education. Washington, D.C.: American Council on Education.

Goodman, L. H., Beard, R. L. and Martin, C. L. (1975).

Counseling services in the two-year college: A southeastern survey. NASPA Journal, XII, 241-248. Gordon, T. J. and Ament, R. H. (1969). Forecasts of some technological and scientific developments and their societal consequences. Middletown, New Jersey: Institute for the Future.

Grauer, S. R. (1989). Think globally, act locally: A Delphi study of educational leadership through the development of international resources in the local community. Unpublished doctoral dissertation, University of San Diego, San Diego, California. Harman, A. J. (1975, July). Collecting and Analyzing expert group judgment data. (Available from the RAND Corporation, Santa Monica, California.) Harris, P. R. (1968). Guidance and counseling in the year 2000. Counselor Education and Supervision, I (Spring), 262-266.

Helmer, O. (1964, September). Convergence of expert consensus through feedback. (Available from the RAND Corporation, Santa Monica, California.) 
Helmer, 0. (1966). The use of the Delphi technique in problems of educational innovations. Santa Monica, California: The Rand Corporation.

Helmer, O. (1967, March). Analysis of the future: The Delphi method. (Available from the RAND Corporation, Santa Monica, California.)

Helmer, O. (1983). Looking forward: A guide to futures research. Beverly Hills, California: Sage Publications.

Helmer, O. and Rescher, N. (1959). On the epistemology of the inexact sciences. Management Science, I, 25-52.

Higgins, S. and Thurston, A. (1966). Student personnel in the junior colleges in the years ahead. College Student Work in the Years Ahead. Washington, D.C.: American Personnel and Guidance Association, 54-59. Hinko, P. M. (1971). A national survey of counseling services. Junior College Journal, XIII, 20-24. Hodgkinson, H. L. (1986). California: The state and its educational system. Washington, D.C.: The Institute for Educational Leadership. Hopkins, C. O. (1972). Delphi: A planning tool, report of a study conducted by the Division on Research, Planning and Education. Presented to oklahoma State Department of Vocational and Technical Education, Stillwater, Oklahoma. 
Hopkins, E. H. (1948). The essentials of a student personnel program. Educational and Psychological Measurement, 8 (3), 430-450.

Isaac, S. and Michael, W. B. (1972). Handbook in research and evaluation. San Diego, California: Robert R. Knapp. Joint committee for the review of the master plan in higher education. (1988). California faces... California's future: Education for citizenship in a multicultural democracy. Sacramento, California: California Legislature. Jonassen, E. O. and Stripling, P. O. (1977). Priorities for community college student personnel services during the next decade. Journal of College student Personnel, 18 (2), 83-86. Jones, T. (1970). The counselor and his role. Junior College Journal, XL, 10-14. Judd, R. C. (1970). Delphi method: Computerized oracle accelerates consensus formation. College and University Business, XLIX, 30-34.

Judd, R. C. (1972). Forecasting to consensus gathering:

Delphi grows up to college needs. College and University Business, 53, 35-43. Knoell, D. (1983). Serving today's diverse students. In Vaughan and Associates, Issues for Community 
College Leaders in a New Era. San Francisco, California: Jossey-Bass, Inc. Publishers. Koltveit, T. H. (1973). Counselor--consultant as quasiombudsman. Personnel and Guidance Journal, LII, 198- 200 .

Lewis, M. and Lewis, J. (1970). The counselor and civil liberties. Personnel and Guidance Journal, XLIX, 9-13.

Linstone, H. A. and Turoff, M. (1975). The Delphi method: Techniques and Applications. London, England: Addison-Wesley Publishing Company. Litwack, I. (1978). Counseling services in community colleges. Journal of College Student Personnel, XIX, 359-361.

Maples, M. F. (1980) - Guidance and counseling: Perspectives on an emerging profession. Washington, D.C.: The National Institute of Education. Matson, J. E. (1967). Student personnel services in junior colleges: A special challenge. National Assocation of Student Personnel Administrators Journal, 4 (4), 161-64. Matson, J. E. (1972). Student personnel work four years later: The Carnegie study and its impact. In T. O'Banion and A. Thurston (Eds.), Student Development Program in the Community Junior College. Englewood Cliffs, New Jersey: Prentice-Hall. 
Matson, J. E. (1978). Reduction and student services. New Directions for Community Colleges, $22,53-72$. Matson, J. E. (1983). Primary roles for community college counselors. In Alice Thurston, William Robbins (eds.), Counseling: A Crucial Function for the 1980's. New Directions for Community Colleges, $\underline{43}, 19-28$.

McGabe, R. H. and Skidmore, S. B. (1983). New concepts for community colleges. In George B. Vaughan and Associates, Issues for Community College Leaders in a New Era. San Francisco, California: Jossey-Bass, Inc. Publishers.

McIntyre, J. P. (1975). Student personnel: the challenge of the future. Journal of the National Association of Women Deans and Counselors, 38, 59-64. Medsker, L. I. (1960). The junior college: program and prospect. New York: McGraw-Hill Book Company. Medsker, I. I. (1972). The crucial role of student personnel services in the junior college. In T. O'Banion and A. Thurston (Eds.), Student Development Program in the Community Junior College. Englewood Cliffs, New Jersey: Prentice-Hall. Mertes, D. (1989). New tomorrows for community colleges. The News, $34,3,1$. 
Miller, B. W. (1977). Higher education and the community colleges. Washington, D.C.: University Press of America.

Miller, P. (1988). The response of continuing higher education. In David M. Johnson (ed.). Challenges for Continuing Education Leadership. Washington, D.C.: National University Continuing Education Association.

Miller, T. M. (1979). A study of counseling services in two-year colleges. Journal of College Student Personnel, XX, 9-14.

Monroe, C. R. (1973). Profile of the community college. San Francisco, California: Jossey-Bass, Inc. Publishers.

Morrow, J.E. (1972). A Delphi approach to the future of management. Unpublished doctor's dissertation, Georgia State University.

Mortvedt, D. F. (1972). Inventoried perceptions of key administrative officers in Illinois community colleges concerning student personnel services. Dissertation Abstracts International, 33, 2740-A.

Mueller, K. H. (1961). Student personnel work in higher education. Boston, Massachusetts: Houghton-Mifflin. Murray, T. V. (1968). The development and test of a concept and methodology for long-range forecasting 
(Doctoral Dissertation, University of Colorado, 1967). Dissertation Abstracts International, 29, 358A.

Newton, F. B. (1974). Prospectus: Student personnel in the community college. National Association of Student Personnel Administrators Journal, 11 (3), $37-41$.

O'Banion, T. (1970). The function of college and university personnel workers. College and University, 45 (3), 296-304.

O'Banion, T. and Thurston, A. (Eds.). (1972). Student development program in the community junior college. Englewood Cliffs, New Jersey: Prentice-Hall. O'Banion, T., Thurston, A., and Gulden, J. (1970).

Student personnel work: An emerging model. Junior College Journal, $41,6-14$. Packwood, W. T. (Ed.). (1977). College student personnel services. Springfield, Illinois: Charles C. Thomas Publisher.

Palinchak, R. S. (1973). The evolution of the community college. Metuchen, New Jersey: The Scarecrow Press, Inc.

Parker, C. A. (1971). "Institutional self-renewal in higher education." Journal of College Student Personnel, 12 (6), 405-409.

Parker, C. and Vecchitto, D. (1973). A noncampus system for Vermont. In John Lombardi (ed.), New Directions 
for Community Colleges: Meeting the Financial Crisis. San Francisco, California: Jossey-Bass, Inc. Publishers.

Parker, J. T. and Taylor, P. H. (1980). The Delphi survey: CBAE through the eyes of leading educators. Belmont, California: Fearson Pitman Publishers, Inc. Peterson, R. E. (1971) Toward institutional goal consciousness. Princeton, New Jersey: Educational Testing Service.

Phi Delta Kappa Commission on Schooling for the 21st Century. (1984). Handbook for conducting future studies in education. Bloomington, Indiana: Phi Delta Kappa.

Rasp, A. (1973) . Delphi: A decision-maker's dream. Nation's Schools, I, 29-32.

Rasp, A. (1974). A new tool for administrators: Delphi and decision making. North Central Association Quarterly, VIII, 320-325.

Robbins, W. A. (1983). Counseling for today's community college students. In Alice Thurston, William Robbins (eds.), Counseling: A Crucial Function for the 1980 's. New Direction for Community Colleges, 43, 5-17:

Sackman, H. (1975). Delphi critique. Lexington, Massachusetts: D. C. Heath and Company. 
Schoenberg, B. M. (ed.). (1978). A handbook and guide for the college and university counseling center. Westport, Connecticut: Greenwood Press.

Seashore, C. E. (1940) . The junior college movement.

New York: Henry Holt and Company.

Shepardson, R. D. (1972). Survey lutilizing the Delphi method) to assess and objectively display the arguments for and against developing a performancebased teacher education program. Journal of Teacher Education, XXIII, 166-168.

Shertzer, B. and Stone, S. (1963). A problem in role definition. Personnel and Guidance Journal, XLL, 687-693.

Shertzer, B. and Stone, S. (1974). Fundamentals of Counseling. Boston, Massachusetts: Houghton-Mifflin Company .

Strauss, H. and Zeigler, L. H. (1975). The Delphi technique and its uses in social science research. Journal of Creative Behavior, IX, 253-59.

Task Force on Counseling. (1979). Community College Counseling Services in California. Sacramento, California: State Chancellor's Office for Communty Colleges.

Thomas, L. (1980) . The medusa and the snail. New York: Bantam Books. 
Thornton, J. W. (1966), 2nd edition. The community junior college. New York: John Wiley and Sons. Thurston, A. S. (1972). The decade ahead. In T. O'Banion and A. Thurston (Eds.), Student Development Program in the Community Junior College. Englewood Cliffs, New Jersey: Prentice-Hall. Thurston, A. S. (1983). The decade ahead for community college counseling. New Directions for Community Colleges, 43. San Francisco, California: Jossey-Bass, Inc. Publishers.

Tiedemann, D. A. (1985). Media services in higher education: A Delphi study for the 1990's. Unpublished doctoral dissertation, University of San Diego, San Diego, California. Toeffler, A. (Ed.). (1974). Learning for tomorrow. The role of the future in education. New York: Vintage Books.

Trembly, E. L. and Bishop, J. B. (1974). Counseling centers and the issue of accountability. Personnel and Guidance Journal, LII, 647-52.

Uhl, N. P. (1971). Identifying institutional goals. Durham, North Carolina: National Laboratory for Higher Education. Uhl, N. P. (1983). Using the Delphi technique in institutional planning. New Directions for 
Institutional Research, 37, San Francsico,

California: Jossey-Bass, Inc. Publishers.

Vaughan, G. B. and Assocates. (1983). Issues for

community college leaders in a new era. San

Francisco, California: Jossey-Bass, Inc. Publishers.

Wagschall, P. H. (1983). Judgmental forecasting

techniques and institutional planning: An example.

In J. L. Morrison, W. I. Renfo, and W. I. Boucher

(eds.), Applying Methods and Techniques of Futures

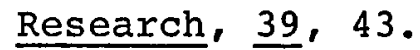

Walz, G. R. and Benjamin, L. (1979). A futuristic

perspective for counselors. Washington, D.C.: The

National Institute of Education.

Walz, G. R. and Lew, J. (1979). Futuristic images of

guidance and student services. Ann Arbor, Michigan:

ERIC/CAPS, The University of Michigan.

Warnath, C. F. (1972). College counseling: Between a

rock and a hard place. Personnel and Guidance

Journal, LI, 226-236.

Wattenburger, J. L., Schafer, S. and Zucker, J. (1973) .

Tuition and the open door. In John Lombardi (ed.),

New Directions for the Community Colleges: Meeting

the Financial Crisis. San Francisco, California:

Jossey-Bass, Inc. Publishers.

Weaver, W. T. (1971). Delphi forecasting method. Phi

Delta Kappon, I, 267-71. 
Weaver, W. T. (1972). Delphi, a critical review (prepared for U.S. Office of Education, EPRC RR-7). Syracuse, New York: Syracuse University Educational Policy Research Center.

Williamson, E. G. (1961). Student personnel services in colleges and universities. New York: McGraw-Hill. Wilson, I. (1965). Form and function in American higher education. In Logan Wilson (ed.), Emerging Patterns in American Higher Education. Washington, D.C.: American Council on Education.

Wrenn, C. G. and Leonard, L. (1973). The world of the contemporary counselor. Boston, Massachusetts: Houghton-Mifflin Company.

Yoder, M. and Beals, L. (1966). Student personnel services in the west. Junior College Journal, 37, $38-41$.

Zwerling, L. S. (1976). Second best. New York: McGrawHill Book Company. 


\section{APPENDIX A: BACKGROUND INFORMATION}

A DELPHI STUDY OF CALIFORNIA COMMUNITY COLLEGE COUNSELORS' RESPONSIBILITIES AND COMPETENCIES FOR THE 1990'S AS PERCEIVED BY CHIEF STUDENT SERVICES ADMINISTRATORS

\section{Background Information}

The main objectives of the study are to:

1. identify the responsibilities of California Community College Counselors during the 1990's,

2. identify the competencies they will need to fulfill their responsibilities during the $1990^{\prime} \mathrm{s}$,

3. identify the staff development needs of currently employed counselors to prepare them to effectively fulfill their responsibilities in the $1990^{\prime} \mathrm{s}$, and to

4. identify course or seminar topics that should be included in counselor education programs to prepare prospective California Community College Counselors for the 1990's and beyond.

It is hoped that the results of the study will serve as a foundation for:

1. the revision of the counselor job description at the campus level in California Community Colleges,

2. comprehensive planning for counseling services at California Community Colleges,

3. the development of recommendations by the professional organizational groups to influence minimum standards, qualifications and requirements for California Community College Counseling Services as listed in Title $\mathrm{V}$ and in the Education Code.

Your participation is valuable and greatly appreciated!

Noelia Vela

Vice President of Student Affairs

Irvine Valley College

5500 Irvine Center Drive

Irvine, $\mathrm{CA} 92720$ 
APPENDIX B: DEMOGRAPHIC QUESTIONNAIRE

\section{A DELPHI STUDY OF CALIFORNIA COMMUNITY COLLEGE COUNSELORS' RESPONSIBILITIES AND COMPETENCIES FOR THE 1990'S AS PERCEIVED BY CHIEF STUDENT SERVICES ADMINISTRATORS}

\section{Demographic Questionnaire}

\section{Personal Background}

Your responses to the following items are requested for the development of an overall profile of the respondents and institutions participating in this Delphi Study. Your specific responses will be kept anonymous in the development of this general profile.

1. (a) Name:

(b) Institution/District:

(c) Phone Number: $(1)$

(d) Job Title:

(e) Your Direct Supervisor's Job Title:

(f) Number of Years in Your Present Position:

(g) Your Immediate Previous Position:

(h) Number of Years in Previous Position:

(i) Have You Been a Community College Counselor?

Yes No Number of Years

(j) Number of Years in Student Services Profession:

(k) Responsible For (check only one): Student Services Student Services and Instruction

2. (a) Your Age (check only one):

$\begin{array}{r}20-30 \\ 31-40 \\ \hline\end{array}$

(b) Your Gender:

Female Male

3. Academic Degree(s) You Have Earned (check all that apply and indicate major or specialization, school and year):
Degree
Major
School
$\underline{\text { Year }}$
(a) Bachelor's
(b) Master's
(c) Doctoral
(d) other
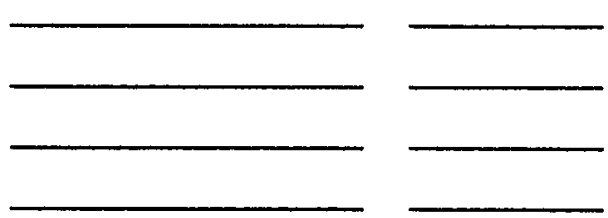
4. Nationa1, State or Local Conferences Related to Community College Counseling Which You Have Attended in the Last Two Years (please list):

5. Presentations by Title and Topic That You Have Made Within the Last Two Years at Local, State, or National Conferences (please list):

6. Student Enrollment at Your Institution (head count):
(a) 5,000 or less
(b)
$5,001-10,000$
(c) $10,001-15,000$
(d) $15,001-20,000$
(e) $20,001-25,000$
(f) More than 25,000

7. Ethnic Breakdown (percentage) of Your Enrollment:
(a) American Indian or Alaskan Native
(b) Asian or Pacific Islander
(c) Black (Not Hispanic)
(d) Caucasian (Not Hispanic)
(e) Filipino
(f) Hispanic
(g) Other

\section{PLEASE RETURN TO:}

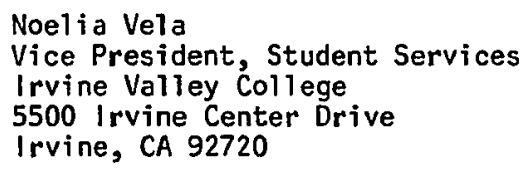

If you have any questions, please feel free to call: (714) 559-3214.

THANK YOU FOR YOUR COOPERATION AND ASSISTANCE 


\section{A DELPHI STUDY OF CALIFORNIA COMMUNITY COLLEGE COUNSELORS' RESPONSIBILITIES AND COMPETENCIES FOR THE 1990 'S AS PERCEIVED BY CHIEF STUDENT SERVICES ADMINISTRATORS}

\section{Delphi Instrument}

\section{Part 1: Responsibilities}

Definition of Responsibility: A. trust, obligation, or duty; that for which one is responsible.

Directions: This list consists of credentialed community college counselor responsibilities that have been identified from current (1987-1988) job descriptions of California community college counselors. You are asked to:

a. Indicate how important you believe each responsibility will be for credentialed California community college counselors in the 1990 's.

b. Focus on each responsibility as if it were held by a credentialed community college counselor and respond accordingly. Although the responsibility may be important, it may not be appropriate for a credentialed counselor to perform.

c. Add and rate other responsibilities you believe are important for the 1990's.

d. Add any comments you might have about the responsibility.

e. Respond with a futuristic perspective keeping the following background information in mind.

Background Information: (From AB1725, Looking Ahead, Data for Planning, 1987 and California Faces. . California's Future, 1988)

California community colleges face the following during the 1990's:

a. Continuing demands to:

(1) strengthen academic standards,

(2) implement matriculation,

(3) increase the transfer rate, and

(4) revitalize administrators, counselors, instructors and staff;

b. Continuing budgetary constraints; and

c. Demographic changes resulting in:

(1) increase of part-time students,

(2) increase of returning adults,

(3) increase of underprepared students,

(4) increase of Hispanic, Black and Asian students,

(5) proportional decrease of Caucasian students,

(6) decrease of recent high school graduates,

(7) increase of limited English proficient (LEP) students, and

(8) increase of unskilled, unemployed and underemployed adults.

Importance-Level Scale: Write the numerical value indicating the level of importance on the Tine provided adjacent to each responsibility statement. Note: For the purpose of this study, a rating of "1" (No Importance) indicates that the 1 isting should not be a responsibility of credentialed Cal ifornia community college counseTors. 


$\begin{array}{lllll}\text { No Importance } & - & 1 & \text { Very Important } & 4 \\ \text { Little Importance } & : & 2 & \text { Extremely Important } & 5 \\ \text { Important . } & - & 3 & & \end{array}$

Example: Credentialed Counselor Responsibility

Counsel provisional/probationary or disqualified students

In the example above, the respondent believes the credentialed counselor responsibility will be extremely important in the 1990's and gave it a numerical value of 5 .

\section{RESPONSIBILITIES}

\begin{tabular}{|c|c|c|}
\hline $\begin{array}{l}\text { No Importance } \\
\text { Little Importance }\end{array}$ & $\begin{array}{l}1 \\
: \quad 2\end{array}$ & $\begin{array}{l}\text { Very Important } \\
\text { Extremely Important }\end{array}$ \\
\hline
\end{tabular}
$\begin{array}{ll}\text { Little Importance : } & 2 \\ \text { Important. } & 3\end{array}$

1. Academic advising (course selection assistance) -

2. Educational planning (goal selection assistance) .

3. Personal counseling (assistance in personal adjustment and problem areas) ..

4. Career counseling (career exploration and selection)

5. Life planning (goal, decision-making, lifestyle assistance)

6. Conduct new student orientation sessions

7. Prepare written handouts, handbooks, brochures, video and slide presentations.

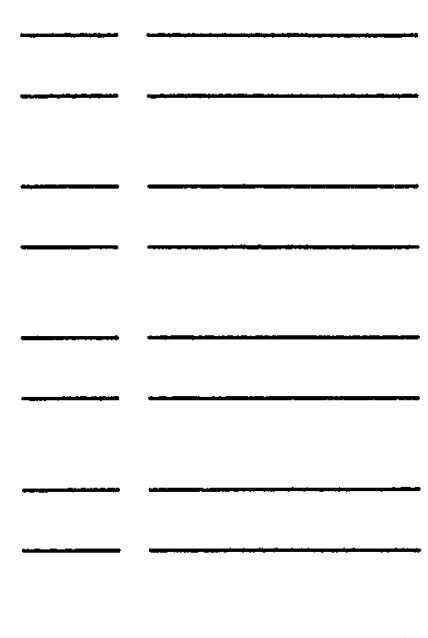

9. Develop and teach traditional academic discipline classes

10. Administer and interpret academic placement tests .

11. Administer and interpret tests of interests, values, personalities and career planning

12. Program approval and assistance during registration

13. Assist student with college forms and applications

14. Provide information about scholarships and financial aid services

15. Work with instructors to establish test data to determine student $\mathrm{placement}$

16. Assist instructors in monitoring student progress (early warning system)

17. Counsel provisiona1/probationary or disqualified students.

18. Coordinate, develop and assist in the implementation of the Matriculation Plan

19. Develop effective liaison relationships with instructors to facilitate communication and staff development 
20. Develop and teach counseling/personal development classes .

21. Initiate, plan, develop, implement and evaluate programs and services to meet student needs

22. Meet the special counseling needs of:

(a) international students

(b) re-entering adults.

(c) veterans

(d) displaced workers.

(e) limited English-speaking students

(f) transfer students

23. Facilitate crisis intervention

24. Develop and work with network of community resources

25. Refer students to appropriate on- and off-campus services.

26. Develop liaison and articulation relationships with high schools

27. Develop liaison and articulation relationships with colleges and universities

28. Keep current with labor market trends and local employment opportunities.

29. Develop, update and maintain records of accountability and documentation

30. Assist in grant writing .

31. Work with counseling related computer assisted systems

32. Plan and conduct relevant research in student personnel areas

33. Prepare written reports and data analys is

34. Provide work direction and supervision to paraprofessionals

35. Participate in the college governance process and curriculum development

36.

37.

38.

39.

40. 
Part 2: Competencies

Definition of Competency: Ability, expertise, mastery, proficiency or skill.

Directions: This list consists of credentialied community college counselor competencies that have been identified from current (1987-1988) job descriptions of California community college counselors. You are asked to:

a. Indicate how important you believe each competency will be for credentialed California community college counselors in the 1990's.

b. Focus on each competency as if it were held by a credentialed community college counselor and respond accordingly. Although the competency may be important, it may not be appropriate or necessary for a credentialed counselor to have.

c. Add and rate other competencies you believe are important for the 1990's.

d. Add any comments you might have about the competency.

e. Respond with a futuristic perspective keeping the following background information in mind.

Background Information: (From AB1725, Looking Ahead, Data for Planning, 1987 and California Faces. - Cal ifornia's Future, 1988)

California community colleges face the following during the 1990's:

a. Continuing demands to:

(1) strengthen academic standards,

(2) implement matriculation,

(3) increase the transfer rate, and

(4) revitalize administrators, counselors, instructors and staff;

b. Continuing budgetary constraints; and

c. Demographic changes including:

(1) increase of part-time students,

(2) increase of returning adults,

(3) increase of underprepared students,

(4) increase of Hispanic, Black and Asian students,

(5) proportional decrease of Caucasian students,

(6) decrease of recent high school graduates,

(7) increase of limited English proficient (LEP) students, and

(8) increase of unskilled, unemployed and underemployed adults.

Importance-Level Scale: Write the numerical value indicating the level of importance on the line provided adjacent to each competency statement.

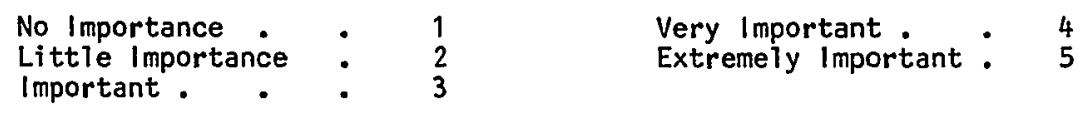

Example: Credentialed Counselor Competency $\quad$ 1990's

Ability to work effectively with underprepared students $\quad$. 4

In the example above, the respondent believes the credentialed counselor competency will be very important in the 1990 's and gave it a numerical value of 4. 


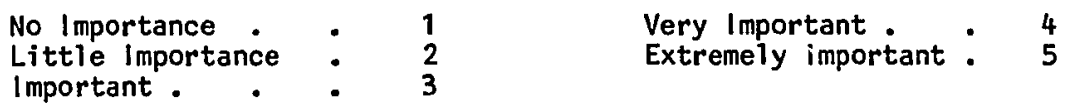

1. Educational planning skills

2. Career counseling skills.

3. Life planning and counseling skill

4. Personal counseling skills

5. Group dynamics/process skills .

6. Teaching skills

7. Knowledge of assessment tests and test interpretation.

8. Knowledge of study skills

9. Knowledge of learning theory

10. Knowledge of adult development theory

11. Knowledge of human motivation and behavior

12. Ability to work effectively with underprepared students

13. Ability to work effectively with a diverse age group

14. Ability to interact effectively with persons of diverse socio-economic and ethnic backgrounds

15. Ability to work effectively with re-entry adults

16. Ability to assimilate large volumes of changing academic information

17. Ability to assimilate large volumes of changing career information.

18. Ability to interpret, apply and explain policies and procedures.

19. Ability to analyze a situation correctly and adopt effective course of action

20. Knowledge of the Matriculation Plan for community colleges

21. Knowledge of community college mission and philosophy

22. Understanding of applicable sections of the State Education Code.
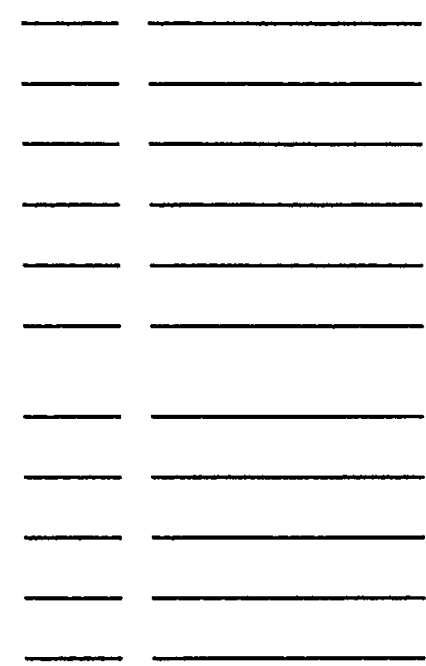

23. Knowledge of articulation

24. Knowledge of admissions, financial aid and veterans affairs

25. Ability to communicate effectively in written and verbal form 
26. Organizational and program development skills

27. Skills with counseling-related computer-assisted systems

28. Knowledge of community social agencies, services and resources.

29. Knowledge of basic research principles .

30. Previous paid community college counseling experience

31. Internship or practicum at a community college setting

32. California Community College Counseling Credential

33.

34.

35.

36.

37.

38.

39.

40.

PLEASE RETURN TO:

Noelia Vela

Vice President, Student Services

Irvine Valley College

5500 Irvine Center Drive

Irvine, CA 92720

If you have any questions, please feel free to call: (714) 559-3214.

THANK YOU FOR YOUR COOPERATION AND ASSISTANCE 


\section{APPENDIX D: DELPHI INSTRUMENT \\ PARTS T AND? \\ DELPHI SUMMARY FOR ROUND 1}

\section{A DELPHI STUDY OF CALIFORNIA COMMUNITY COLLEGE COUNSELORS' RESPONSIBILITIES AND COMPETENCIES FOR THE 1990'S AS PERCEIVED BY CHIEF STUDENT SERVICES ADMINISTRATORS}

\section{Delphi Instrument}

Percentage of Respondents During Round 1

96 Percent

\section{Part 1: Responsibilities}

Definition of Responsibility: A trust, obligation, or duty; that for which one is responsible.

This list of counselor responsibilities is a duplicate to the one you received in Round 1 of this study with the additional recommended responsibilities, the modal responses and comments of the respondents. The modal response (consensus) is marked with a black square and your rating of each responsibility, if different from the mode, is marked with a red circle. Respondents' comments about the responsibility is listed below each item.

THE FUNCTION OF THIS ROUND IN THE STUDY IS BOTH TO INCREASE CONSENSUS AND TO DEFINE MINORITY OPINION. THE RESULTS OF THIS ROUND WILL COMPRISE THE JOB DESCRIPTION FOR CALIFORNIA COMMUNITY COLLEGE COUNSELORS FOR THE 1990'S!

\section{Directions:}

1. If you agree with the consensus, leave the item blank.

2. If you wish to remain outside the consensus, please state the primary reason by writing it directly below the item.

3. If your response is the same as the consensus, leave it blank.

4. Keep in mind the "Background Information" 1isted on the goldenrod-colored page which is attached.
CONSENSUS

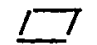
YOUR RESPONSE

1. Academic advising (course selection assistance) • $12234 \sqrt{5}$ Reason:

Round 1 Comments:

2. Conduct new student orientation sessions $1 2 3 4 \longdiv { 5 7 }$

Reason: Can and should be done by well-trained paraprofessionals.

Round 1 Comments:

3. Life planning (goal, decision-making, lifestyle assistance)

Reason:

Round 1 Comments: 
EXPLANATION

1. In Statement 1, the respondent's rating differed from consensus; however, the respondent wished to join consensus and indicated so by leaving the "Reason" space bl ank.

2. In Statement 2, the respondent's rating differed from consensus. Writing the "reason" in the space provided indicated that the respondent did not wish to join consensus.

3. In Statement 3, the respondent's rating was the same as the consensus rating so no further consideration was necessary.

\section{BACKGROUND INFORMATION}

Counselors have often been critized for being "Jacks of all trades but masters of none."

In light of this criticism, please focus:

1. On each responsibility/competency as if it were held by a credentialed community college counselor. Although the responsibility/competency may be important, it may not be appropriate for a credentialed professional counselor to perform or have.

2. Add any comments you might have about counselors' responsibilities/competencies for the 1990's.

3. Respond with a FUTURISTIC PERSPECTIVE keeping the following information in mind. California community colleges face the following during the 1990's:

a. Continuing demands to:

(1) strengthen academic standards,

(2) implement matriculation,

(3) increase the transfer rate, and

(4) revitalize administrators, counselors, instructors and staff;

b. Continuing budgetary constraints; and

c. Demographic changes including:

(1) increase of part-time students,

(2) increase of returning adults,

(3) increase of underprepared students,

(4) increase of Hispanic, Black and Asian students,

(5) proportional decrease of Caucasian students,

(6) decrease of recent high school graduates,

(7) increase of limited English proficient (LEP) students, and

(8) increase of unskilled, unemployed and underemployed adults.

(From AB1725, Looking Ahead, Data for Planning, 1987 and California Faces. . . California's Future, 1988) 
RESPONSIBILITIES

General Comments from Round 1 Respondents:

- A number of current counselor responsibilities can be efficiently done by well-trained paraprofessionals. Counselors will then be free to do more skill-demanding things for which they have little or no time.

- I believe the highest priority must go to academic counseling. If a counseling staff performs this function poorly, they are going to be in big trouble regardless of how well they perform career counseling and personal counseling. Career counseling is then the second priority if adequate funding is not available. Personal counseling is the third priority and if funds are not available, this function (except for crises intervention) must be assigned to the private sector.

- Adequate staffing for full implementation of matriculation should have first priority on funds. The priority should be to first make sure that you are doing all you can to make currently enrolled students successful in their pursuit of higher education. To the extent that funds allow, emphasis can and should then be placed on outreach/recruiting functions.

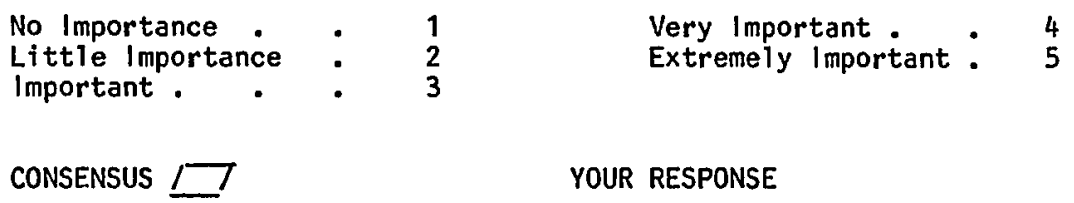

1. Academic advising (course selection assistance) • $\quad \begin{array}{llll}1 & 2 & 3 & 57\end{array}$

Reason:

Round 1 Comments:

- Paraprofessionals and computer access programs.

- Paraprofessionals can do adequately.

- In team with faculty.

- Key to transfer.

- We must do this exceptionally well.

2. Educational planning (goal selection assistance) • . $1 2 3 4 \longdiv { 5 }$

Reason:

Round 1 Comments:

- Orientation course and/or career planning courses very useful.

- Key to matriculation.

- Since students' goals change frequently, new expertise is needed.

- We must do this exceptionally well.

3. Personal counseling (assistance in personal adjustment

and problem areas) $\quad . \quad$. $\quad . \quad$. $\quad . 1 2 \longdiv { 3 } 4 5$

Reason:

Round 1 Comments:

Sensitivity to problems is important but not therapy.

Not long term.

Lack of funds forces to a lower priority. 
RESPONSIBILITIES (continued)

4. Career counseling (career exploration and selection) - $1234 / 5$ Reason:

Round 1 Comments:

- Paraprofessionals can guide students to resources for exploring and selecting if a professional counselor assists with goal determination.

5. Life planning (goal, decision-making, lifestyle assistance)

Reason:

Round 1 Comments: None.

6. Conduct new student orientation sessions

Reason:

Round 1 Comments:

- But not in traditional mode.

- Paraprofessionals can help.

- Can and should be done by well-trained paraprofessionals.

- Paraprofessionals under "eye" of counselor.

- Critical to expand this service.

7. Prepare written handouts, handbooks, brochures, video

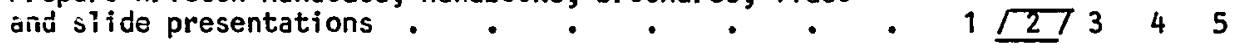

Reason:

Round 1 Comments:

- Assist responsible person.

- Another office's job--however provide assistance.

- Can provide input and guidance for preparation but classified or paraprofessionals can do this.

- Paraprofessionals can handle this.

- Need other staff for this.

- We must define and explain matriculation.

8. Participate in outreach/recruiting functions . - . $123 / 45$

Reason:

Round 1 Comments:

- Need other staff for this.

- Can be done by paraprofessionals.

- Lack of funds forces to lower priority. 
RESPONSIBILITIES (continued)

9. Develop and teach traditional academic discipline

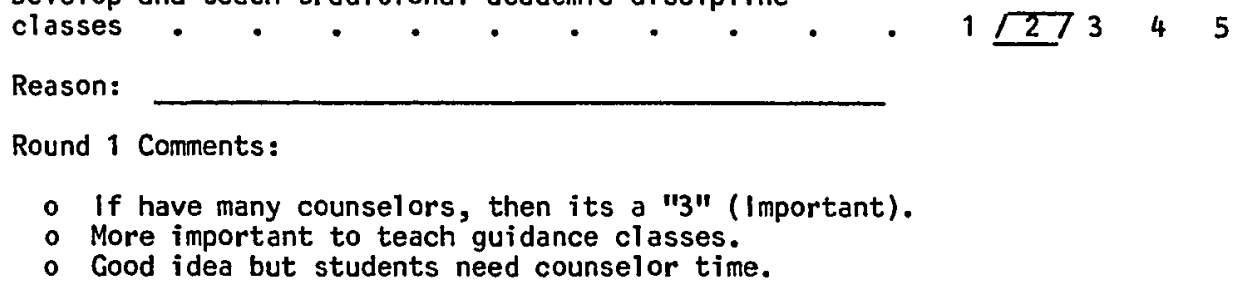

10. Administer and interpret academic placement tests .

Reason:

Round 1 Comments:

- Interpret only.

- Need Assessment Staff for this.

- Paraprofessionals can help (with administering).

- Interpret only.

- Not all--identify a testing service office.

- Interpret, yes--administer by assessment office staff.

- Support staff can help here.

11. Administer and interpret tests of interests, values, personalities and career planning

Reason:

Round 1 Comments:

- Interpret yes--administer by assessment office staff.

- Career Planning Office staff should do this.

- Interpret only.

- Need assessment staff.

- Support staff can heip here.

12. Program approval and assistance during registration

Reason:

Round 1 Comments:

- Should be done before registration.

- Registration assistance "4" (Very important).

- Final approval, yes--paraprofessionals can assist in registration.

- Paraprofessionals can help.

- Support staff can help here.

13. Assist student with college forms and applications $1 \longdiv { 2 7 3 4 5 }$

Reason:

Round 1 Comments:

- Paraprofessionals should do this.

- Paraprofessionals can help.

- Support staff can help here. 
RESPONSIBILITIES (continued)

14. Provide information about scholarships and financial

aid services

Reason:

Round 1 Comments:

- Refer to Financial Aid Office.

- Along with Financial Aid Office.

- Paraprofessionals can help.

- Refer to Financial Aid Office.

- Refer to Financial Aid Office.

15. Work with instructors to establish test data to

determine student placement

Reason:

Round 1 Comments:

- Assessment office function.

- Important for liaison with departments.

- Better if assessment staff do it.

- A great joint project.

16. Assist instructors in monitoring student progress

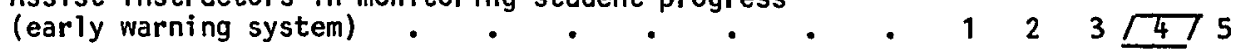

Reason:

Round 1 Comments:

- Important for liaison with departments.

- Oniy on students needing assistance with goals.

- Support staff can help here.

17. Counsel provisional/probationary or disqualified students

Reason:

Round 1 Comments: None.

18. Coordinate, develop and assist in the implementation of the Matriculation Plan

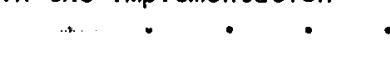

Reason:

Round 1 Comments:

- Coordination should be an administrative responsibility.

- Others can assist.

- Along with instructors.

- Imperative to assist with implementation and in the development of M.P. Coordination less important for counselors than for some others. 
RESPONSIBILITIES (continued)

19. Develop effective liaison relationships with

instructors to facilitate communication and

staff development . $\quad . \quad+\quad \cdot \quad \cdot \quad \cdot \quad 1 \quad 2345$

Reason:

Round 1 Comments: None.

20. Develop and teach counseling/personal development

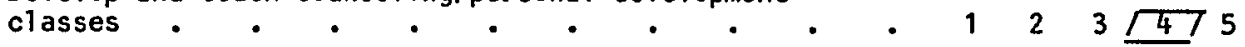

Reason:

Round 1 Comments:

- Orientation class.

21. Initiate, plan, develop, implement and evaluate programs and services to meet student needs.

Reason:

Round 1 Comments:

- Within scope of counseling duties.

- Provide ideas/suggestions and react to drafts of plans only.

- More need than ever for this emphasis.

22. Meet the special counseling needs of:

(a) international students . . . . . $12 / 345$ Reason:

Round 1 Comments:

- Designate one counselor.

(b) re-entering adults . $\quad . \quad+\quad . \quad$. $123 / 45$

Reason:

Round 1 Comments:

- Have a re-entry counselor.

- Support staff can help here.

(c)

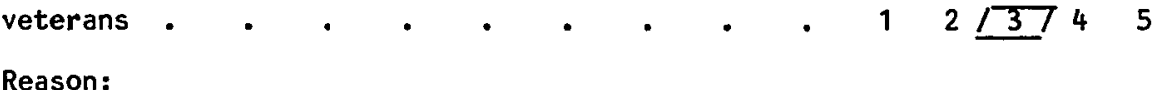

Round 1 Comments:

- Needs are no longer so "special."

- Support staff can help here. 
RESPONSIBILITIES (continued)

(d) displaced workers $\quad . \quad$. $\quad . \quad$. $1 2 3 \longdiv { 4 5 }$ Reason:

Round 1 Comments: None.

(e) limited English-speaking students . . . . $\quad 1 \quad 2 \quad 34 / 57$ Reason:

Round 1 Comments:

- ESL faculty plays important role also.

(f) transfer students $\quad . \quad+\quad . \quad . \quad . \quad . \quad 1 \quad 2 \quad 3 \quad 4 / 57$

Reason:

Round 1 Comments: None.

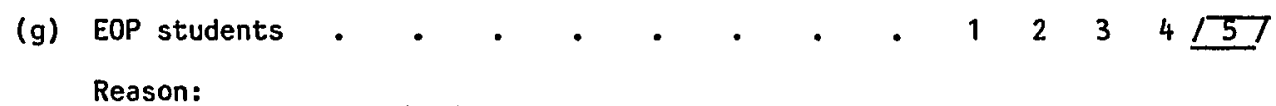
Round 1 Comments: None.

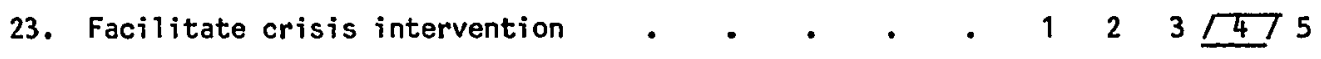
Reason:

Round 1 Comments:

- Should designate an expert.

- This is the highest priority under category of "personal counseling."

24. Develop and work with network of community resources $\quad 1 \quad 2 \quad 3 / 475$ Reason:

Round 1 Comments: None.

25. Refer students to appropriate on- and off-campus services $1 \quad 2 \quad 3 \quad 475$ Reason:

Round 1 Comments:

- Related to liability issues.

- Support staff can help here. 
RESPONSIBILITIES (continued)

26. Develop liaison and articulation relationships with high schools

Reason:

Round 1 Comments:

- Especially with growth in high schools.

- Only a "3" (Important) if have an articulation office.

- May be assigned to specific counselor(s).

27. Develop liaison and articulation relationships with

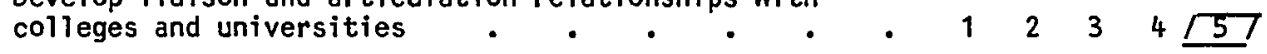

Reason:

Round 1 Comments:

- Only a "3" (Important) if have an articulation office.

- May be assigned to specific counselor(s).

28. Keep current with labor market trends and local

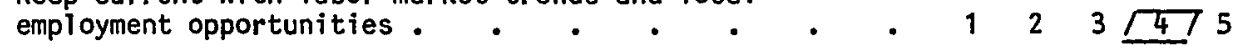

Reason:

Round 1 Comments:

- Job Placement Office should do this.

- Particulariy those counselors working with vocational divisions.

- Others can help with this.

- Need Career Placement Office.

- May be assigned to specific counselor(s).

29. Develop, update and maintain records of accountability and documentation

Reason:

Round 1 Comments:

- Matriculation coordinator.

- Results must be quantified.

- Others can help with this.

- Computer should do this for counselors.

30. Assist in grant writing

Reason:

Round 1 Comments:

- When appropriate.

- Need grants staff. 
RESPONSIBILITIES (continued)

31. Work with counseling related computer assisted systems . $123 \quad 3 \quad 45$ Reason:

Round 1 Comments:

- Help with accountability.

32. Plan and conduct relevant research in student personnel areas

Reason:

Round 1 Comments:

- Not all research.

- Others should assist.

- Administrators and researchers should do this.

- Need research staff.

33. Prepare written reports and data analysis . . $\quad 1 2 \longdiv { 3 7 4 }$ Reason:

Round 1 Comments:

- Depends on nature (of reports).

- Suggest areas only--others can do this.

- 1 assume this is different than Question 29.

34. Provide work direction and supervision to

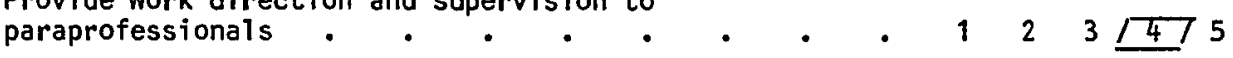
Reason:

Round 1 Comments: None.

35. Participate in the college governance process and curriculum development

Reason:

Round 1 Comments:

- Student Services staff need to be part of the big picture.

- Should be represented on all committees.

\section{Responsibilities Added by Round 1 Respondents}

36. In-service training for teaching staff $\quad$. $\quad$. $\quad \begin{array}{llllllll} & 1 & 2 & 3 & 4 & 5\end{array}$ Reason:

Round 1 Comments: None. 
RESPONSIBILITIES (continued)

37. Providing learning consultation for staff $\quad$ - $\quad$ - $\quad \begin{array}{lllll} & 1 & 2 & 4 & 5\end{array}$

Reason:

Round 1 Comments: None.

38. Own personal development . . . . . . . . 142345

Reason:

Round 1 Comments: None.

39. Take a leadership role in student retention activities . $\begin{array}{llllll} & 1 & 2 & 3 & 4 & 5\end{array}$ Reason:

Round 1 Comments: None.

40. Take a leadership role in meeting the challenge of the

"new" student populations

Reason:

Round 1 Comments: None.

41. Evaluate student services frequently . $\quad$ - $\quad$ - 122345 Reason:

Round 1 Comments: None.

42. Attend state conferences to keep informed

$\begin{array}{llll}2 & 3 & 4 & 5\end{array}$

Reason:

Round 1 Comments: None.

43. Participate in teaching teams.

$\begin{array}{llll}2 & 3 & 4 & 5\end{array}$

Reason:

Round 1 Comments: None.

\section{Additional Comments:}

List below any comments or feedback about future counselor responsibilities (job description) you wish the researcher or other respondents to know. These comments will be shared during Round 3 . 
Part 2: Competencies

Definition of Competency: Ability, expertise, mastery, proficiency or skill.

This list of counselor competencies is a duplicate to the one you received in Round 1 of this study with the additional recommended competencies, the modal responses and comments of the respondents. The modal response (consensus) is marked with a black square and your rating of each competency, if different from the mode, is marked with a red circle. Respondents' comments about the competency is listed below each item.

THE FUNCTION OF THIS ROUND IN THE STUDY IS BOTH TO INCREASE CONSENSUS AND TO DEFINE MINORITY OPINION. THE RESULTS OF THIS ROUND WILL COMPRISE THE JOB DESCRIPTION FOR CALIFORNIA COMMUNITY COLLEGE COUNSELORS FOR THE 1990'S!

\section{Directions:}

1. If you agree with the consensus, leave the item blank.

2. If you wish to remain outside the consensus, please state the primary reason by writing it directly below the item.

3. If your response is the same as the consensus, leave it blank.

4. Keep in mind the "Background Information" listed on the goldenrod-colored page which is attached.

CONSENSUS

1. Teaching skills $\quad$ - $\quad . \quad$. $\quad . 1 2 3 \longdiv { 4 } 5$

Reason:

Round 1 Comments:

2. Understanding of applicable section of the State

Education Code.

Reason: Registrars and administration need to know this, not counselors.

Round 1 Comments:

3. Life planning and counseling skills $\quad$ - $\quad$ - 12 3 4 5

Reason:

Round 1 Comments:

EXPLANATION

1. In Statement 1, the respondent's rating differed from consensus; however, the respondent wished to join consensus and indicated so by leaving the "Reason" blank.

2. In Statement 2, the respondent's rating differed from consensus. Writing the "reason" in the space provided indicated that the respondent did not wish to join consensus.

3. In statement 3, the respondent's rating was the same as the consensus rating so no further consideration was necessary. 


\section{COMPETENCIES}

\section{General Comments from Round 1 Respondents:}

- I struggled with Question 26. I am not as concerned about program development skills. Certain assigned counseling staff can take care of this. However, "organizational skills" is a different matter. I believe that good academic counseling requires that a counselor be well organized in dealing with a voluminous amount of complex and ever changing information (see Questions 7, 8, $16,17,22$ and 23). The same reasoning would apply to those counselors given major responsibility for career counseling (see Question 17).

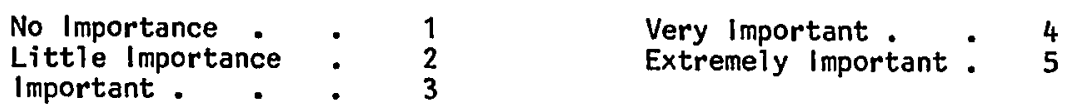

1. Educational planning skills . . . . . . $\quad 1 \quad 234 / 57$

Reason:

Round 1 Comments:

- Student success inside the college is central.

- Critical.

2. Career counseling skills . . - . $\quad$ - $\quad$ - $1 2 2 3 4 \longdiv { 5 7 }$

Reason:

Round 1 Comments:

- This could be specialized for a few counselors.

- But can be specialty of assigned counselor.

3. Life planning and counseling skills

$1234 \underline{157}$

Reason:

Round 1 Comments: None.

4. Personal counseling skilis - . $\quad$ - . $\quad$ - $1 2 3 4 \longdiv { 5 7 }$

Reason:

Round 1 Comments:

- But with one or more specialists on staff.

5. Group dynamics/process skills . . - . . . $1 2 3 4 \longdiv { 5 7 }$

Reason:

Round 1 Comments:

- We will need to do more with groups in the 90's. 
COMPETENCIES (continued)

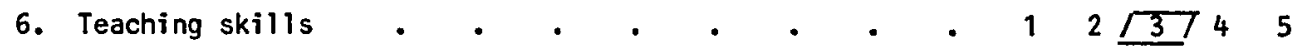

Reason:

Round 1 Comments:

- For counseling classes.

7. Knowledge of assessment tests and test interpretation . $1 \quad 2 \quad 3 \quad 4 \longdiv { 5 }$ Reason:

Round 1 Comments: None.

8. Knowledge of study skills . . . . . $\quad$ - 123 I 5

Reason:

Round 1 Comments:

- But the skill can be provided via classes.

9. Knowledge of learning theory . . . . . . $1 2 3 \longdiv { 4 7 5 }$

Reason:

Round 1 Comments:

- Desirable.

- But I haven't thought of this before.

10. Knowledge of adult development theory - . $\quad$ - $12 \sqrt{3} 45$ Reason:

Round 1 Comments:

- But I haven't thought of this before.

11. Knowledge of human motivation and behavior . $\quad . \quad 123 / 45$ Reason:

Round 1 Comments: None.

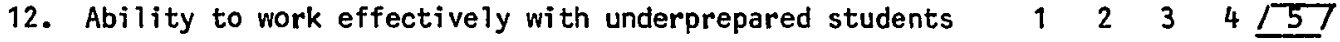
Reason:

Round 1 Comments: None. 
COMPETENCIES (continued)

13. Ability to work effectively with a diverse age group $\quad \begin{array}{rrrr}1 & 2 & 4 & / 57\end{array}$ Reason:

Round 1 Comments: None.

14. Ability to interact effectively with persons of diverse socio-economic and ethnic backgrounds

Reason:

Round 1 Comments: None.

15. Ability to work effectively with re-entry adults

Reason:

Round 1 Comments:

- But can be assigned to specific counselor(s).

16. Ability to assimilate large volumes of changing academic information

Reason:

Round 1 Comments:

- Ability to utilize, not assimilate.

- . . or ability to use data sources effectively.

- A major challenge for counseling staff.

17. Ability to assimilate large volumes of changing career information

Reason:

Round 1 Comments:

- Career Center staff.

- . or ability to use data sources effectively.

- Can be coordinated in career center with help from support staff.

18. Ability to interpret, apply and explain policies and procedures.

Reason:

Round 1 Comments:

- Currently a weak area.

- Support staff can help here. 
COMPETENCIES (continued)

19. Ability to analyze a situation correctly and adopt effective course of action . . . . . . $123 / 45$

Reason:

Round 1 Comments: None.

20. Knowledge of the Matriculation Plan for community colleges

Reason:

Round 1 Comments:

- Know local plan.

21. Knowledge of community college mission and philosophy $\quad 1 \quad 2 \quad 34 / 57$ Reason:

Round 1 Comments: None.

22. Understanding of applicable sections of the State

Education Code..$\quad$. . . . . $1 2 \longdiv { 3 7 4 5 }$

Reason:

Round 1 Comments:

o Specialized for Registrar.

23. Knowl edge of articulation

Reason:

Round 1 Comments:

- Work with Articulation Officer.

24. Knowledge of admissions, financial aid and veterans affairs . . . . . . . . . $1 2 \longdiv { 3 4 5 }$

Reason:

Round 1 Comments:

- For speciailized staff.

- Appropriate referrals. 
COMPETENCIES (continued)

25. Ability to communicate effectively in written and verbal form

Reason:

Round 1 Comments:

- "3" (Important) for written form.

- "5" (Extremely Important) for verbal form.

26. Organizational and program development skills $\quad$ - $1 2 \longdiv { 3 } 4 5$ Reason:

Round 1 Comments: None.

27. Skilis with counseling-related computer-assisted systems $\begin{array}{llll}1 & 2 & 3 & 4\end{array}$ Reason:

Round 1 Comments: None.

28. Knowledge of community social agencies, services and resources.

Reason:

Round 1 Comments:

- But a "5" (Extremely Important) responsibility for some counselors like psych services, career, etc.

29. Knowledge of basic research principles . . . $\quad 1 \longdiv { 2 7 3 4 }$ Reason:

Round 1 Comments:

- Depends on tasks.

30. Previous paid community college counseling experience $\quad 12 \sqrt{3 / 4} 5$ Reason:

Round 1 Comments:

o Skills may be obtained in settings similar to community colleges and is possible through unpaid status.

31. Internship or practicum at a community college setting . $12 \sqrt{3} 45$ Reason:

Round 1 Comments: None. 
COMPETENCIES (continued)

32. California Community College Counseling Credential $\quad \begin{array}{llll}1 & 2 & 4 & 5\end{array}$

Reason:

Round 1 Comments:

o Skills through education and experiences is likely to replace the credential as per AB1725.

- The credential system does not belong in colleges.

o Won't be needed in a few years. Preparation, however, should be at least equal.

\section{Competencies Added by Round 1 Respondents}

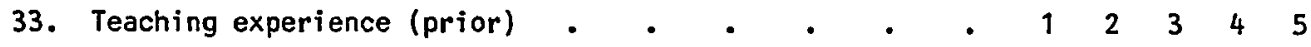

Reason:

Round 1 Comments: None.

34. Integrity - • . . . . . . . . 12345

Reason:

Round 1 Comments: None.

35. Free from mental problems - . . . . . 12345

Reason:

Round 1 Comments: None.

36. Sensitivity to cultures . . . . . . . 12345

Reason:

Round 1 Comments: None.

37. Possibly bilingual (depending on location) . . . 122345 Reason:

Round 1 Comments: None.

38. Flexibility and tolerance . . . . . . 12345 Reason:

Round 1 Comments: None. 
COMPETENCIES (continued)

39. Understand and provide linkage between counseling and instruction

Reason:

Round 1 Comments: None.

40. Be able to fulfill variety of functions but with

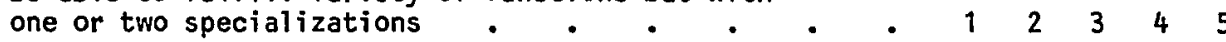

Reason:

Round 1 Comments: None.

41. Be active in professional organizations . . . . 122345 Reason:

Round 1 Comments: None.

42. Knowledge and participatory skills in program review $\begin{array}{lllllll} & 1 & 2 & 3 & 4 & 5\end{array}$ Reason:

Round 1 Comments: None.

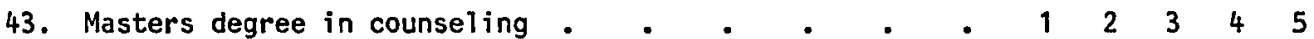

Reason:

Round 1 Comments: None.

Additional Comments:

List below any comments or feedback about future counselor competencies (job description) you wish the researcher or other respondents to know. These comments will be shared during Round 3 .

PLEASE RETURN TO:

Noelia Vela

Vice President, Student Services

Irvine Valley College

5500 Irvine Center Drive

Irvine, CA 92720

If you have any questions, please feel free to call: (714) 559-3214.

THANK YOU FOR YOUR COOPERATION AND ASSISTANCE 
APPENDIX E: DELPHI INSTRUMENT PARTS 3 AND 4

A DELPHI STUDY OF CALIFORNIA COMMUNITY COLLECE COUNSELORS' RESPONSIBILITIES AND COMPETENCIES FOR THE 1990'S AS PERCEIVED BY CHIEF STUDENT SERVICES ADMINISTRATORS

\section{Delphi Instrument}

\section{Part 3: Staff Development Needs}

Directions: This is a partial list of topics that could be addressed in staff development programs. You are asked to:

a. Indicate the degree to which you believe each topic is a staff development need of currentiy employed California community college counselors to prepare them to fulfill their responsibilities effectively during the 1990 's.

b. Ask yourself, "Do today's counselors have the needed competencies to meet the job description of the 1990's? What is missing?" Add and rate other topics you believe are staff development needs of currently employed California community college counselors to prepare them for the 1990's.

c. Select and rank order the ten most important staff development topic needs for the 1990's.

d. Respond with a futuristic perspective keeping the attached recomended job job description and following background information in mind.

Background Information: (From AB1725, Looking Ahead, Data for Planning, 1987 and California Faces. - California's Future, 1988)

California community colleges face the following during the 1990's:

a. Continuing demands to:

(1) strengthen academic standards,

(2) implement matriculation,

(3) increase the transfer rate, and

(4) revitalize administrators, counselors, instructors and staff;

b. Continuing budgetary constraints; and

c. Demographic changes including:

(1) increase of part-time students,

(2) increase of returning adults,

(3) increase of underprepared students,

(4) increase of Hispanic, Black and Asian students,

(5) proportional decrease of Caucasian students,

(6) decrease of recent high school graduates,

(7) increase of limited English proficient (LEP) students, and

(8) increase of unskilled, unemployed and underemployed adults.

Importance-Level Scale: Circle the numerical value indicating the level of importance on the right of each item.

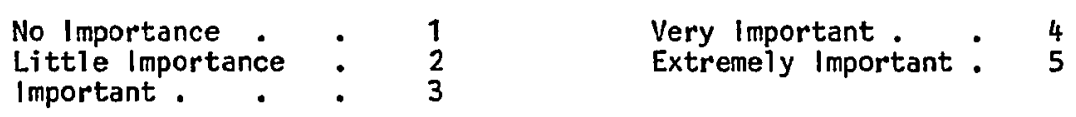




\section{Example:}

Learning needs of ESL students - . . . . . 12345

In the example above, the respondent believes the importance level of this topic as a staff development need is very important and gave it a numerical value of 4 .

\section{STAFF DEVELOPMENT NEEDS}

\begin{tabular}{|c|c|c|}
\hline $\begin{array}{l}\text { No Importance } \\
\text { Little Importance }\end{array}$ & $\begin{array}{l}1 \\
-\quad 2\end{array}$ & $\begin{array}{l}\text { Very Important } \\
\text { Extremely Important }\end{array}$ \\
\hline
\end{tabular}

1. Affective domain assessment principles . . . . $\quad 12345$

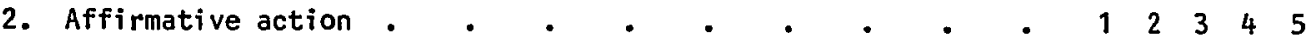

3. Adult development theory - • • . . . . . 12345

4. Cognitive assessment principles . . . . . . 12345

5. Computer skills for counselors . . . . . . 12345

6. Cultural awareness, understanding and sensitivity . . . 12345

7. Grievance policies and procedures . . . . . . 12345

8. Higher education $1 \mathrm{aw}$. $\quad . \quad$. $\quad$ • 12345

9. Learning needs of ESL students . . . . . $\quad 12345$

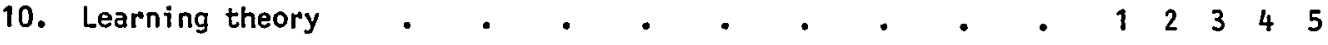

11. Second language skills . . . . . . . . 12345

12. Sexual harassment . . . . . . . . . 12345

13. State Codes (Education and Title V) . . . . . 12345

14. State Matriculation Plan . . . . . . . . 12345

15. Substance abuse.$\quad$. . . . . . 12345

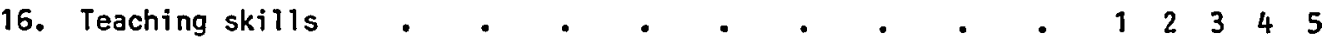

17.

18.

19.

20.

21.

22.

23.

24.

25. 
RANK ORDER OF STAFF DEVELOPMENT NEEDS

(1 BEING THE MOST IMPORTANT)

1.

2.

3.

4.

5.

\section{Part 4: Professional Preparation Needs}

6.

7.

8.

9.

10.

Directions: This is a partial list of topics/courses that could be part of a counselor education program or other formal education program. You are asked to:

a. Indicate the degree to which you believe each topic/course is a professional preparation need of prospective California community college counselors to prepare them to fulfill their responsibilities effectively during the 1990's.

b. Add and rate other topics you believe are professional preparation needs of prospective California community college counselors.

c. Select and rank order the ten most important professional preparation needs for the 1990's.

d. Respond with a futuristic perspective keeping the attached recomended job job description and following background information in mind.

Background Information: (From AB1725, Looking Ahead, Data for Planning, 1987 and California Faces. - California's Future, 1988)

California community colleges face the following during the 1990 's:

a. Continuing demands to:

(1) strengthen academic standards,

(2) implement matriculation,

(3) increase the transfer rate, and

(4) revitalize administrators, counselors, instructors and staff;

b. Continuing budgetary constraints; and

c. Demographic changes including:

(1) increase of part-time students,

(2) increase of returning adults,

(3) increase of underprepared students,

(4) increase of Hispanic, Black and Asian students,

(5) proportional decrease of Caucasian students,

(6) decrease of recent high school graduates,

(7) increase of limited English proficient (LEP) students, and

(8) increase of unskilled, unemployed and underemployed adults.

Importance-Level Scale: Circle the numerical value indicating the level of importance on the right of each item.

$\begin{array}{lll}\text { No Importance : } & : & 1 \\ \text { Little Importance } & : & 2 \\ \text { Important. } & : & 3\end{array}$

$\begin{array}{ll}\text { Very Important : } & 4 \\ \text { Extremely Important: } & 5\end{array}$ 


\section{Example:}

Adult development theory . . - . . . . . 12345

In the example above, the respondent believes the importance level of this topic as a professional preparation need is extremely important and gave it a numerical value of 5 .

\section{PROFESSIONAL PREPARATION NEEDS}

$\begin{array}{lllll}\text { No Importance } & \text { : } & 1 & \text { Very Important . } & 4 \\ \text { Little Importance } & : & 2 & \text { Extremely Important } & 5 \\ \text { Important. } & - & 3 & \end{array}$

1. Abnormal psychology • • • . . . . . . . 12345

2. Adult development theory - • . . . . . . 12345

3. Assessment of cognitive and affective domains . . . 12345

4. Career development theories - . . . . . 12345

5. Community college mission and philosophy . . . . 12345

6. Community college practicum . . . . . . . 12345

7. Counseling theories..$\quad$ - . . . . 12345

8. Cultures in American society - • • . • . . 12345

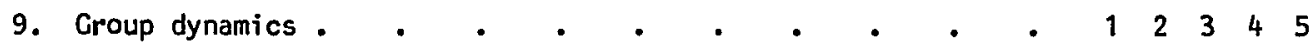

10. Higher education 1 aw . . . . . . . . 12345

11. Learning theory - . . - . . . . . 12345

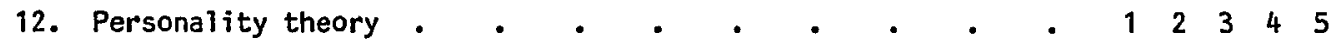

13. Teaching methodology $\quad$ - . . . . . . 12345

14.

15.

16.

17.

18.

19.

20.

21.

22.

23.

24.

25. 
RANK ORDER OF PROFESSIONAL PREPARATION NEEDS

(1 BEING THE MOST IMPORTANT)
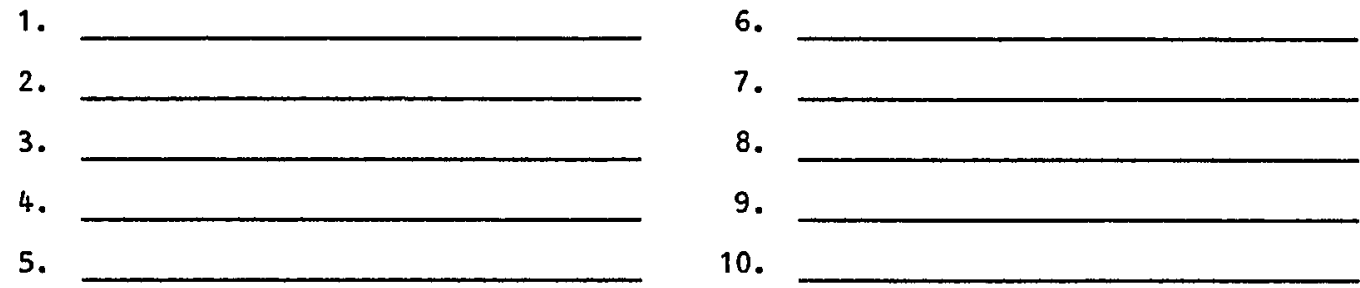

DEVELOPMENT OF JOB DESCRIPTION AND FINAL OPPORTUNITY FOR REVISIONS

\section{Background Information}

The Job Description (Appendix G) for California community college counselors for the 1990 's was developed from the respondents' Round Two input. All returns were studied and an item analysis for modal response and degree of consensus (percentage of respondents choosing the modal response) was completed. All responsibility and competency items receiving an importance level score of 5 (Extremely Important) and 4 (Very Important) were ordered according to category and degree of consensus. t tems receiving importance level scores of 3 or less were not included in the Job Description.

Directions: Please review the Abbreviated Summary for Round Two (Appendix F) and the Job Description (Appendix G) and take this opportunity to add any responsibility or competency you strongly believe should be included in the Job Description for Counselors for the $1990^{\prime} \mathrm{s}$. Please submit your rationale for including them. This provides a final opportunity for reflection on your returns from Round Two, $A B 1725$ and demographic information and the Job Description.

\section{Added Responsibilities}

1.

Rationale:

Rationale:

3.

Rationale:

4.

Rationale: 
Added Competencies

1 .

Rationale:

2.

Rationale:

3.

Rationale:

4.

Rationale:

PLEASE RETURN TO:

Noelia Vela

Vice President, Student Services

Irvine Valley College

5500 Irvine Center Drive

Irvine, CA 92720

If you have any questions, please feel free to cal1: (714) 559-3214. THANK YOU FOR YOUR COOPERATION AND ASSISTANCE 
APPENDIX F: DELPHI SUMMARY FOR ROUND 2

\title{
A DELPHI STUDY OF CALIFORNIA COMMUNITY COLLEGE COUNSELORS' RESPONSIBILITIES AND COMPETENCIES FOR THE 1990 'S AS PERCEIVED BY CHIEF STUDENT SERVICES ADMINISTRATORS
}

\begin{abstract}
Summary

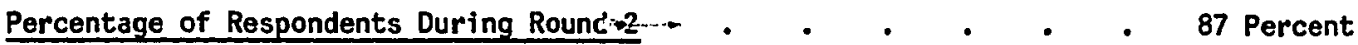

The modal response (the response which occurs most frequentiy) is 1 isted for each item along with the percentage of respondents choosing the modal response. This indicates the degree of consensus for each $i$ tem. The modal response as opposed to the mean response is used to indicate consensus because this study is gaining opinions about future conditions. The degree of consensus indicates future directions and trends but does not predict the future. As can be noted, consensus (at least 50 percent of respondents selecting the modal response) was reached for each responsibility and competency item during Round 2.
\end{abstract}

\section{Part 1: Responsibilities}

Definition of Responsibility: A trust, obligation, or duty; that for which one is responsible.

Importance-Level Scale: Write the numerical value indicating the level of importance on the line provided adjacent to each responsibility statement. Note: For the purpose of this study, a rating of "1" (No Importance) indicates that the listing should not be a responsibility/competency of a credentialed California community college counselor.

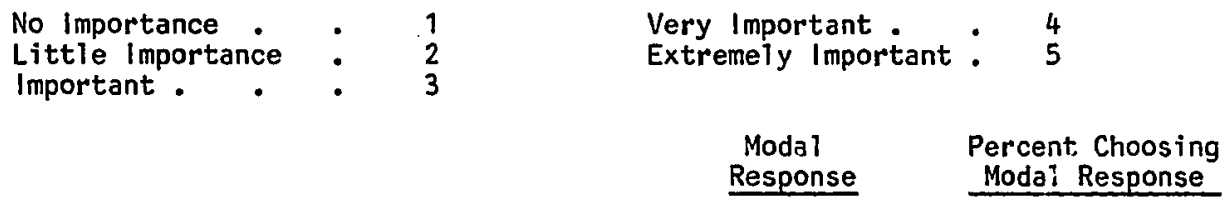

1. Academic advising (course selection assistance)

85 Percent

Round 2 Comments:

- This should be under the direction of a counseior.

- Paraprofessionals and computers should do this.

- Well-defined graduation requirements and articulation agreements can be interpreted and disseminated more cost effectively by well-trained paraprofessionals. Counselors are needed for goal clarification--not programming.

- I believe that much of what we call academic advising will be computerized.

2. Educational planning (goal selection assistance) 5

90 Percent

Round 2 Comments:

- Highly trained paraprofessionals should do this.

- Faculty need involvement. 
3. Personal counseling (assistance in personal adjustment and problem areas).

\section{Round 2 Comments:}

- I don't feel that most counselors have the training in psychology to do personal counseling.

- Items 3 and 5 are similar in that they depend on each other.

- Increasing diversity of student population will require more personal counseling.

- Current and future students are bringing more personal problems to the academic environment. Counselors must address short-term problems that will interfere with educational success.

- Our students are coping with a lot of transition.

- The kind of students we anticipate serving because of the change in demographics will require this kind of assistance more than ever. Students can't succeed academicaliy unless their problems are resolved.

- With the increase of reentry and under-prepared students, counselors must be able to respond effectively.

4. Career counseling (career exploration and selection

Round 2 Comments:

- A large amount of this is accomplished in classes set up for this.

- If career and goals are interrelated as they should be, then counselors should be the best resource for assistance to students.

- May be limited to test interpretation.

- Can be done by a paraprofessiona1.

- A paraprofessional can be most effective.

5. Life planning (goal, decision-making, lifestyle assistance)

\section{Round 2 Comments:}

- Not more important than personal counseling.

- Too vague--"life style assistance" a bit too clinical.

- Seems to be a function of personal counseling rather than academic counseling.

6. Conduct new student orientation sessions

\section{Round 2 Comments:}

- Well-trained paraprofessionals should do this.

- Cost effectively can be done often by paraprofessionals.

- Counselors can train paraprofessionals to do this.

- Others can do this.

- Can be effectively done by others as well.

- Counselors' skills best applied here as first major student contact with institution. 
7. Prepare written handouts, handbooks, brochures, video and slide presentations. .

\section{Round 2 Comments:}

- Counselor involvement is important.

- Counselors bring broad understanding of what is effective.

- I assumed that this means take a concept, program, idea--think through how best to present in written and/or video mode. I think this is the job of the counselor. Putting it together and distributing is the job of the counseling support staff.

- Need other staff--not a certificated function--establish a clearer partnership with public information office.

8. Participate in outreach/recruiting functions .

Round 2 Comments:

- Counselors should direct energies to assisting with retraining students. Paraprofessionals can do those activities with only occasional help from counselors.

- Can be effectively done by others as well.

- Need other staff for this. Counselors are not necessarily recruiters.

- Others should do this too--expensive otherwise.

- First priority must be to serve those outreach-type students al ready on campus. Counselors can then be involved in outreach/recruiting functions if adequate counseling staff is available to provide this expanded service.

- This activity should be performed by school relations people.

- Highly important in small rural college.

- Recruitment of underrepresented students--expectations relayed.

- This is too time consuming--use teams of students or peer advisors or contract with high school counselors.

9. Develop and teach traditional academic

discipline classes. . . . . . . .

280 Percent

Round 2 Comments:

- Counselors should focus on counseling.

- Not possible with demands of matriculation.

- I don't see this happening now. Academic areas seem to want credentials higher than most counselors have.

- Not efficient utilization of staff.

10. Administer and interpret academic placement

tests

Round 2 Comments:

- "Interpret only" needs emphasis.

- Not required for large number of current part-time students.

- Administer-a paraprofessional can do. Interpret is a "4" (Very Important).

- The paraprofessional would be appropriate.

- Agree with assisted by assessment. 
11. Administer and interpret tests of interests, values, personalities and career planning

\section{Round 2 Comments:}

- Administer--a paraprofessional can do. Interpret is a "4" (Very Important).

- Ties to outcomes--broader student goal perspective.

12. Program approval and assistance during

registration

and assis

Round 2 Comments:

- Paraprofessionals more effective.

- We require for all nine-unit students (by counselors).

- Ties to orientation and follow-up.

- I believe that registration by mail and telephone will decrease this function.

- "3" should be okay if we had other staff. We don't and only counselors have the expertise.

- Many late registrants are students with most need.

- To ensure students take appropriate classes.

- Applied academic counseling involves program approval.

- Agree with comments.

13. Assist students with college forms and applications

\section{Round 2 Comments:}

- We do this for both our enrollees and those going on to universities.

- No need for credentialed counselors to do this.

o This is a good forum for meeting the student.

14. Provide information about scholarships and

financial aid services

\section{Round 2 Comments:}

- Refer to financial aid.

- Financial Aid Office is the best equipped and skilled to assume the responsibility.

- Paraprofessionals or Financial Aid Advisors should do this.

- Done by another office now.

- Counselors should refer to Financial Aid Office and not be involved with learning and keeping up-to-date on even elementary student financial aid information.

- Staff in Financial Aid Office are very effective and better informed.

- Should provide general information but refer to financial aid for specifics. 


\section{Round 2 Comments:}

- I just hired a classified Assessment Technician so a "3" makes sense to me.

- This is not done by counselors. It is done by our Assessment office.

- Based on student contacts, good source of information.

- Instructional staff need counselors' perspective.

- Academic counseling involves knowing how assessment information affects placement and persistence.

- Counselors need to be part of this process.

16. Assist instructors in monitoring student progress (early warning system) . . . 4

\section{Round 2 Comments:}

- Will be key to retention.

- Crucial to student success.

- We require for all who receive mid-semester deficiency notice.

- Very important interaction--1'm pushing for more linkage between counseling and instruction.

17. Counsel provisional/probationary or disqualified students

Round 2 Comments:

- The tendency is to spend too much time with problem students.

18. Coordinate, develop and assist in the implementation of the Matriculation Plan . . .

Round 2 Comments:

- Coordinate and develop are more administrative--doing and planning is the role of the counselor.

- Coordination should be an administrative responsibility.

- Coordination is more of an administrative function.

- Others can do this.

- Matriculation is administration responsibility in cooperation with staff.

- Develop and assist due to key role on process--not coordination.

- Only as matriculation plan applies to their area.

- Along with matriculation.

19. Develop effective 1 iaison relationships with instructors to facilitate communication and staff development

\section{Round 2 Comments:}

o This is not "Extrenely Important." 
20. Develop and teach counseling/personal development classes

85 Percent

\section{Round 2 Comments:}

- State seems to be moving away from approval. This is the only area where we cannot cat program approval.

- As time allows or department focus.

- Too much emphasis on personal development.

21. Initiate, plan, develop, implement and evaluate programs and services to meet student needs.

\section{Round 2 Comments:}

- My "5" is in reference to counseling programs and services specifically-not student services in general. For student services in general, I will agree with the " 3 ".

- Essential for future program evaluation and accountability.

- Part of our Program Review Process.

- Must have planning and evaluation involvement.

- More need than ever for this emphasis. This is a vital new role.

22. Meet the special counseling needs of:

(a) international students . . . 30 Percent

\section{Round 2 Comments:}

- Far too specific for all counselors to know and do.

- This can be done by paraprofessionals.

- District should utilize funds (tuition) for this.

- Designated counselor needed.

- These students have special needs and should have counselor support.

- These students have additional needs.

- I would concede to the "mode" if a specialist is available.

(b)

re-entering adults . . . . . . 4

Round 2 Comments:

- They make up over 50 percent of our students.

- Re-entry adults constitute a substantial percentage of our population.

- A large part of our enrollees--this is every counselor's duty.

- Should be viewed as any other student.

- They have special needs and all counselors need to be prepared.

(c)

veterans - $\quad$ - $\quad$ - $\quad$ - $\quad$ - $\quad 3 \quad 85$ Percent

Round 2 Comments:

- Viet Nam era veterans still need special assistance.

- Enrollment growing for this area again--this is every counselor's duty.

- Have a separate office for this function with para-professional.

- Awareness and 10-unit letters are still necessary. 
(d) displaced workers $\quad . \quad, \quad, \quad, \quad$,
Round 2 Comments:

- Only done as part of retraining contract.

- GAIN Program.

- Not such a "special" group.

(e) limited English-speaking students . .

\section{Round 2 Comments:}

- Only in those areas that have large populations of such students.

- ESL/LEP faculty have greater impact.

- Growing population dictates.

- Too special.

- Too specialized for most/all counselors to handle.

- Greater need emerging for bilingual, bicultural counselors.

(f) transfer students . . . . . .

95 Percent

Round 2 Comments:

o Will be important.

- Applies to all counselors.
(g) EOP students
Round 2 Comments: None.

23. Facilitate crisis intervention

4

80 Percent

Round 2 Comments:

- Most counselors not trained in this area which is ripe for lawsuit if student commits suicide, etc.

- Because of counselor load and sporadic nature, need assignment at other locations where expertise is available.

- During a "crisis" someone must intervene.

- One person's "crisis" is another person's challenge. All counselors should be prepared to intervene.

24. Develop and work with network of community resources.

Round 2 Comments:

- In a rural setting, these resources are not available.

- Referral is the key department activity. 
25. Refer students to appropriate on- and

off-campus services.

\section{Round 2 Comments:}

- Should back away from areas where appropriate expertise does not exist.

26. Develop liaison and articulation relationships with high schools

Round 2 Comments:

- Articulation Officer and school relations should have primary responsibility.

- Not the role of all counselors. School/college relations office should handle. Depends somewhat on size of institution and number of students. - Others can do this as well.

27. Develop liaison and articulation relationships with colleges and universities...

\section{Round 2 Comments:}

- Articulation Officer and school relations should have primary responsibility.

- Role of Articulation Office. Spare me from 20 counselors articulating with 20 different universities.

- Others can do this as well.

28. Keep current with labor market trends and local employment opportunities . . . $\quad 4 \quad 85$ Percent

\section{Round 2 Comments:}

- Counselors should be aware of the outcomes as well as the process.

- U.S. Department of Labor predicts major changes this decade.

- Though referrals can be made to job placement area, this information is important in goal determination and counselors should do it.

- Crucial for counselors to be knowledgeable.

- Placement office function.

29. Develop, update and maintain records of accountability and documentation . . . 365 Percent

Round 2 Comments:

- With differential funding and matriculation, we will all become record keepers.

- Though this is very important, the development and maintenance functions can be by committee. Individual counselors need to know computers so they will help in documentation.

- Matriculation requires this. Counselors must initiate this process for their one-on-one appointments. Support staff and computers can take it from there. By this definition I will go with a "3".

- All staff must be part of accountability effort.

- Computer and clerical staff support. 


\section{Round 2 Comments: (continued)}

- Counselors must ensure they do this proper documentation--others can help but we must become more accountable.

- Counselors need to be accountable for decisions.

- Accountability is becoming more important--not "average".

- Part of our Program Review.

Assist in grant writing $\quad$ - $\quad$ - $\quad$ - $\quad 2 \quad 80$ Percent

\section{Round 2 Comments:}

- There will be more money available for projects in this area.

- Grant staff responsibility--counselors can serve as resource.

- Requires special expertise.

- Grant proposals related to counseling functions should be written with input from counseling.

31. Work with counseling related computer assisted systems

Round 2 Comments:

- Improve information delivery and enhance student development activities.

32. Plan and conduct relevant research in student personnel areas

\section{Round 2 Comments:}

- If counselors don't plan and conduct, they must realize the impact of research.

- Not done enough--Program Review helps.

- Counselors should be more involved in research that affects their discipline.

33. Prepare written reports and data analysis .

Round 2 Comments:

o Suggest areas only--others can do this.

34. Provide work direction and supervision to paraprofessionals . . . . .

Round 2 Comments: None. 


\section{Round 2 Comments:}

- Counselors are the main focus for student input and need to be heard.

- AB 1725 mandates.

- Counseling cannot have an institutional impact without this.

- Counselors should participate as equal partners with instruction in college governance. They should be a resource in curriculum development.

- Who is better prepared than counselors.

36. In-service training for teaching staff

Round 2 Comments:

- No one else has the expertise.

- Especially in regards to retention and student motivation.

37. Providing learning consultation for staff

Round 2 Comments: None.

38. Own personal development.

Round 2 Comments: None.

39. Take a leadership role in student retention activities

Round 2 Comments:

- Follow up is key matriculation component.

- Matriculation makes specific mention of follow-up. Counselors have a direct responsibility for intervention.

40. Take a leadership role in meeting the challenge of the "new" student populations...

Round 2 Comments:

- Total campus responsibility.

- In cooperation with faculty.

41. Evaluate student services frequently

\section{Round 2 Comments:}

- Have a responsibility for the quality of services.

- Participate in student services evaluation because counselors do not have the entire perspective and are not part of the program.

- How is this different than No 21 ? 
42. Attend state conferences to keep informed

80 Percent

\section{Round 2 Comments:}

- Is this part of No 38 ?
43. Participate in teaching teams - . . . 48 Percent Round 2 Comments:

- Depends on the type of teaching.

- I see collaborative learning as a key vehicle for counselor involvement in the instructional process.

\section{Additional Comments:}

List below comments or feedback about future counselor responsibilities (job description) you wish the researcher or other respondents to know. These comments will be shared during Round 3.

o Counselors must become more involved in providing information about student needs to other areas of the college.

\section{Part 2: Competencies}

Definition of Competency: Ability, expertise, mastery, proficiency or skill.

\begin{tabular}{cl} 
Modal & $\begin{array}{l}\text { Percent Choosing } \\
\text { Response }\end{array}$ \\
\hline
\end{tabular}

1. Educational planning skills . $\quad$ - $\quad 5 \quad 5$ Percent

Round 2 Comments:

- It is not "Extremely Important" that every counselor have all of these skills. This is where you round out your staff by adding those with skills missing in your counseling team.

2. Career counseling skills • • • . $\quad$ - 5

95 Percent

Round 2 Comments:

- It is not "Extremely Important" that every counselor have all of these skills. This is where you round out your staff by adding those with skills missing in your counseling team.

3. Life planning and counseling skills

Round 2 Comments:

- It is not "Extremely Important" that every counselor have all of these skills. This is where you round out your staff by adding those with skills missing in your counseling team.

- Again, I favor less emphasis on after college counseling. 
Round 2 Comments:

- It is not "Extremely Important" that every counselor have all of these skills. This is where you round out your staff by adding those with skills missing in your counseling team.

- I'11 go with "5" but I am assuming that there is one or more true specialists on staff who are trained in psychological services to at least the MFC level to deal with the truly difficult psychological and emotional problems.

- Main emphasis is on academic counseling and new partnership with instruction.

5. Group dynamics/process skills . . . . 5

Round 2 Comments:

- It is not "Extremely Important" that every counselor have all of these skills. This is where you round out your staff by adding those with skills missing in your counseling team.

- Cost efficient.

6. Teaching skills

85 Percent

Round 2 Comments:

- Duse to need to serve on group situation more frequently.

- The instructional mode may be most viable system for delivery of career and other counseling related information.

- Counselor will have too much to do to teach.

7. Knowledge of assessment tests and test interpretation.

Round 2 Comments:

- We have a special office for assessment tests--interpretation important.

8. Knowledge of study skills

Round 2 Comments:

- Crucial for student retention.

- Key skill to success.

- Only if counselor is teaching class.

- Why would counselors do this?

9. Knowledge of learning theory

Round 2 Comments:

- Crucial for student retention.

o Counselor can then integrate with student goals. 
Round 2 Comments:

- With older returning adults comprising our largest community college population, counselors must be more knowledgeable about adult development theory. They can be more helpful with this knowledge.

- Crucial for student retention.

- Average age of community college student is 30 .

- Learning styles of re-entry students extremely important.

11. Knowledge of human motivation and behaviop

\section{Round 2 Comments:}

- Important for educational planning.

- Crucial for student retention.

o Why not--reason for their skills!

- Key activity for our students.

12. Ability to work effectively with underprepared students . . . . . . . .

Round 2 Comments: None.

13. Ability to work effectively with a diverse age group.

Round 2 Comments:

- Important but not paramount.

14. Ability to interact effectively with persons of diverse socio-economic and ethnic backgrounds

Round 2 Comments: None.

15. Ability to work effectively with re-entry adults

\section{Round 2 Comments:}

- I find that support groups are better than counseling for this group.

16. Ability to assimilate large volumes of changing academic information

Round 2 Comments:

- Computers can help.

- Make best use, but not memorize; hence the use of computers.

- Paraprofessional academic advisors need to have this ability more than counselors. 
17. Ability to assimilate large volumes of changing career information.

80 Percent

\section{Round 2 Comments:}

- Career is one major element of community college education.

- This area requires more each year.

- Crucial with community college students.

18. Ability to interpret, apply and explain policies and procedures. . . . 4

\section{Round 2 Comments:}

- Essential function for counselor especially as related to counseling matters such as probation and dismissal, transfer procedures, etc.

- Support staff should assume leadership.

- People will increasingly question every policy--at a time when we are adding more of them.

- Support staff can help here.

19. Ability to analyze a situation correctly and adopt effective course of action.

90 Percent

\section{Round 2 Comments:}

- Expectation of all employees.

- A1l student services staff should have this ability--essential.

20. Knowlenge of the Matriculation Plan for community
colleges

Round 2 Comments:

- Ability/competency to apply their plan in their area.

- Only if it stays around.

o Need understanding of campus matriculation, not statewide perspective.

21. Knowledge of community college mission and philosophy

Round 2 Comments:

- Isn't this obvious?

22. Understanding of applicable sections of the

State Education Code..$\quad$ - .30 Percent

\section{Round 2 Comments:}

- They need to receive appropriate interpretation rather than direct interpretation.

- Necessary to assist students with certain problems, e.g., academic renewal, course repetition.

- Essential that all employees understand Education Code Sections that impact the way in which they do their job.

- Specialized for Registrar. 
Round 2 Comments:

- Articulation office responsibility.

- This can be given out in written form.

- Essential in effective academic advising.

- Articulation office should show leadership.

- Essential with increasing interest in transfer among students. Impacts every planning step for a student.

24. Knowledge of admissions, financial aid and veterans affairs

Round 2 Comments:

- Matriculation requires greater student service knowledge per assessment.

- Students may be mislead or make bad academic and career decisions unless counselors have accurate information to share with students about these areas.

- General knowledge of above areas is essential in meeting needs of community college students.

- Assists in facilitating role.

- Currently often is inadequate. Only sends student from office to office.

- For specialized staff.

25. Ability to communicate effectively in written and verbal form . . . . .

Round 2 Comments:

- Verbal by far is the most important, but it is not a "5". Otherwise 25 percent of staff would not be competent.

26. Organizational and program development skills

Round 2 Comments:

- With various specialties and activities, this is a necessary skill.

- Needed for adaptability to new student needs.

- Increased role counselor will play in the institution.

27. Skills with counseling-related computer-assisted systems

Round 2 Cominents:

- Can be trained. 
28. Knowledge of community social agencies, services and resources

\section{Round 2 Comments:}

- Definitely required-who refers and where.

- We are community related--essential knowledge for our students.

- The kinds of students we serve require this if the counselor is going to bring to bear all available resources.

29. Knowledge of basic research principles

\section{Round 2 Comments:}

- Needed for accountability requirements.

- Research staff responsibility.

- Sign of a professional.

- Essential that counselors become more involved in research that relates to functions.

30. Previous paid community college counseling experience

\section{ents:}

Round 2 Comments:

- The paid portion of this statement is irrelevant.

- With over 50 applicants for each opening, anyone without this is quickly el iminated from selection.

- An unpaid experience can be as beneficial as paid.

- Skills may be obtained in settings similar to community college and is possible through unpaid status.

31. Internship or practicum at a community college setting

\section{Round 2 Comments:}

- Absolutely a must.

- Absolutely a "must"--without credentials what's going to be criteria?

- An understanding of the community college, its goals and missions, is critical. You gain that by exposure.

- This is helpful but other experiences are proving as helpful.

32. California Community College Counseling Credential

\section{Round 2 Comments:}

- What happens when there is not credentialing? My guess is that a comparison of the results of this survey to the requirements for a credential will show little correlation.

- "Important" but not "Extremely Important."

- The credential system does not belong in colleges.

- AB 1725 locally determined minimum qualifications.

- Appropriate skills, education and experience are important but do not have to require credential. 


\section{Round 2 Comments:}

- State is doing away with credentials.

- The credential means little; the experience and education that the counselor has does mean something.

- Skills through education and experiences are likely to replace the credential as per AB 1725.

33. Teaching experience (prior) • . . . 5

75 Percent

Round 2 Comments:

- Teaching is not a prerequisite for counseling.

34. Integrity

Round 2 Comments: None.

35. Free from mental problems . . . .

Round 2 Comments:

- The job will place enough stress without prior problems.

- What does this mean?

36. Sensitivity to cultures

60 Percent

Round 2 Comments: None.

37. Possibly bilingual (depending on location)

75 Percent

Round 2 Comments:

- A coming need due to demographics of state.

38. Flexibility and tolerance

60 Percent

Round 2 Comments: None.

39. Understand and provide linkage between

counseling and instruction

Round 2 Comments:

- Feedback and follow-up do not work without proper linkages.

40. Be able to fulfill variety of functions but with one or two specializations . .

Round 2 Comments: None. 
41. Be active in professional organizations.

4

70 Percent

Round 2 Comments: None.

42. Knowledge and participatory skills in

program review.

75 Percent

Round 2 Comments:

- More and more important--accountability.

- Must have an active voice in accountability measures that directly relate to counseling.

43. Masters degree in counseling .

\section{Round 2 Comments:}

- Or doctorate or related field.

- The masters degree must be a minimum competency.

\section{Additional Comments:}

List below any comments or feedback about future counselor competencies (job description) you wish the researcher or other respondents to know. These comments will be shared during Round 3 .

o Counselors must have ability to handle conflict and pressure. 
APPENDIX G: ABBREVIATED DELPHI SUMMARY FOR ROUND 2

\title{
A DELPHI STUDY OF CALIFORNIA COMMUNITY COLLEGE COUNSELORS' RESPONSIBILITIES AND COMPETENCIES FOR THE 1990'S AS PERCEIVED BY CHIEF STUDENT SERVICES ADMINISTRATORS
}

\begin{abstract}
Summary
Percentage of Respondents During Round 2 $\quad$ - $\quad$ - $\quad$ - $\quad$ - 87 Percenic

The modal response (the response which occurs most frequently) is 1 isted for each item along with the percentage of respondents choosing the modal response. This indicates the degree of consensus for each item. The modal response as opposed to the mean response is used to indicate consensus because this study is gaining opinions about future conditions. The degree of consensus indicates future directions and trends but does not predict the future.
\end{abstract}

Since consensus (at least 50 percent of respondents selecting the modal response) was reached for each responsibility and competency item during Round 2, the comments submitted for each item are not included in this abbreviated sumary.

\section{Part 1: Responsfbilities}

Definition of Responsibility: A trust, obligation, or duty; that for which one is responsible.

importance-Level Scale: Write the numerical value indicating the level of importance on the Tine provided adjacent to each responsibility statement. Note: For the purpose of this study, a rating of " 1 " (No Importance) indicates that the listing should not be a responsibility/competency of a credentialed California community col $\overline{\text { ege }}$ counselor.

No Importance
Little Importance
Important.

$\begin{array}{ll}\text { Very Important } & 4 \\ \text { Extremely Important: } & 5\end{array}$
\begin{tabular}{c} 
Modal \\
Response \\
\hline
\end{tabular}
1. Academic advising (course selection assistance)
5
5
Percent Choosing
2. Educational planning (goal selection assistance)
85 Percent
3. Personal counseling (assistance in personal adjustment and problem areas).
90 Percent
4. Career counseling (career exploration and selection) . . . . . . 5
70 Percent
Life planning (goal, decision-making, lifestyle assistance)
75 Percent
85 Percent
6. Conduct new student orientation sessions
7. Prepare written handouts, handbooks, brochures, video and slide presentations.
8. Participate in outreach/recruiting functions .
9. Develop and teach traditional academic discipline classes
80 Percent
10. Administer and interpret academic placement tests

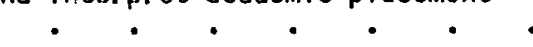
85 Percent 
11. Administer and interpret tests of interests,

12. Program approval and assistance during

13. Assist student with college forms and applications . .

85 Percent

14. Provide information about scholarships and financial aid services . . . . . 3

65 Percent

15. Work with instructors to establish test data to determine student placement . . . 3

75 Percent

16. Assist instructors in monitoring student progress (early warning system)

80 Percent

17. Counsel provisional/probationary or disqualified students . . . . . 5

95 Percent

18. Coordinate, develop and assist in the implementation of the Matriculation Plan

60 Percent

19. Develop effective liaison relationships with instructors to facilitate communication and staff development . . . . . 5

95 Percent

20. Develop and teach counseling/personal development classes. . . . . . 4

85 Percent

21. Initiate, plan, develop, implement and evaluate programs and services to meet student needs.

75 Percent

22. Meet the special counseling needs of:

(a) international students . . . . 3

(b) re-entering adults . . . . . 4

(c) veterans . . . . . . . . . 3

(d) displaced workers . . . . . . 4

(e) Iimited English-speaking students . 5

(f) transfer students . . . . . . 5

(g) EOP students . . . . . . . 5

23. Facilitate crisis intervention . . . 4

24. Develop and work with network of community resources. . . . . . . . 4

25. Refer students to appropriate on- and off-campus services. . . . . . . . 4

70 Percent

75 Percent

85 Percent

85 Percent

80 Percent

95 Percent

100 Percent

80 Percent

90 Percent

26. Develop liaison and articulation relationships with high schools. . . . . .

27. Develop liaison and articulation relationships with colleges and universities

85 Percent

28. Keep current with labor market trends and local employment opportunities

85 Percent 
29. Develop, update and maintain records of accountability and documentation . . . 3

30. Assist in grant writing . . . . . . 2

65 Percent

31. Work with counseling related computer assisted systems

32. Plan and conduct relevant research in student personnel areas . . . . . . 2

33. Prepare written reports and data analysis . 3

90 Percent

34. Provide work direction and supervision to paraprofessionals . . . . . . 4

100 Percent

35. Participate in the college governance process and curriculum development . . . 4

36. In-service training for teaching staff . . 4

75 Percent

37. Providing learning consultation for staff . 4

85 Percent

38. Own personal development . . . . . . 4

85 Percent

39. Take a leadersinip role in student retention activities...$\quad$. . . 5

80 Percent

40. Take a leadership role in meeting the challenge of the "new" student populations . . . 5

90 Percent

41. Evaluate student services frequently . . 5

90 Percent

42. Attend state conferences to keep informed . 4

60 Percent

43. Participate in teaching teams . . . . 4

80 Percent

80 Percent

\section{Additional Comments:}

List below comments or feedback about future counselor responsibilities (job description) you wish the researcher or other respondients :o know. These comments will be shared during Round 3 .

o Counselors must become more involved in providing information about student needs to other areas of the college.

\section{Part 2: Competencies}

Definition of Competency: Ability, expertise, mastery, proficiency or skill.

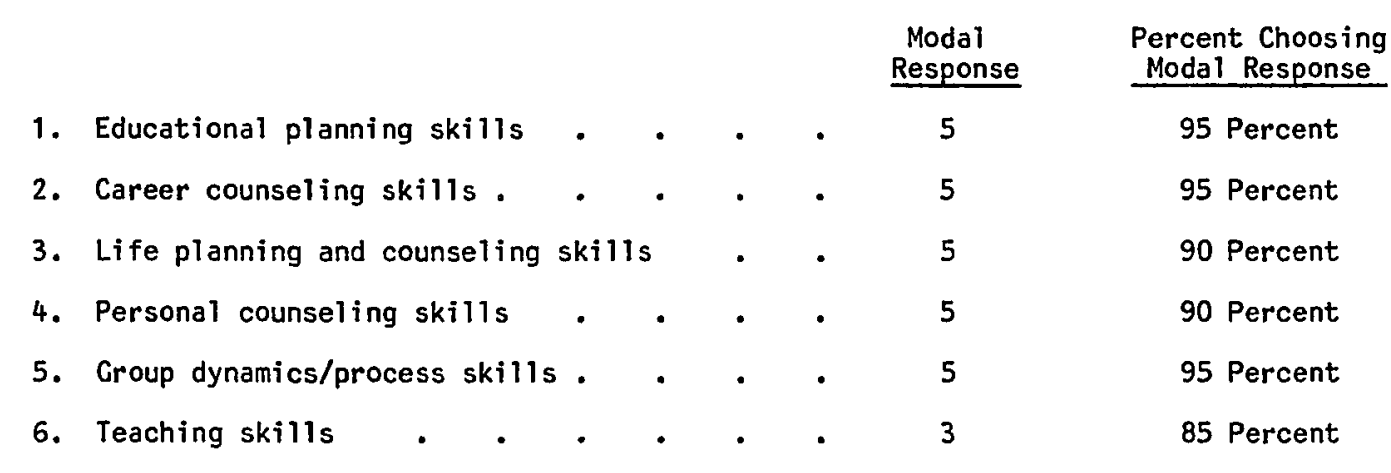


7. Knowledge of assessment tests and test

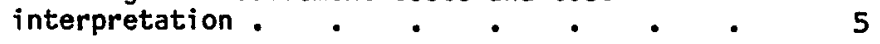

8. Knowledge of study skills . . . . . 4

95 Percent

9. Knowledge of learning theory - . . . 4

80 Percent

10. Knowledge of adult development theory . . 3

90 Percent

11. Knowledge of human motivation and behavior

80 Percent

12. Ability to work effectively with underprepared students . . . . . . .

13. Ability to work effectively with a diverse

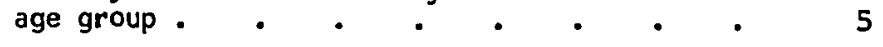

80 Percent

100 Percent

14. Ability to interact effectively with persons of diverse socio-economic and ethnic backgrounds

15. Ability to work effectively with re-entry adults 100 Percent

16. Ability to assimilate large volumes of changing academic information . . . . .

17. Ability to assimilate large volumes of changing career information . $. \quad . \quad . \quad \cdot \quad \cdot$

18. Ability to interpret, apply and explain policies and procedures.

19. Ability to analyze a situation correctly and adopt effective course of action

20. Knowledge of the Matriculation Plan for

21. Knowledge of community college mission and phi losophy

22. Understanding of applicable sections of the State Education Code

23. Knowledge of articulation . . . . . 4

24. Knowledge of admissions, financial aid and veterans affairs . . . . . 3

90 Percent

25. Ability to communicate effectively in written and verbal form... .45

80 Percent

26. Organizational and program development skills

27. Skills with counseling-related computerassisted systems . . . . . 5

85 Percent

28. Knowledge of community social agencies, services and resources . . . . . . . . 3

95 Percent

80 Percent

29. Knowledge of basic research principles . .

30. Previous paid community college counseling experience

31. Internship or practicum at a community college setting 
32. California Community College Counseling Credential

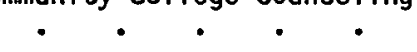

55 Percent

33. Teaching experience (prior) . . . . 5

75 Percent

34. Integrity

95 Percent

35. Free from mental problems . . . . . 4

36. Sensitivity to cultures . . . . . 4

70 Percent

37. Possibly bilingual (depending on location)

60 Percent

38. Flexibility and tolerance

75 Percent

39. Understand and provide linkage between counseling and instruction . . . . 5

60 Percent

40. Be able to fulfill variety of functions but with one or two specializations . . . 4

41. Be active in professional organizations .

42. Knowledge and participatory skills in program review

43. Masters degree in counseling

\section{Additional Comments:}

List below any comments or feedback about future counselor competencies (job description) you wish the researcher or other respondents to know. These comments will be shared during Round 3 .

- Counselors must have ability to handle conflict and pressure. 


\section{APPENDIX H: JOB DESCRIPTION FOR \\ CALIFORNIA COMMUNTTY COLLEGE COUNSELORS FOR THE 1990'S}

\section{A DELPHI STUDY OF CALIFORNIA COMMUNITY COLLEGE COUNSELORS' RESPONSIBILITIES AND COMPETENCIES FOR THE 1990'S AS PERCEIVED BY CHIEF STUDENT SERVICES ADMINISTRATORS}

Job Description

for California Community ColTege Counselors for the $1990^{\prime} \mathrm{s}$

\section{General Responsibilities}

It is the responsibility of all counselors to participate in development, implementation and evaluation of counseling services that will result in educational, vocational and personal development of students.

\section{Specific Responsibilities}

\section{A. Counseling (in order of importance)}

1. Meet the special counseling needs of EOP students.

2. Counsel provisional/probationary or di squalified students.

3. Meet the special counseling needs of transfer students.

4. Provide educational planning (goal selection assistance).

5. Work with counseling-related computer-assisted systems.

6. Take a leadership role in meeting the challenge of the "new" student.

7. Provide academic advising (course selection assistance).

8. Provide life planning (goal, decision-making, lifestyle assistance).

9. Meet the special counseling needs of limited English-speaking students.

10. Provide career counseling

11. Refer students to appropriate on- and off-campus services.

12. Devel op and work with network of community resources.

13. Meet the special counseling needs of displaced workers.

14. Maintain currency with labor market trends and local employment.

15. Assist instructors in monitoring student progress (early warning system).

16. Facilitate "crisis" intervention.

17. Meet the special counseling needs of re-entering adults.

B. Instruction (in order of importance)

1. Develop effective liaison relationships with instructors to facilitate communication and staff development.

2. Develop and teach counseling/personal development classes.

3. Participate in teaching teams.

4. Conduct new student orientation sessions.

C. Evaluation

1. Evaluate student services frequently.

D. Professional Development (in order of importance)

1. Provide in-service training for teaching staff.

2. Provide learning consultation for staff.

3. Participate in own personal development.

4. Attend state conferences to keep informed.

E. Institutional (in order of importance)

1. Take a leadership role in student retention activities.

2. Develop liaison and articulation relationships with high schools.

3. Develop liaison and articulation relationships with colleges and universities. 
4. Coordinate, develop and assist in the implementation of the Matriculation Plan.

5. Participate in the college governance process and curriculum development.

6. Participate in outreach/recruiting functions.

F. Other

1. Provide work direction and supervision to paraprofessionals.

Specific Competencies

A. Skills and Abilities Required (in order of importance)

1. Ability to work effectively with underprepared students.

2. Ability to interact effectively with persons of diverse socio-economic and ethnic backgrounds.

3. Educational planning skills.

4. Career counseling skills.

5. Group dynamics/process skills.

6. Ability to work effectively with a diverse age group.

7. Ability to work effectively with re-entry adults.

8. Ability to communicate effectively in written and verbal form.

9. Skills with counseling-related computer-assisted systems.

10. Life planning and counseling skills.

11. Personal counseling skills.

12. Ability to assimilate large volumes of changing academic information.

13. Ability to analyze a situation correctly and adopt effective course of action.

14. Ability to fulfill variety of functions but with one or two specializations.

15. Ability to interpret, apply and explain policies and procedures.

16. Bilingual (depending on location).

B. Knowledge Required (in order of importance)

1. Knowledge of community college mission and philosophy.

2. Knowledge of assessment tests and test interpretation.

3. Knowledge of the Matriculation Plan for community colleges.

4. Knowledge of learning theory.

5. Knowledge of study skills.

6. Knowledge of human motivation and behavior.

7. Knowledge of articulation.

C. Other Requirements (in order of importance)

1. Integrity.

2. Understand and provide linkage between counseling and instruction.

3. Masters degree in counseling.

4. Teaching experience.

5. California Community College Counseling Credential.

6. Free from mental problems.

7. Be active in professional organizations.

8. Sensitivity to cultures.

9. Flexibility and tolerance. 
APPENDIX I: STAFF DEVELOPMENT AND PROFESSIONAL PREPARATION NEEDS OF CALLFORNIA COMMUNITY COLLECE COUNSELORS FOR THE 1990'S DELPHI SUMWARY FOR ROUND 3

\section{A DELPHI STUDY OF CALIFORNIA COMMUNITY COLLEGE COUNSELORS ' RESPONSIRILITIES AND COMPETENCIES FOR THE 1990 'S AS PERCEIVED BY CHIEF STUDENT SERVICES ADMINISTRATORS}

Staff Development and Professional Preparation Needs of California Comunity College Counselors for the 1990 's

Percentage of Respondents During Round 3

96 Percent

Staff Development Needs:

Staff Development opportunities usually include credit or non-credit course work, workshops, seminars or field studies which are designed to enhance one's professional qualifications for one's current position.

California's rapidly changing demographics and the reform mandates included in Assembly Bill 1725 will directly trigger changes in the responsibilities and thus needed competencies of the currently employed community college counselors. Through this study, an expert panel of chief student services administrators, identified the foll lowing list, in rank order, of staff development needs. Participation in staff development opportunities addressing the following topics will enable currently employed California community college counselors to fulfill their responsibilities effectively during the 1990 's.

\section{Ranked Staff Development Topics}

(Ten points were assigned to each topic each time it was given the highest rank of One and descending points of nine to one were assigned to lower ranked topics. The "total ranking points" represent the cumulative total of points for each topic. All respondents ranked the first 16 listed topics. The other topics were added and ranked by those respondents who added the same topic.) 
Ranked Staff Development Topics (continued)

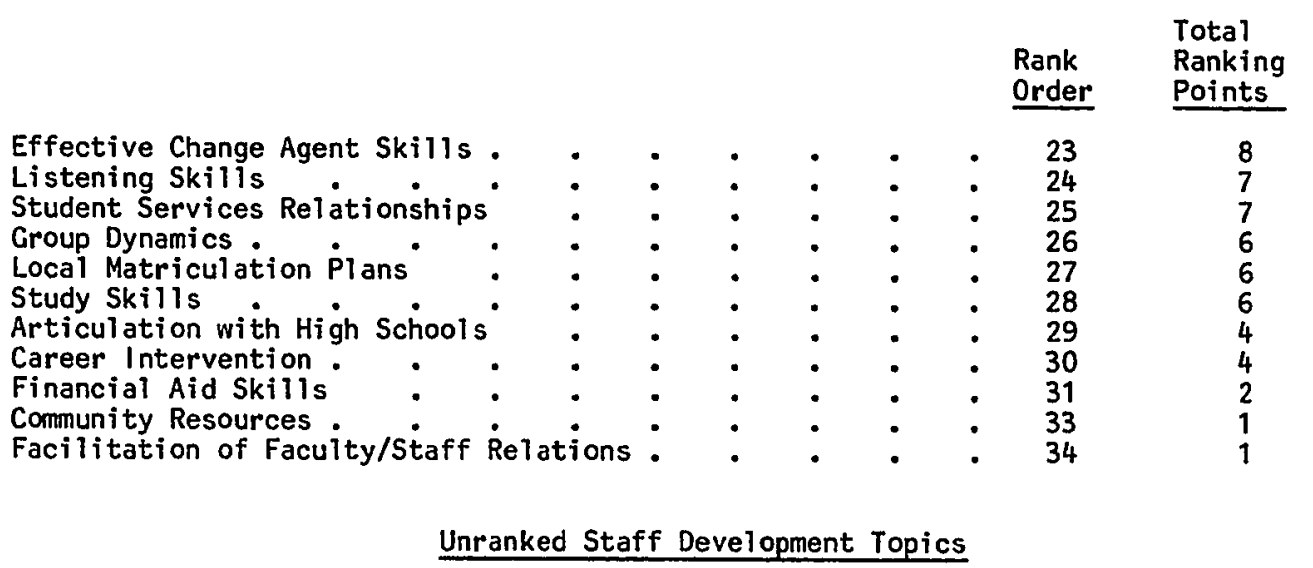

(This list includes topics that were added to the original list by the participants and were given an importance level rating but were not included in any participant's list of the top ten ranked topics. They are presented here in alphabetical order.)

AIDS Awareness

$2+2+2$ Articulation

Budget Development

Coping with Stress

Disabied Student Awareness, Understanding and Sensitivity

Economic Deveiopment

Global Society and Impact on Jobs

Learning Needs of Handicapped

Team Building

Vocational Curriculum Development

Professional Preparation Needs:

Professional Preparation generally includes college credit course work and educational program completion from an accredited institution to become qualified for employment in a profession.

Through this study, an expert panel of chief student services administrators, identified the following list, in rank order of professional preparation topics/courses. They were asked to develop the list with the perspective of the anticipated changes for California community college counselor responsibilities and competencies for the 1990 's. Participation in professional preparation programs that include the following topics will enable prospective California community college counselors to fulfill their responsibilities effectively during the $1990^{\prime} \mathrm{s}$.

\section{Ranked Professional Preparation Topics/Courses}

(Ten points were assigned to each topic each time it was given the highest rank of One and descending points of nine to one were assigned to lower ranked topics. The "total ranking points" represent the cumulative total of points for each topic. All respondents ranked the first 13 listed topics. The other topics were added and ranked by those respondents who added the same topic.) 


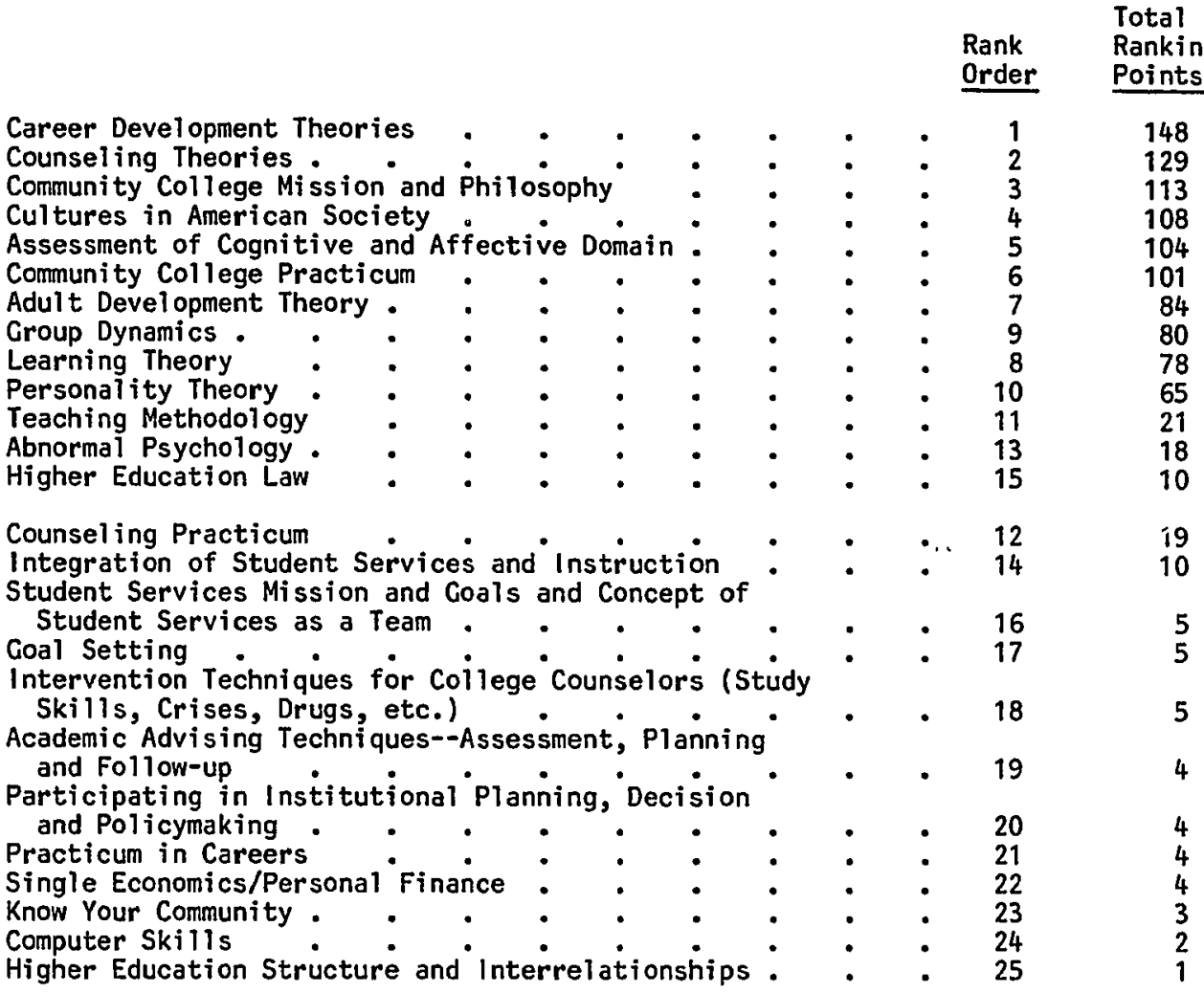

\section{Unranked Professional Preparation Topics/Courses}

(This list includes topics that were added to the original list by the participants and were given an importance level rating but were not included in any participant's list of the top ten ranked topics. They are presented here in alphabetical order.)

Articulation

Conflict Resolution

Curriculum Theories

Development/Training of Paraprofessionals

Effective Use of Community Resources

Finance/Budget Devel opment

Grant Writing Skills

Integration of Instruction to Student Services

Mental Health and Wellness

Orientation Issues and Skills

Research Methodology

Strategic Planning

Substance Abuse

Time Management/Stress Management 
Revisions and Comments Submitted by Round 3 Respondents

\section{Added Responsibilities}

- Interpret placement/assessment instruments.

This statement is meant to include both cognitive and affective measures. Counselors should be part of giving student the "big picture."

- Assist in monitoring student progress.

Who better to do it. See "big picture" comment above.

- Participate in development and coordination of needed information.

Counselors don't need to gather and disseminate information in the old way, but should have a say in "what" and "how."

- Provide educational, career and personal counseling to students of diverse backgrounds.

It is important to include a general statement like this to ensure that counselors are prepared to do a variety of counseling to diverse students under changing circumstances. This is a primary responsibility that should be covered--most of the duties fall underneath this one.

- Serve on college committees.

New requirements of staff development with management of $A B 1725$.

- Effective participation in institutional planning and decisions.

Shift from advising role to leadership role.

o Know your community and local schools.

Recruitment and student flow models need to be developed and implemented.

- Meet the special needs of disabled students.

To serve or refer the disabled students appropriately.

- Meet the special needs of foreign/international students.

A counselor or counselors need to be identified with special skills and knowledge in working with international students.

- An addendum to A.11 (Refer students to appropriate on and off-campus services.) -. . and assist with follow-up to these and other referrals.

One of the least developed components of matriculation is that of follow-up and it is imperative for some one to know if the proposed remedy "took" to determine if the "patient" lived.

\section{Added Competencies}

- Change No. 12 from "Ability to assimilate large volumes of changing academic information." to "Ability to organize and process large volumes of information."

They will never be able to assimilate it all! and "academic" is not the only kind! The information should include career, resources, etc.

- Be able to intervene. Take Teadership.

Need to be able to work with students who don't know they need help. 
Added Competencies (continued)

- Personality characteristics--friendly, open and caring.

Need to be able to serve students without evaluating or criticizing them.

- Ability to develop and implement student flow models and activities.

- Ability to detect learning difficulties; to be sensitive to students with learning disability problems and to refer them to appropriate services.

- Knowledge of wellness concepts and preventions of diseases, particularly AlDS and of substance abuse to not only enhance retention but ai so to enhance wellness.

\section{General Comments}

- I do not agree with the order of importance 1 isted in the job description.

- It's probably apparent that since 1 listed skills under staff development, I believe the skili levels for many counselors is inadequate--too many see themselves as academic advisors.

o The timing of this study could not be better--or more important--due to the impact of matriculation on community college counseling programs.

- You have done an excellent job in compiling information. This study will be very beneficial.

- This study is very timely and useful to us as we are developing job descriptions for two new counselor positions. Thanks for your help. 
APPENDIX J: DEMOGRAPHIC QUESTIONNAIRE SUMMARY

\section{A DELPHI STUDY OF CALIFORNIA COMMUNITY COLLEGE COUNSELORS' RESPONSIBILITIES AND COMPETENCIES FOR THE 1990 'S AS PERCEIVED BY CHIEF STUDENT SERVICES ADMINISTRATORS}

\section{Demographic Questionnaire Summary}

This is a summary of the demographic questionnaire completed by twenty two expert panel members. Items $1(a), 1(b)$ and $1(c)$ are not summarized to insure the anonymity of the respondents. Item 3 shows only total number of degrees. Item 6 will show the number of institutions with each indicated enrollment. Item 7 will show the average ethnic breakdown of all institutions for ethnic category. All other items have comprehensive summaries of the responses.

1. (a) Name:

(b) Institution/District:

(c) Phone Number: (1)

(d) Job Title:

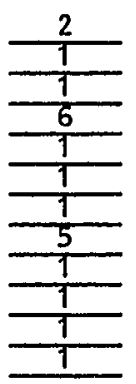

Assistant Superintendent/Vice President of Student Services Superintendent/President

Vice President, Student Development and Student Services

Dean of Student Services

Vice Chancellor, Student Affairs and Community Services

Vice President, Educational Services

Dean, Student Personnel Services

Vice President, Student Services

Dean, Student and Enrollment Services

Vice President

Dean of Academic Affairs

Vice President, Community and Student Services

(e) Your Direct Supervisor's Job Title:

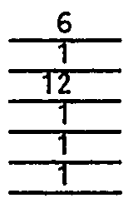

Superintendent/President

Board of Trustees

President

Vice President, Academic Services

Chancellor

Vice President, Instruction and Student Services

(f) Number of Years in Your Present Position:

Total :

Average:

Range:

$\frac{143 \text { years }}{6.5 \text { years }}$

(g) Your Immediate Previous Position:

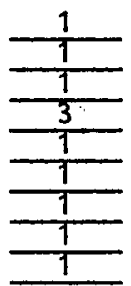

Associate Dean of Admissions and Records

Vice President, Student Services

Associate Dean

Dean of Students

Vice President of Instruction

Dean of Student Personnel

Associate Dean of Instruction

Counselor/Affirmative Action Officer

Associate Dean, Student Affairs 
1. (g) Your Immediate Previous Position: (continued)

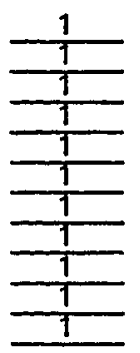

Director, Advising Services

Department Chairperson, Counseling

Assistant Dean, Student Services

Dean of Counseling

Assistant to the President

Dean of Special Programs

Dean, Admissions and Records

Director, Learning Center

Dean of Counseling and Student Services

Admissions Officer and Registrar

Bl ank

(h) Number of Years in Previous Position:

Total :

Average: $\quad 5.6$ years

124 years

Range: $\quad T-20$ years

(i) Have You Been a Community College Counselor?

$\frac{15}{7}$ Yes

Number of Years:

Total :

Average:

Range:

$\frac{80 \text { years }}{\frac{5.7 \text { years }}{1-10 \text { years }}}$ ( 1 Blank)

(j) Number of Years in Student Services Profession:

Total :

Average:

Range:

$\frac{\frac{395 \text { years }}{18.8 \text { years }}}{\frac{7-28 \text { years }}{7 \text { Blank) }}}$

(k) Responsible For (check oniy one):

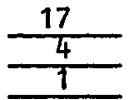

Student Services

Student Services and Instruction

College (Respondent is Superintendent/President)

2. (a) Your Age (check only one):

\begin{tabular}{cr}
0 & $20-30$ \\
$\frac{1}{10}$ & $31-40$ \\
\hline 10 & $41-50$
\end{tabular}

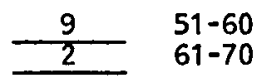

(b) Your Gender:

7 Female Male

3. Academic Degree(s) You Have Earned (check all that apply and indicate major or specialization, school and year):
(a) 22
(b) $\frac{\frac{22}{15}}{6}$
Bachelor's
Master's
Doctoral
Other (Associates, Specialist Certificate, Second Masters and Second Doctorate) 
4. Nationa1, State or Local Conferences Related to Community College Counseling Which You Have Attended in the Last Two Years (please 1ist): (Many respondents attended several of these conferences)

ACT Workshops

American Association of Community and Junior Colleges

American Association of Higher Education

American College Personnel Association

Assessment (State)

Association of California Community College Administrators

California Association of Community Colleges

California Community College Chief Student Services Administrators

Cal ifornia Community College Counselors Association

Chancellor's Office Task Force

Deans of Vocational Education

DSP\&S/EOP\&S

EOPS

Freshmen Year Experience National Conference

LARC

League of Innovations

Matriculation

National Conference of College Board

National Council of Black American Affairs

National Council on Student Development

Regional CCCCSSAA

San Diego, Imperial Valley Community College Counselors Association Student Services Program Review

5. Presentations by Title and Topic That You Have Made the Last Two Years at Local, State or National Conferences (please list): (Several respondents made numerous presentations)

A Comparison of Assessment Practices in Two Community Colleges in Cal ifornia A Perspective on Student Affairs

Assessment

Athletic Matriculation

Changing Demographics and New Directions

Counseling/Advising

Differential Funding

Don't Apologize for Being a Student Services Warrior

Effective Counseling and Follow-up

Evaiuation of Student Services

Expectation: The Role It Plays in Student Services

Faculty Advising

Implementing a Vocational Counseling Component in the Matriculation Process

Instruction/Student Services Relationship

Job Training and Education for Greater Economic Opportunities

LARC

Matriculation

Matriculation: A Pragmatic Approach With Financial Aid

Orientation

Program Based Funding

Strengthening Student Services With 2.5 Million Dollar Grant

Student Outcomes

Student Retention

Student Retention, Graduation and Continuation--Models That Work

Student Services Program Review

Student Success is a Team Effort

The Development of Assessment/Placement/Instruction/Evaluation Programs

The Reverse and Lateral Transfer Student

Use of Faculty Advisors

Women in Administration

Women in Community Colleges 
6. Student Enroliment at Your Institution (head count):
(a) $3 \quad 5,000$ or less
(b) $5,001-10,000$
(c) $\frac{5}{4} \quad 10,001-15,000$
(d) $15,001-20,000$
(e) $20,001-25,000$
(f) $\frac{2}{2}$ More than 25,000

7. Ethnic Breakdown (Percentage) of Your Enrollment:
(a) 1.45 American Indian or Alaskan Native
(b) $\frac{1.95}{5.20}$ Asian or Pacific Islander
(c) 5.20 Black (Not Hispanic)
(d) $\frac{69.26}{}$ Caucasian (Not Hispanic)
(e) $\frac{1.45}{13.62}$ Filipino
(f) $\frac{1.65}{3.62}$ Hispanic
(g) $\lcm{2.05}$ Other 
APPEND IX K: COVER LETTERS FOR DELPHI ROUNDS ONE, TWO AND THREE

A DELPHI STUDY OF CALIFORNIA COMMUNITY COLLEGE COUNSELORS'

RESPONSIBILITIES AND COMPETENCIES FOR THE 1990 'S AS PERCEIVED BY CHIEF STUDENT SERVICES ADMINISTRATORS

Cover Lettars for Delphi Rounds One, Two and Three 


\section{OIAVINE

5500 Invine Center Drive a inine. Callifornie 92720 a 714/559-9300

October 18, 1988

\section{Dear}

We are writing to ask your participation in a Delphi study of community college counseling responsibilities and competencles for the 1990's and beyond. With the current teform movement and demographlc changes affecting California's community colleges, It is important that we examine future responsibllities, competencies, staff development needs and professlonsh preparation needs of commity college counselors. Th1s research w11 provide valuable decision making and planning information about these four critical areas for the future of counseling services.

Your particular participation is sought and requested because of your expertise and leadership in the student services profession. The leadershlp of our assoclation, CCCCss , has nominated you as a leader whose expertise could contribute greatly to this research study. Since you and other chlef student services officers are the decision and policymakers influencing counseling and other student services, your input is critical to the effectlveness and success of this study.

You and a few other leaders will comprise the expert panel of the study. The expert panel's participation involves responding to three rounds of questionnalres interspersed with summary feedback from the previous round. You will be given information and asked to share your opinions about the future for counseling. The instruments have been constructed to irvolve a minimm of your time for completion. In addition there is also a demographic questionnalre whlch w111 be distributed only in the flrst round to gather data to develop an overall profile of the expert panel and their institutions. Although speciflc information is requested in the demographic questionnalre, neither the panelist nor their institution will be linked to specific responses without prior written authorization.

The results of the study should provide useful information as we all prepare for the implementation of $A B 1725$ and as we move into the 1990's. If all goes on schedule and the results are received in time, I plan to present the results of the study at a workshop at the CCCCSShA spring Conference. The results will also be available via University Microfilms and the University of San Diego when the dissertation is completed and published.

\footnotetext{
SADRLTFACK COMMUNITY COLLFGE DISTRICT

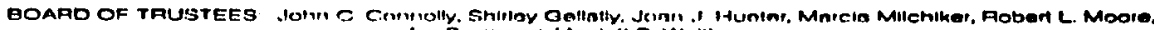

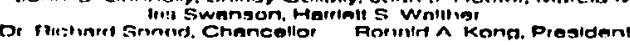

an equal opporturity insthutlon serving south orenpe county 


\begin{abstract}
The demographic questionnalre and the Delphi instruments for the flrst round are enclosed. A stamped and addressed envelope is enclosed for your use. The results will provide valuable information for future planning of counselors and counseling services In our community colleges over the next ten to twenty years. Please call Noella vela at Irvine valley college at (714) 559-3214 if you have any questions.

Please mail your responses to the first round no later than November 1, 1988 to allow sufficlent time for sumarization prior to the malling of the second
\end{abstract} round.

Your particlpation In this study is valuable and greatly appreclated.

Respecteflly yours,

Noella vela

Vice President, Student Services

Irvine Valley College

143.8/wps
Mike Keenan

President, CCCCSSAA

Vice President, Student Services

Antelope valley College 
5500 Invine Center Drive a Inine, California 92720 | 714/559-9300

November 7, 1988

Dear

Several weeks ago you received a letter and Delphi instruments asking you to participate in a study to determine the future responsibilities and competencies for California Community College Counselors. You were selected, along with a few other chief student services administrators, because of your identified leadership in the field of student services. As is often the case, leaders' schedules are very busy.

However, I have not heard from you yet and I urge you to please take a few minutes to respond. Your input to this study is valuable as it will help shape the future of community college counseling in California. In case you have misplaced the first set, another set of instruments, along with a stamped, self-addressed envelope, are enclosed. Please return as soon as possible but not later than November 15 .

Once again, your input is critical to this study. Thank you very much for your support and cooperation.

Respectfully yours,

Noelia Vela

Vice President of Student Services

Enclosures: Delphi Instruments

SADDLEBACK COMMUNITY COLLEOE OISTRICT

BOARD OF TRUSTEES John C Connolly. Smiley Gellally. Joan J Huetor, Marein Mileniker, Fobert L. Moore.

U. Fienard Sneed. Chancellor Forritild A Kong. Preardent

an equal opportunity institution serving south orange county 
Thank you for participating in Round one of this study. The response was excellent and individuals provided helpful comments and suggested additional responsibilities and competencies for comminity college counselors for the 1990 's.

Your continued participation by responding to the second part of this study is as important as responding to the first part. The purpose of Round Two is both to increase consensus and define minority opinion about future counselor responsibilities and competencies. The enclosed document is lengthy because of the format used to include all the comments received. However, let me assure you that it should only take twenty minutes to complete. The results of this round will comprise your recomnended job description for callfornia Community College counselors for the 1990's.

Your expertise as a student services leader is needed for the examination of the future of community college counseling in California. Therefore, your continued support and participation is greatly appreciated.

The results of the entire study (three Delphi rounds) are of immediate importance as we plan to meet the hiring and staff development requirements of $A B$ 1725. Round Three of this study specifically addresses staff development needs of currently employed counselors and professional preparation (minimum standards) of prospective counselors. Please continue your participation in the study so that we all can benefit from your thoughts and input on these key issues. 
DELPHI/ROUND TWO

Novembet 22, 1988

Page 2

Found Three, which will be the final round of this study, will be mailed to you as soon as Round Two responses are recelved and summarized. With your prompt assistance, this can be done before the Christmas holidays. The final results of the study will be shared at the CCCCSSAA conference and will be mailed to you at the completion of the study.

Please mail your responses immediately. A self-addressed, stamped envelope is enclosed for your convenience.

Respectfully yours,

Noelia Vela

Vice President of Student Services

Enclosure

141.3/wps 


\section{IRVINE

5500 Inine Center Dilve a Invine, Calitornia 92720 - 714/559-9300

December 7. 1988

Dear

Several weeks ago you received a letter and Delphi instruments for Round Two of a study to determine the future responsibilities and competencies for California Community College Counselors. To date I have not received your response.

I an sure your schedule is quite busy with end-of-the year responsibilitles. However, would you please take a few minutes to respond. please help keep the response rate to Round Two as high as 1 t was for Round one. Your input to this study is valuable as it will help shape the future of community college counseling in California.

Those who have already responded indicated that it took less time than they anticipated. They were interested in Round one results and look forward to Round Two results.

please feel free to call me at (714)559-3214 if you have any questions or if you need a second set of Round Two materials. I will rush the materials out to you.

once again, your input is critical to this study. Thank you very much for your support and cooperation.

Respectfully yours,

Noelia Vela

Vice President of Student Services

$141.3 /$ wps

SAODLEAACK COMMUNITY COLLFGE DISTRICT

BOARD OF TRUSTEES John C Connolly. Snifley Gellally. Jonn J Hueler, Marcie Mitchiker, Robert $L$ Moore.

D. Aichard Sneisd, Chancellar Pontid A Kong. Prosidont

en equal opportunity institution seming south orange county 


\section{9.mente}

5500 Invine Center Drive a Inine, California 92720 - 714/559-9300

January 6, 1989

Dear

Thank you for participating in Round Two of this study. With your assistance, the rate of response has remained high and your responses have yielded interesting results which you can review in the enclosed sumary of Round Two. You might note the high degree of consensus which was reached for each responsibility and competency item.

Round Three is a different aspect and final part of this study. It specifically addresses staff development needs of currently employed counselors and professional preparation needs (minimum standards) of prospective counselors who will be expected to meet the responsibilities and have the competencies as identified in your recommended job description for the 1990's. The results of the entire study are of immediate importance as we plan to meet the hiring and staff development requirements of $\mathrm{AB} 1725$.

Enclosed is a summary of Round Two, a copy of your recommended job description for counselors in the 1990's and a set of Delphi Round Three materials. Please continue your participation in this study by completing the Round Three materials. This should take just a few minutes.

with your prompt assistance, the results of the entire study can be analyzed and complled for presentation at the CCCCSSAA conference. Please mail your responses immediately. A self addressed, stamped envelope is enclosed for your convenience.

Your continued time, energy, support and participation are greatly appreciated. May you have happiness, peace and success in 1989.

Respectfully yours,

Noella Vela

Vice President of student Services

Enclosures

wps 141.3

SADDLEBACK COMMUNITY COLLEGE DISTAICT

BOARD OF TAUSTEES John C Cnnnolly, Smirloy Beltally, Joan J. Hueler, Mercla Millatiker, Roberl L. Moors. Dr Pichard Sneed. Chancellor Fonald A Kong. President

an equal opportunity institution serving south orange county 


\section{IRVINE \\ VALLEY \\ COLLEGE}

5500 Irvine Center Drive a Irvine, Californla 92720 a 714/559-9300

January 18, 1989

Dear

A couple of weeks ago you recelved a letter and Delphi materials for Round Three, the final part, of a study to determine the staff development needs and professional preparation needs of community college counselors for the 1990's. To date I have not received your response.

I an sure your schedule is quite busy with start-up activities of a new semester. However, this last round is the shortest and least time consuming. please help keep the response rate to Round Three as high as it was for Round Two. Your input to this study is valuable as it will help shape the future of community college counseling in Callfornia.

Please feel free to call me at (714) 559-3214 if you have any questions or if you need a second set of Round Three materials. I will cush the materials out to you.

Once again, your input is critical to this study. Thank you very much for your support and participation.

Respecteully yours,

Noelia Vela

Vice President of Student Services

wps $/ 141.3$

SADDLEBACK COMMUNITY COLLEGE DISTRICT

BOAAD OF TRUSTEES: John C Connolly, Snirley Gollatly, Joan J Hueter, Marcia Milchiker, Robert L. Moore. Dr. Richera Sneed. Chanceliot Ponatd A Kong. Presudent

an equal opportunity institution serving south orange county 